University of Louisville

ThinkIR: The University of Louisville's Institutional Repository

Electronic Theses and Dissertations

8-2006

\title{
Using auditory evoked brain responses to detect anxious vulnerabilities in neonates.
}

Kyle William Harvison

University of Louisville

Follow this and additional works at: https://ir.library.louisville.edu/etd

\section{Recommended Citation}

Harvison, Kyle William, "Using auditory evoked brain responses to detect anxious vulnerabilities in neonates." (2006). Electronic Theses and Dissertations. Paper 581.

https://doi.org/10.18297/etd/581

This Doctoral Dissertation is brought to you for free and open access by ThinkIR: The University of Louisville's Institutional Repository. It has been accepted for inclusion in Electronic Theses and Dissertations by an authorized administrator of ThinkIR: The University of Louisville's Institutional Repository. This title appears here courtesy of the author, who has retained all other copyrights. For more information, please contact thinkir@louisville.edu. 


\author{
By \\ Kyle William Harvison \\ B.S., Louisiana State University, 1999 \\ M.A., University of Louisville, 2003

\begin{abstract}
A Dissertation
Submitted to the Faculty of the

Graduate School of the University of Louisville

in Partial Fulfillment of the Requirements
\end{abstract} \\ for the Degree of \\ Doctor of Philosophy \\ Department of Psychological and Brain Sciences \\ University of Louisville \\ Louisville, Kentucky
}

August 2006 
USING AUDITORY EVOKED BRAIN RESPONSES TO DETECT ANXIOUS VULNERABILITIES IN NEONATES

\author{
By \\ Kyle William Harvison \\ B.S., Louisiana State University, 1999 \\ M.A., University of Louisville, 2003 \\ A Dissertation Approved on
}

December 16, 2005

by the following Dissertation Committee:

Dissertation Director 


\title{
ABSTRACT \\ USING AUDITORY EVOKED BRAIN RESPONSES TO DETECT ANXIOUS VULNERABILITIES IN NEONATES
}

\author{
Kyle William Harvison
}

August 4, 2006

Anxiety disorders are prevalent in both adult and child populations, and are associated with significant economic and psychosocial costs. There are clearly familial patterns of transmission within the anxiety disorders, and the inherited risk is likely a non-specific vulnerability toward negative affect, with a biologicalenvironmental interaction leading to specific manifestations within the anxiety disorders. Among the vulnerabilities toward anxiety may be information processing biases that predispose individuals to be more vigilant to novelty, processes that may be specifically associated with the right cerebral hemisphere. The current study utilized auditory event related potentials (ERPs) to explore the degree to which such processes may be related to risk toward anxiety disorders in a neonatal population $(n=30)$. Findings supported the growing evidence that predispositions toward anxious patterns of responding are associated with greater activation of the right cerebral hemisphere, as neonates of more highly anxious mothers displayed more positive right hemisphere responses overall. Further, consistent with theories that attentional biases toward novelty are associated with the development and maintenance of pathological anxiety, it was found that 
measures of both maternal state and trait anxiety were significant predictors of the neonate's brain response to a stranger's voice. These findings are discussed in terms of implications for further understanding the developmental pathways associated pathological anxiety. 


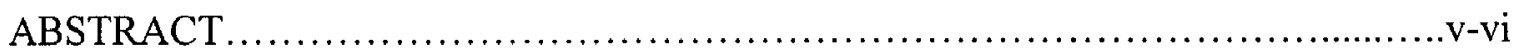

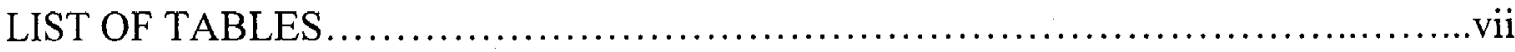

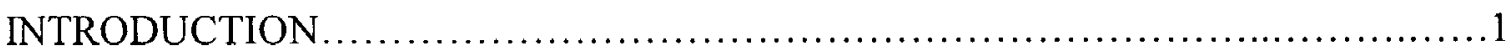

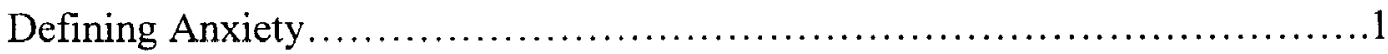

Models of Anxiety Development...........................................17

Initial Summary and Integration...........................................34

Event Related Potentials in the Study of Anxiety.............................36

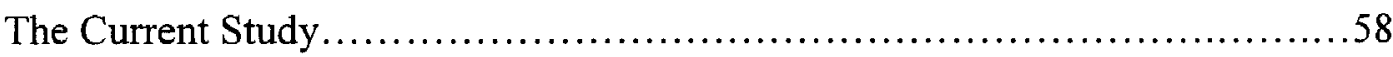

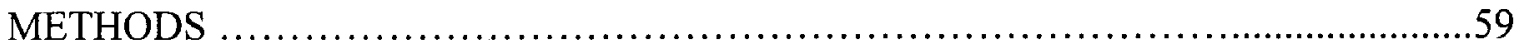

Considerations for Sample Selection....................................59

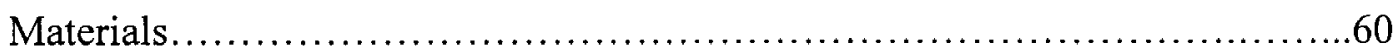

Procedures.................................................................

Planned Analyses....................................................... 67

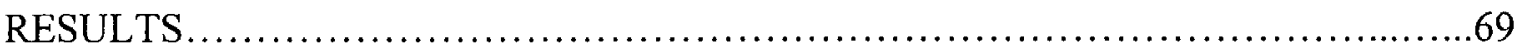

Descriptive Statistics ...............................................69

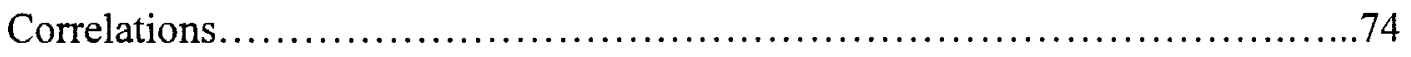

Regressions......................................................... 75

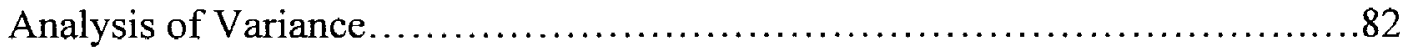


Lateralization of Anxious Vulnerabilities 84

Response to Novelty .87

Future Directions .90

Summary .93

REFERENCES .95

CURRICULUM VITAE 114 


\section{LIST OF TABLES}

TABLE

PAGE

1. Frequency and Descriptive Statistics for Maternal Variables....................71

2. Descriptive Statistics for Maternal Self-Report Measures......................72

3. Frequency/Descriptives Statistics for Neonate and Birth-Related Variables......73

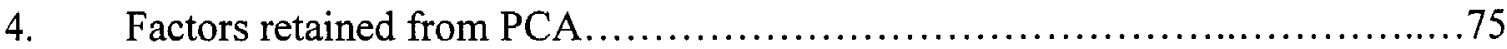

5. Summary of Hierarchical Regression Analyses for Variables

Predicting Neonate Right Central Brain Response to the Stranger

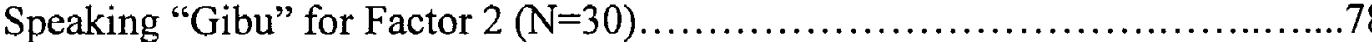

6. Summary of Hierarchical Regression Analysis for Variables

Predicting Neonate Right Central Brain Response to the Stranger

Speaking "Bidu" for Factor $4(\mathrm{~N}=30)$ .81 


\section{INTRODUCTION}

\section{Defining Anxiety}

Anxiety is an age-old term whose precise meaning is difficult to establish given its variety of usages in both lay and scientific contexts. It has roots in the Indo-European word angh, meaning "weighted down with burdens," and its subsequent iterations in other languages have come to encompass the state's characteristic somatic arousal, subjective fear in the absence of imminent threat, and concerns about existence and the future (Himmelhoch, Levine, \& Gershon, 2001). Lader and Wing (1964) illustrate the variety of clinical usages for this term, stating that anxiety "may refer to a personality variable, to a symptom accompanying physical or mental illness, or it may be a symptom occurring in relative isolation" (p. 210). Kagan (1994b) also highlights the myriad of usages for this term, describing anxiety in as a transient, quantitatively measured state, a more enduring and environmentally acquired quality, or a genetically determined trait.

Barlow (2002) defines anxiety as an emotional state of vigilance or "anxious apprehension" directed toward future threat (p. 64). He suggests that this future oriented emotional state is characterized by a diffuse and objectless apprehension accompanied by a sense of uncontrollability, and that it has unique cognitive, physiological and affective components based in the defensive motivational system. In this conceptual framework, anxiety is differentiated from the emotional state of fear, which is hypothesized to be a qualitatively different, although closely related emotion in terms of phenomenological, psychological, and biological dimensions (Barlow, Brown, \& Craske, 1994). Barlow's 
conceptualization is largely consistent with the tripartite model of anxiety and depression originally presented by Clark and Watson (1991).

In the tripartite model, anxiety and depression are closely related emotions in both their normal and pathological states. This relationship is evident, for example, in the consistently found moderate to high correlations among self-report measures of anxiety and depression (Clark \& Watson, 1991). Although much of this overlap is accounted for by taxonomic and psychometric issues, a relationship remains even in the face of improved methodologies, and is also evident in correlations between clinician ratings of the states, as well as in the high comorbidity of anxiety and mood disorders (Watson, Clark et al., 1995). To explain this robust relationship, the tripartite model adopts the notion that anxiety and depression share a common non-specific component called negative affect. This construct captures the general distress common to both states in terms of such symptoms as negative mood, disrupted sleep, and disruptions in cognitive processes such as attention and concentration. However, these states are differentiated based on the proposition that depression is more specifically related to anhedonia, or lack of positive affect, while anxiety is uniquely characterized by dimensions of physiological hyperarousal, as discussed in more detail below. This model has been supported by factor analyses utilizing a variety of measurement approaches across a diverse range of adult and child clinical and non-clinical samples (e.g. Brown, Chorpita, \& Barlow, 1998; Clark, Steer, \& Beck, 1994; Joiner Jr., Catanzaro, \& Laurent, 1996; Watson, Clark et al., 1995; Watson, Weber et al,, 1995).

It has long been recognized that anxiety is adaptive, if not essential, for humans. For example, Yerkes and Dodson (1908) found that moderate levels of stimulus intensity 
actually serve to facilitate performance. Yerkes and Dodson's highly respected work has been replicated with modern techniques such as neural network modeling (Schreter, 1990). As seen in the work of Hebb (1955), this relationship may be evident for more general states of arousal, with recent theorists applying this law to states of anxiety (Teigen, 1994). While anxiety is both useful and necessary for humans in terms of facilitating planning and adaptation (Barlow, 2002), it can also have devastating effects when present at excess levels, with disorders of anxiety counted among the most prevalent and debilitating conditions worldwide. Therefore, understanding the developmental psychopathology of anxiety, a quest that is in its infancy at best, is of critical importance. Before establishing a model for such an investigation, it is necessary to more fully explore the components, functions, and consequences of anxiety across the lifespan.

\section{Cognitive Components of Anxiety}

Beck and his colleagues (Beck, Laude, \& Bohnert, 1975) studied ideational components of anxiety in a group of adults with anxiety neurosis. They found consistent themes that accompanied increased anxiety in these patients characterized by unrealistic fears of personal danger. These included fears of physical harm or more interpersonally based fears of rejection and humiliation. Matthews and Shaw (1977) later reported this connection in a mixed group of anxious patients, with patients reporting increased cognitions related to potential catastrophe or personal threat that accompanied states of increased anxiety. Hibbert (1984) extended this work in patients. with both generalized anxiety disorder and panic disorder, and again found that increased anxiety was related to fears of personal danger, with the fears of generalized anxiety disorder patients relating 
less to impending physical harm. Instead, they reported more vaguely defined fears related to being inadequate and unable to cope.

Butler and Matthews (1983) also explored cognitive components of anxiety, and reported that anxious patients show interpretive biases in which they are more likely than controls to judge ambiguous material as threatening. Although this was also seen in depressed/anxious patients, anxiety seemed to be more specifically related to overestimating the possibility of personal risks (e.g., risk of threats to personal health) in the absence of overestimating the risk of such misfortunes befalling others. The data are interpreted in the context of Beck's cognitive triad model of depression, with the authors suggesting that clinically anxious individuals "may not regard the world as a universally unpleasant or dangerous place; rather they might see themselves as especially at risk" (p. 60). Further, the authors posited a circular interaction model in which anxiety, triggered by perceived threat, activates "danger schemata" that serve to increase risk estimation and maintain or increase levels of anxiety (p. 61).

Attentional processes are seen as integral to the process of emotion regulation (Wilson \& Gottman, 1996), and there is a large body of literature exploring attentional biases as they relate to the emotional state of anxiety. Overall, it appears that anxiety is characterized by attentional biases toward perceived threat, with the degree of one's vulnerability toward anxious responding predicting the level of threat that will elicit such responding (Mogg et al., 2000; Wilson \& MacLeod, 2003). Mogg and Bradley's (1998) cognitive-motivational view of anxiety attempts to account for the findings in this line of research, purporting that while all individuals attend to stimuli perceived as threatening, anxious individuals have lower thresholds for the perception of threat. Matthews and 
Mackintosh (1998) present a similar cognitive account whereby the tendency to perceive threat is affected by anxiety, and in turn, perceived threat heightens attention to threat related properties of the stimulus. These processes are also likely affected by individual differences in attentional control, with improved control over voluntary attentional allocation allowing even anxious individuals to effectively shift attention away from threat, allowing for improved coping in the face of such threat (Derryberry \& Reed, 2002). However, anxious individuals exhibit not only attentional biases toward threat, but may also have more general difficulties in sustaining attentional focus (Fox, 1993). This interesting finding supports neurobiological accounts of prefrontal cortical involvement in anxiety, a proposition that will be further explored later.

Anxiety-related attention biases have consistently been demonstrated across a number of adult populations with a variety of stimuli, both auditory and visual. For example, high trait anxiety has been associated with increased attention to threatening cues, as well as difficulty disengaging from such cues (e.g., Yiend \& Matthews, 2001). Using a dot probe task, Macleod, Matthews, and Tata (1986) found that patients referred for anxiety management training were more likely to attend to threat related words than a control sample who largely diverted attention away from such stimuli. Such processes are also at work in social anxiety, as clinically socially anxious patients show an attentional bias toward angry and threatening faces, rather than toward happy or neutral ones. (Mogg, Philippot, \& Bradley, 2004; Pishyar, Harris, \& Menzies, 2004). In an examination of cognitive biases of individuals high in health anxiety, Owens, Asmundson, Hadjistavropoulos, and Owens (2004) found that those high in health anxiety showed an attentional bias toward stimuli related to threat of illness, while others 
have demonstrated that individuals high in physical anxiety sensitivity have attentional biases toward stimuli associated with physical threat (Keogh, Dillon, Georgiou, \& Hunt, 2001). Similar effects are found in panic disorder populations who show attentional biases toward panic or physical threat related words (Asmundson, Sandler, Wilson, \& Walker, 1992; Horenstein \& Segui, 1997; Lundh, Wikström, Westerlund, \& Öst, 1999; McNally, Reimann, \& Kim, 1990), in obsessive-compulsive patients who show attentional biases toward threatening obsessive-compulsive related stimuli (Lavy, van Oppen, \& van den Hout, 1994), and in highly symptomatic post-traumatic stress disorder patients who show attentional biases toward relevant trauma related words (Thrasher, Dalgleish, \& Yule, 1994).

Attentional biases toward threat appear to differ across anxiety disorders, as well as between clinically and non-clinically anxious populations. Logan and Goetsch (1994) reviewed the literature in this area and concluded that clinically anxious subjects show disorder specific attentional biases, while non-clinically anxious individuals show more generalized threat related attentional biases. Later work by Becker, Rinck, Margraf, and Roth (2001) demonstrated that generalized anxiety disorder patients showed attentional biases across a range of emotional verbal stimuli, both positive and threatening, while social phobia patients only demonstrated this effect with stimuli specifically relevant to their social anxiety. As discussed below, anxiety-related cognitive biases emerge early in development and represent a key vulnerability toward the development of pathological states of anxiety.

\section{Behavioral Components of Anxiety}

Behaviorally, anxiety is characterized by attempts to eliminate, reduce, or avoid 
the source of anxiety. Such behaviors may take the form of suppression of ongoing activity, scanning the environment for signs of danger, worry and preparation, and avoidance of anxiety provoking cues. For example, in Gray's (1981) view, anxiety is based in the behavioral inhibition system (BIS), which is responsible for inhibition of ongoing behavior and hyperalertness to environmental cues. The BIS is closely linked to the above cognitive biases and, as discussed below, is hypothesized to have unique neurobiological underpinnings responsible for its activation. While behavioral components of anxiety may be adaptive in the presence of true threat, they are often maladaptive and actually impair performance in their more chronic forms (Barlow, 2002). Further, such behavioral patterns are associated with the perpetuation of anxious responding as they limit an individual's exposure to anxiety provoking cues, and thus limit mastery experiences that would serve to lessen such anxiety.

Fox (1994) views the behavioral patterns associated with approach vs. withdrawal as important precursors to the expression of discrete emotions and the development of social behavior. As discussed further below, he and other researchers (e.g., Kagan) have demonstrated that individuals exhibit a range of tendencies toward approach vs. withdrawal that are correlated with distinct neurophysiological patterns and predict the later emergence of anxious psychopathology. Fox (1994) purports that an infant's initial responses to his or her environment, rather than representing specific emotions such as anxiety, may reflect their tendencies along the approach vs. withdrawal continuum. Such tendencies will then shape the maturing individual's repertoire for dealing with stress, and hence are important in their development of emotion regulation skills. This is similar to Kagan's (1994a) view that a behaviorally inhibited temperament is a risk factor for the 
emergence of anxious psychopathology, although his data suggest that behavioral inhibition is a categorically distinct construct, and not necessarily on a continuum with non-inhibited behavior.

\section{Physiological Components of Anxiety}

Physiologically, anxiety is generally characterized by increased and restricted autonomic and somatic activity. Lang proposes that anxiety and fear arise when primitive defensive motivational circuits are activated in the face of relevant stimuli (Lang, Bradley, \& Cuthbert, 1998). In this regard, he sees these states as involving distinct autonomic and somatic circuits that manifest themselves in the activity of muscles and glands. Psychophysiological measurement indeed supports this, as patients with anxiety disorders have shown marked increases in autonomic activity, including increased heart rate and skin conductance in response to relevant anxiety provoking stimuli compared to emotionally neutral stimuli (Cook, Melamed, Cuthbert, McNeil, \& Lang, 1998).

The Beck Anxiety Inventory (BAI; Beck \& Steer, 1990) taps a number of the hypothesized physiological symptoms of anxiety. Research using this instrument (Joiner Jr., Steer, Beck, Schmidt, Rudd, \& Catanzaro, 1999) suggested that six of these symptoms: feeling hot, wobbliness in the legs, dizziness/ lightheadedness, pounding or racing heart, difficulty breathing, and flushed face hang together as an important dimension of anxiety termed physiological hyperarousal (PH). In this study, the construct of PH held up across four distinct samples, was separable from subjective anxiety, and was more closely related to panic than generalized anxiety and mood disorders. This is consistent with previous investigations of the tripartite model in which 
physiological hyperarousal has been differentiated from the constructs of positive and negative affect. The PH items were also closely related to the BAI's other somatic anxiety symptoms: numbness or tingling, trembling hands, shakiness, indigestion/ abdominal discomfort, and sweating.

A number of other factor analyses of the BAI have been undertaken, providing further understanding of the distinct somatic components characteristic of anxiety. For example, Osman, Kopper, Barrios, Osman, and Wade (1997) provided support for a previously studied four-factor structure that included the more cognitively valenced factor, subjective anxiety, with the somatically focused BAI items being characterized by neurophysiological symptoms, autonomic elevation, and panic symptoms (Beck \& Steer, 1991; Osman, Barrios, Aukes, Osman, \& Markway, 1993). While other investigations have suggested that the BAI is best characterized by 2 factor (Beck, Epstein, Brown, \& Steer, 1988; Kumar, Steer, \& Beck, 1993) or 5 factor structures (Borden, Peterson, \& Jackson, 1991), the data converge to suggest that both clinical and non-clinical anxiety as measured by the BAI is characterized by not only subjective apprehension, but also distinct physiological responses in terms of elevated autonomic and neurophysiological arousal.

\section{Neurobiology of Anxiety}

Gray's BIS theory $(1981 ; 1982)$ incorporates one of the most elaborate models of the neurobiology of anxiety. This model is grounded in research related to the psychopharmacology of anxiety, as well as in principles of behavioral neuroanatomy and neurophysiology. In Gray's view, the septo-hippocampal system and its afferent and efferent limbic pathways are key structures in anxiety. Physiologically, in this view, 
anxiety at its most basic level is likely grounded in noradrenergic and seretonergic afferent pathways to the septo-hippocampal system from the locus ceruleus and raphé nuclei. These pathways are hypothesized to play crucial roles in vigilance to and labeling of sensory information. In humans especially, anxiety is also associated with descending pathways from the neocortex, specifically the prefrontal cortex, which incorporate scanning of ongoing behavior and language capacities to give rise to the experience of anxiety. The BIS, which utilizes a variety of cortical and subcortical structures and contains an intricate system of interconnections, is activated by three primary classes of stimulation: signals of punishment, signals of non-reward, and novelty. Gray suggests that anxiety is a phylogenetically old emotion that is dependent upon scanning the environment for threat in the form of such stimuli. When the BIS is activated, it acts to inhibit ongoing behavior, increase arousal, and increase attention to relevant stimuli. Therefore, individuals with a highly-reactive BIS are considered more likely to experience the emotion of anxiety.

Reiman, Fusselman, Fox, and Raichle (1989) presented evidence of parahippocampal involvement in anxious states. They utilized positron emission tomography to examine regional blood flow during anticipatory anxiety in 8 participants with no history of psychiatric or other medical disorders. Increased anticipatory anxiety from the threat of shock was associated with increased regional blood flow in both temporal poles. Although the resolution of the scans left the full scope of this increased blood flow unseen, it appeared that it likely continued into bilateral frontal regions as well. In line with Gray's system, it was suggested that the temporal poles might be implicated in the affective evaluation of environmental stimuli as potentially dangerous. 
These investigators had similar findings in a group of panic disorder patients, as those susceptible to lactate-induced panic showed greater blood flow and metabolism in the right parahippocampal region, as well as greater whole brain oxygen metabolism (Reiman, Raichle, Butler, Herscovitch, \& Robins, 1984; Reiman et al., 1986).

Lang and colleagues (1998) formulation of the neurobiology of anxiety has a great deal of overlap with Gray's propositions. In the Langian view the amygdala is of central importance, as it receives input on potential threat from the sensory cortex via sensory thalamus. From the amygdala, information is then passed on to specific aversion circuit branches which mediate specific behavioral outputs. Specifically, efferent transmission through the hypothalamus may give rise to autonomic increases, transmission through central gray matter mediates fight/flight and freezing reactions, and involvement of the nucleus reticularis pontis caudalis mediates the startle reflex. This is supported by LeDoux's work (2001) indicating that fear conditioning follows parallel cortical-amygdaloid and thalamic-amygdaloid routes. In both routes, he suggests that lateral and central portions of the amygdala play a key role in acquiring and storing fear related memory, as well as in their expression through efferent connections to the brainstem, autonomic nervous system, and hypothalamic-pituitary-adrenal (HPA) axis. The more primitive thalamus-amygdala circuit involves basic stimulus representations from the sensory thalamus activating the amygdala, more quickly triggering lower-level, "hard-wired" behavioral reactions. At the same time, cortical sensory areas may stimulate the amygdale and produce different behavioral patterns. Further, the amygdala is hypothesized to have reciprocal influences on cortex, potentially influencing cortical sensory processing when activated. Such limbic influence on cortex is believed to 
account for the generalized frontal lobe activation observed during emotional states, a mechanism believed to increase overall readiness to process and respond to environmental stimulation (Dawson, 1994).

Kalin's study of anxious temperament in rhesus monkeys (Kalin, Shelton, Davidson, \& Kelley, 2001) suggested that the amygdala, although likely important in unconditioned fear responses, may not be crucial for the maintenance of longstanding, temperamentally based anxious responding. While his line of investigations has not yet identified specific brain structures involved, he hypothesizes that orbitofrontal cortex plays a key role in long-term maintenance of anxious responding (Kalin, 2003). Although the underlying structural components are unclear in Kalin's formulation, his work does suggest that temperamental anxiety in these animals is associated with right hemisphere asymmetry, a finding that has been consistently found in humans as discussed further below. In addition, his work suggests that such cerebral asymmetry is associated with chronically elevated levels of cortisol (Kalin, Larson, Shelton, \& Davidson, 1998) and corticotropin-releasing hormone (Kalin, Shelton, \& Davidson, 2000).

Corticotropin-releasing factor (CRF) acting within the HPA axis is also implicated in the development of anxiety and its disorders in humans. Both anxiety and mood disorders are associated with elevated CRF activity, and CRF administration leads to behavioral profiles consistent with negative affective states (Heim \& Nemeroff, 1999). Heim and Nemeroff (1999) suggested that in addition to serving as a releasing factor, CRF serves as a neurotransmitter that mediates the relationship between stressful life events and the development of mood and anxiety disorders. Specifically, it was 
suggested that stress during early development may result in chronically elevated activity in CRF systems, sensitizing the HPA axis to the effects of stress later in life, thereby lowering the threshold to develop anxiety disorders. In this regard, there is evidence that elevated maternal HPA activity has deleterious effects in terms of infant developmental outcomes (Huizink, Robles de Medina, Mulder, Visser, \& Buitelaar, 2003; Ponirakis, Susman, \& Stifter, 1998).

There is evidence that these HPA circuits are regulated by prefrontal cortex (Diorio, Viau, \& Meany, 1993) and that these prefrontal structures are marked by hemispheric asymmetries that are related to the expression of anxiety and elevated cortisol levels as early as infancy (Buss et al., 2003). In general, anxiety and its behavioral manifestations of inhibition, withdrawal, and avoidance are associated with increased right hemisphere activity, while positive affectivity and approach behavior are associated with relatively increased left hemisphere activity. For example, Jones and Fox (1992) recorded electroencephalogram (EEG) activity from frontal, temporal and parietál locations while undergraduates viewed film clips that elicited happiness, sadness, and disgust. Participants were divided into two groups based on the degree to which they generally experienced positive or negative affectivity. Those high in positive affect showed greater left hemisphere activation in response to the happy film, while those high in negative affectivity showed greater right sided activation in response to the disgust film. Further, examining the data without respect to trait levels of positive/negative affectivity, those who rated the disgust film as most aversive showed greater right hemisphere activation while viewing this film. These results suggest that hemispheric asymmetries may be associated with both the discrete experience of negative affect and 
more general dispositions to experience such affective states.

Heller, Nitschke, Etienne, and Miller (1997) examined an undergraduate sample categorized into anxious or control groups based on their self-report on the State-Trait Anxiety Inventory (Spielberger, Gorsuch, Lushene, Vagg, \& Jacobs, 1983). The study's methodology was based in the conceptual framework that anxious arousal (i.e., panic; Watson et al., 1995) can be differentiated from anxious apprehension (i.e., worry; Barlow, 1991; 2001). EEG activity was recorded from frontal, parietal and central locations, averaged to mastoids, during both a baseline condition and the presentation of verbal narratives of different affective valences. Based on pilot testing, it was purported that the negative and sad narratives chosen would induce a state of anxious arousal that could be differentiated from resting levels of anxious apprehension. While anxious subjects showed frontal asymmetry favoring the left hemisphere in all conditions due to a relative decrease in right hemisphere activity, they exhibited asymmetry characterized by increased right parietal activity during the presentation of fearful and sad narratives. While the authors framed this as evidence of hemispheric differences that differentiate discrete subtypes of anxiety, the findings are necessarily limited by both questionable operationalization of these emotional states and the poor spatial localization of EEG technology.

Nitschke and colleagues (Nitschke, Heller, Palmieri, \& Miller, 1999) had similar findings in an undergraduate sample. Participants were grouped based on experiencing anxiety predominantly characterized by anxious apprehension or anxious arousal, in line with the theoretical proposition that these are emotionally distinct states (Barlow, 2002). During resting EEG, it was found that the anxious arousal group (the construct more 
conceptually linked to panic) showed hemispheric asymmetry characterized by greater right than left activation. The hypothesis that the more linguistically driven emotion of anxious apprehension would be associated with greater left than right activation was not supported, however. Wiedmann and colleagues (1999) studied such patterns of frontal brain asymmetry in panic disorder patients. They recorded spontaneous EEG activity from 25 non-depressed panic disorder patients and 25 controls during a number of conditions including visual presentation of panic and anxiety-related stimuli. During the presentation of neutral stimuli and an emotionally neutral motor task, no asymmetries were observed in either group. However, during baseline periods and in the face of panic/anxiety relevant stimuli, the patient group exhibited greater right than left frontal brain activation, an asymmetry that was not observed in the control group. As will be discussed in detail below, the above neurophysiological correlates of anxiety can be detected early in development and may reflect inherent vulnerabilities toward the development of anxiety disorders throughout the lifespan.

\section{Disorders of Anxiety}

While anxiety and fear are adaptive responses within appropriate contexts, their pervasive occurrence across contexts suggests pathological levels of these emotions and may lead to a range of dysfunctions for the individual (Goldsmith \& Lemery, 2000). This is seen in DSM-IV-TR's (APA, 2000) classification of the anxiety disorders, which includes panic disorder with or without agoraphobia, social phobia, generalized anxiety disorder, obsessive-compulsive disorder, specific phobia, posttraumatic stress disorder, and acute stress disorder, as well as medically induced or substance induced anxiety disorder and anxiety disorder not otherwise specified. While these disorders differ in the 
specific focus of anxiety, they all share the common dimension of the presence of significant distress and functional impairment for individual sufferers. Over 15 million adults in the United States will suffer from an anxiety disorder each year, and over 30 million will be afflicted in their lifetime (Lepine, 2002). These disorders cost over $\$ 40$ billion annually as a result of the costs of psychiatric and non-psychiatric treatment, pharmaceuticals, workplace absenteeism and reduced productivity, and suicide (Greenberg et al., 1999).

Anxiety disorders are also highly prevalent in children and adolescents, representing one of the most common forms of psychopathology in these populations (Kashani \& Orvaschel, 1990), and affecting up to $17 \%$ of non clinic-referred (Kashani \& Orvaschel, 1988) and up to $45 \%$ of clinic-referred populations (Last, Perrin, Hersen, \& Kazdin, 1992). Childhood anxiety disorders are also associated with costs in terms of academic and family difficulties (Costello, 1989) and increased risk for the development of future anxiety and other psychiatric disorders (Last, Perrin, Hersen, \& Kazdin, 1996). Childhood anxiety disorders closely resemble adult anxiety disorders as early as the preschool years. For example, Spence, Rapee, McDonald, and Ingram (2001) found that the structure of anxiety symptoms in a preschool population was well accounted for by a five factor model characterized by social anxiety, separation anxiety, obsessivecompulsive symptoms, fears of physical injury, and generalized anxiety, all subsumed under a general higher order anxiety factor. This structure closely resembles the DSMIV-TR (APA, 2000) structure of anxiety disorders. While suggesting that anxiety disorders may begin to differentiate at an early age, this model also highlights the early presence of a unitary dimension of anxiety that may reflect a predisposition toward the 
development of such disorders. While there is evidence that childhood anxiety disorders are amenable to both cognitive behavioral and pharmacological treatment (e.g., Barrett, Dadds, \& Rapee, 1996; Simeon et al., 1992), there is also evidence that prevention of anxiety disorders is possible through early identification and intervention efforts (Dadds et al., 1999; Sheeber \& Johnson, 1994). Furthering such efforts may be of benefit in reducing the human and financial costs associated with these disorders.

$$
\text { Models of Anxiety Development }
$$

\section{Genetic Contributions}

That anxiety disorders breed true in families is demonstrated in work by Turner and colleagues (Turner, Beidel, \& Costello, 1987) in which children of anxiety disordered parents were seven times more likely than children of control parents to be diagnosed with an anxiety disorder. A genetic component is almost certainly involved in this pattern of familial heritability. For example, Torgersen (1983) found the concordance for anxiety disorders to be twice as high in monozygotic than dizygotic adult twin pairs for a number of anxiety disorders including panic disorder, agoraphobia, social phobia, and obsessive-compulsive disorder. Work by Kendler and colleagues with adult twins (Kendler, Heath, Martin \& Eaves, 1987) also supports the role of genetic underpinnings in anxiety, although the diathesis is seen as a non-specific vulnerability to develop anxiety or depression. The same group (Kendler, Neale, Kessler, Heath \& Eaves, 1992) later added further support, reporting that generalized anxiety disorder and major depressive disorder were influenced by the same genetic factors. The authors concluded that environmental influences likely contribute to specific manifestations within the anxiety and depressive disorders. 
Twin studies in children have also supported the role of a non-specific genetic influence on anxiety and depression. For example, studies using the Child Behavior Checklist (Achenbach, 1991) have found that genetic influences account for 34-65\% of the variance in parent ratings of their children on this measure's anxious/depressed subscale (Edelbrock, Rende, Plomin, \& Thompson, 1995; Hudziak, Rudiger, Neale, Heath, \& Todd, 2000). Eley and Stevenson (1999) had children complete separate anxiety and depression self-report measures, and also concluded that both anxiety and depression appear to be influenced by the same genes. Beidel and Turner (1997) also support a fairly non-specific risk, as children of both depressed and anxious parents were at an increased risk for the development of anxiety disorders. Further, this relationship was moderated by family socioeconomic status, implicating the importance of environmental variables in the expression of such disorders. Before examining such environmental factors, it is important to review temperamentally based anxiety risks that play an interactive role.

\section{Temperament}

Interest in constitutional factors related to the expression of anxiety dates as far back as the time of Hippocrates and Galen (Kagan \& Snidman, 1999; Lonigan \& Phillips, 2001). Recently, Kagan and his colleagues at Harvard have identified a specific temperamental variable that indeed appears closely related to the development of anxiety. Drawing from more broadly focused examinations of temperamental precursors to a range of emotional and behavioral outcomes (e.g., Thomas \& Chess, 1977; Thomas, Chess, \& Birch, 1968), this group has produced longitudinal behavioral observation data that point to behavioral inhibition as an important temperamental precursor to anxiety. 
Behavioral inhibition has been associated with high reactivity in infancy in the form of vigorous limb movements, increased sympathetic cardiovascular arousal, and behavioral manifestations of distress and fear such as crying and avoidance in response to unfamiliar events and situations (Kagan, 1994a; Kagan \& Snidman, 1999): Although marked by such behavioral manifestations that appear more active than inhibited, infants displaying such reactive temperaments are more likely to be rated as inhibited by 14 months of age in terms of their hesitancy to interact with novel people and objects (Kagan, 1994a). By 21 months of age, approximately $10 \%$ of children display extreme behavioral inhibition characterized by long latencies to interact with or avoidance of unfamiliar objects and people, as well as inhibition of play, maternal clinging, crying, and fretting in response to such stimuli (Garcia-Coll, Kagan, \& Reznick, 1984).

This temperamental trait appears to endure, as children rated as behaviorally inhibited at 21 months were found to be more likely to be inhibited at age four (Kagan, Reznick, Clarke, Snidman, \& Garcia-Coll, 1984). This inhibition was evidenced by such indices as increased latency and decreased attempts to engage an unfamiliar peer, as well as greater hesitancy in attempting to answer a difficult problem. Similar results have been observed at age seven, with those who were behaviorally inhibited as infants appearing more socially inhibited in interactions with an adult examiner, as well as exercising greater caution when approaching a problem involving response uncertainty (Kagan, Snidman, Zentner, \& Peterson, 1999). Early reactivity and behavioral inhibition is associated with a greater risk for the development of anxiety symptoms, as well as multiple childhood and adult anxiety disorders, including social phobia, separation anxiety, agoraphobia, and panic disorder (Biederman et al., 1993; Kagan \& Snidman, 
1999; Kagan et al., 1999; Rosenbaum, Biederman, Hirshfeld, Bolduc, \& Chaloff, 1991; Schwartz, Snidman, \& Kagan, 1999).

Rosenbaum et al. (1988) found behavioral inhibition, marked by decreased frequencies of spontaneous comments and increased latencies to speak when interacting with unfamiliar examiners, to be more prevalent in two to six-year-old children of patients being treated for panic disorder and agoraphobia, although more recent work suggested that the presence of parental comorbid major depression was an important variable in explaining this link (Rosenbaum et al., 2000). The same group also reported that behaviorally inhibited children were significantly more likely to be diagnosed with multiple anxiety disorders (Biederman et al., 1990), a finding that was consistent at a 3year follow-up assessment (Biederman et al., 1993). This sample included both an epidemiologically derived group of children who were initially classified as behaviorally inhibited at 21 months of age and first underwent diagnostic assessments at approximately age seven, as well as a cross-sectional cohort of children of panic disorder and agoraphobia patients who were between ages four and seven at the time of initial assessment of both behavioral inhibition and psychopathology.

In related work, Kagan et al. (1999) reported that four-month-old infants classified as highly reactive (increased motor activity and signs of distress such as fretting or crying in response to unfamiliar stimuli) were more likely to display anxious symptoms by seven years of age than those in a non-reactive group. Warren, Huston, Egeland, and Sroufe (1997) provided support for the role of behavioral inhibition over a longer period of time, as infants who were classified as highly reactive based on nurse ratings of crying, motor activity, and ease of relaxation when held were more likely to 
meet criteria for anxiety disorders 16 years later. Those who went on to develop anxiety disorders were also more likely to have been rated as high in arousability and slow to habituate, dimensions which have also been found to differ in infants of anxious versus non-anxious mothers (Field, Sandberg, Quetel, Garcia, \& Rosario, 1985).

In summary, evidence to date suggests that a highly reactive infant temperament is associated with increased risk for the expression of an inhibited temperamental style from 14 months on, as well as increased risk for the development of clinically significant anxiety into adulthood. While a highly reactive temperament does not definitively determine the development of an inhibited, anxious style, it seemingly "constrains the probability of becoming a consistently fearless, uninhibited child" (Kagan et al., 1999, p. 222). Therefore, while the progression from a reactive to an inhibited temperament may represent an inherited diathesis toward developing later anxiety disorders, the expression of such disorders is likely linked to the extent of this inhibition or its interaction with psychosocial variables such as parental psychopathology (Rosenbaum et al., 1991).

\section{Neurobiological Risks}

The literature on temperamental precursors to anxiety is closely related to the study of neurobiological risks that may accompany such temperaments. In one of the first such investigations (Dawson, Grofer Klinger, Pangiotides, Hill, \& Spieker, 1992), evidence was presented that maternal negative emotionality is potentially associated with differences in infant neurophysiological responding. The investigators recorded frontal and parietal EEG from 11 to 17-month-old infants during baseline, maternal playfulness and maternal separation conditions. Behaviorally, infants of mothers reporting elevated depressive symptomatology were quicker to become distressed and exhibited greater 
emotional distress during separation. Further, infants of depressed mothers showed different patterns of electrophysiological activation. Specifically, they did not show the greater left frontal activation during the playful condition observed in the infants of nondepressed mothers. Infants of depressed mothers did exhibit greater left frontal activation during maternal separation, however, a finding not observed in the control group. These were important findings, suggesting that maternal negative emotionality may affect infants very early in development, not only in terms of behavioral responses, but also in terms of potential compromise in the neurophysiological substrates of emotional development and regulation.

In a similar investigation by the same group (Dawson, Pangiotides, Grofer Klinger, \& Hill, 1992), EEG was recorded from 2 frontal and 2 parietal sites in 21month-old infants during conditions of baseline and maternal separation, conditions that were associated with low and high emotional arousal, respectively, in all infants. During periods of increased infant emotional arousal, greater activation was observed in frontal than parietal sites, with greater parietal than frontal activation being observed during baseline conditions. This activation was also correlated with infant facial expression, as greater frontal activation was present during sad and angry expression compared to neutral expression. Further exploration of relative hemispheric differences indicated greater left activation during happy facial expressions and greater right activation during sad expressions. The authors suggested that the generalized increases in frontal activation across hemispheres during emotional arousal may have resulted from the influence of subcortical structures that "serve to increase the infant's 'readiness' to receive and respond to external stimuli" (p. 164), with the frontal structures serving 
associated roles in attention/alertness and readiness to initiate motor responses.

Follow-up work from this group supported the idea that infants of depressed mothers exhibit different patterns of brain activation (Dawson et al., 1999). Frontal and parietal EEG activity was recorded from 13 to 15 -month-old infants during baseline, maternal play, stranger approach, stranger play, and maternal separation conditions. On a separate day, infant behavior during three naturalistic situations was observed and coded, These situations varied in task and structure, allowing assessment of the infant's behavior in an unstructured maternal free play condition, in a condition that allowed assessment of infant self-regulatory abilities when the mother showed divided attention, and in a puzzle task that allowed assessment of mastery motivation. As in the previous study, behavioral differences were observed, with infants of depressed mothers exhibiting less affection toward their mothers and more difficulties in self-regulation when not receiving their mother's full attention. The infants of depressed mothers exhibited reduced left frontal activation, and this pattern of activation was correlated with decreased displays of affection toward their mothers during free play and increased rates of negative behaviors aimed at getting their mothers' attention during the divided attention condition. While no differences were observed in terms of overall levels of frontal activation between the groups, increased frontal activation was significantly positively correlated with displays of negative affect and negative behaviors marked by aggression, hostility, and tantruming in infants of depressed mothers only. Given that no behavioral differences were observed during EEG recording and that EEG activation was correlated with behavior on a different day, the findings are framed as representative of "an acquired trait marker" stemming from both poor self-regulatory mechanisms and exposure to the mother's 
depressive behaviors (p. 602).

Buss and colleagues (Buss et al., 2003) have also observed hemispheric asymmetries associated with negative affect as early as infancy. From their studies of 6month-olds, it has been reported that relatively greater right frontal EEG activity predicts greater expression of negative affect during approach by a stranger, as well as higher fear scores based on maternal report. Further, this asymmetry is significantly positively correlated with baseline and reactive cortisol levels in these infants. Previously, Davidson and Fox (1989) had similar findings in terms of hemispheric asymmetries as correlates of anxious responding. They recorded baseline frontal and parietal EEG from 10-month-old infants before presenting them with maternal separation. Although 35 infants were tested, data from a number of subjects could not be analyzed due to excessive artifacts in the data. Among the 13 infants presented in the study, 6 were classified a criers and 7 as non-criers in response to maternal separation. While the groups were equivalent in terms of overall EEG power, those who cried had greater right frontal activation. It is argued that these hemispheric differences were not simply reflections of those infants experiencing overall dysphoric mood states on the day of testing, as pre-baseline observation showed no differences in facial behavior between the groups. Further, infant differences in response to separation and EEG asymmetry were found to remain relatively stable over seven monthly follow-ups (Bell \& Fox, 1992). Further supporting the stability of these differences, Fox (1992) reported that 14-monthold infants who cried upon maternal separation showed greater right frontal EEG activation during follow-up testing 2 months after the maternal separation assessment.

The infant behaviors of interest in the above studies are consistent with the 
spectrum of behavioral inhibition proposed by Kagan to be a temperamental precursor to anxiety; interestingly, behavioral inhibition has similar evidence of underlying hemispheric asymmetries. Kagan's group (McManis, Kagan, Snidman, \& Woodward, 2002) conducted follow-up EEG testing on one hundred and sixty-six 10 to 12-year-old children who had participated in their original investigation of behavioral inhibition (Kagan, 1994a). These children had been classified into high reactive, low reactive, distressed, or aroused at 4 months, and were also grouped on fearfulness at 14 and 21 months. During follow-up testing, EEG was recorded during a mildly challenging condition in which they were told to prepare to stand and share what they had thought about on the way to the laboratory procedure. The primary variable of interest was hemispheric asymmetries in alpha power, with reduced alpha power suggesting increased cortical activation associated with cognitive processing. For frontal sites, the majority of children showed greater left than right activation; however, $70 \%$ of those who were both high reactive at 4 months and highly fearful during their second year (i.e., behaviorally inhibited) were more right active under at least one of the experimental conditions.

This same group also reported on brainstem auditory evoked response (BAER) assessments conducted on 32 high-reactive and 24 low-reactive 10 to 12 -year-old . children (Woodward et al., 2001), although it is unclear what degree of overlap is present between this and the sample described above. BAERs are characterized by 7 waves arising from discrete brainstem structures, with wave V hypothesized to originate in the inferior colliculus. Consistent with the study's hypotheses, greater wave V amplitudes were observed in children who had been labeled high reactive at four months. The authors proposed a number of explanations for this finding, including the possibility that 
the amygdala and its projections to the inferior colliculus, or the inferior colliculus itself, may be more excitable in this temperamental group. Another possibility set forth is that the difference could arise from the novelty sensitive locus ceruleus, which also projects to the inferior colliculus. Whatever the explanation, these findings suggest the contribution of specific brain circuits in the development of emotional and temperamental outcomes, and the call for use of such physiological investigations in the examination of risk factors for such outcomes.

Field and colleagues (Field, Diego, Hernandez-Reif, Schanberg, \& Kuhn, 2002) reported broader reaching correlates of hemispheric EEG asymmetry in a neonate population. Three minutes of EEG were recorded from 48 healthy newborns from two central and two parietal electrodes. Infants who showed greater right than left activation exhibited more restless sleep, poorer scores on a neonatal behavioral assessment, and higher cortisol levels. Further, their mothers, who also showed greater right activation, reported higher prenatal depression, anxiety, anger, and inhibition/avoidance. These mothers also had lower prenatal and postnatal serotonin levels and higher postnatal cortisol levels. As the authors discuss, EEG asymmetry was associated with biochemical and behavioral outcomes in these newborns, supporting the use of : electroencephalographic techniques in potentially identifying newborns who could benefit from early intervention efforts.

In a more recent and much more methodologically rigorous examination of laterality of brain responses in anxious children, Baving, Laucht, and Schmidt (2002) showed that gender is an important variable to consider. They reported that clinically anxious eight and eleven-year-old girls exhibited greater right frontal than left frontal 
activation. In contrast, control girls with no history of any psychopathology, exhibited no lateralization at 8 years, but had greater left than right frontal activation at age 11 . Boys showed a markedly different pattern. While no laterality of findings was present for anxious 8-year-old boys, anxious 11-year-old boys exhibited greater left than right activation. Control boys, on the other hand, had greater right frontal activation at both ages 8 and 11 . Framing their findings in the context of a broadly scoped literature review, much of which is cited in the above discussion of adult lateralization in negative affect, the authors suggest that "brain organization regarding emotion regulation could be not only inherently asymmetrical, but also differentially lateralized in males and females, as revealed by gender differences in frontal brain activation patterns" (p. 272).

\section{Parenting}

While early genetic, temperamental, and neurobiological profiles are supported as important precursors to anxiety disorders, it is also well established that such variables interact with environmental influences to produce specific outcomes. In regard to these environmental contributions, a variety of approaches have been undertaken to understand factors linked to parental anxiety that may play an important role. Such research has largely been devoted to the study of maternal variables, with some interest in paternal contributions, as well as the role of more general family systems. For example, Barrett, Rapee, Dadds, and Ryan (1996) reported that anxious children were more likely to choose avoidance as a coping mechanism in the face of hypothetical threatening scenarios, and that this bias increased following family discussion. Later analysis of these interactions (Dadds, Barrett, Rapee, \& Ryan, 1996) revealed that parents of anxious children were more likely to reinforce their child's choice of avoidance as a solution, 
agreeing with and listening to their children less when the child proposed a more prosocial plan of action. Although follow-up work (Cobham, Dadds, \& Spence, 1999) failed to replicate this finding when the child was actually confronted with a threatening task (giving a speech in front of a camera), Dadds and Roth (2001) reported that anxious parents were more controlling, directive, and domineering in their attempts to help their children prepare for this task.

A number of other studies have pointed to such parenting styles, marked by negativity/criticism (often termed affectionlessness) and control, as precursors to the development of anxious offspring. For example, in terms of retrospective studies, Wilborg and Dahl (1997) found that adult panic disorder with agoraphobia patients recalled their parents as less caring and more protective than controls, while Morris (2001) presented findings in which college undergraduates who recalled their parents as displaying higher affectionless control were likely to experience elevated levels of trait anxiety and depression. Others have used current ratings of family processes by both parents and children. For example, Messer and Beidel (1994) reported that children with anxiety disorders described their families as promoting less independence than control children did. Siqueland, Kendall and Steinberg (1996) reported that anxious children described their parents as less accepting, while parent report of childrearing styles did not reveal any significant differences. However, observer ratings supported the children's reports, as parents of anxious children appeared to grant less psychological autonomy during a discussion task.

Recently, other observational approaches have yielded similar results. Whaley, Pinto, and Sigman (1999) examined mother-child dyads engaged in three conversations 
designed to elicit different levels of anxiety. Anxious mothers were found to be less warm and less granting of autonomy, and catastrophized and criticized more than their control counterparts. Woodruff-Borden, Morrow, Bourland and Cambron (2002) undertook a similar investigation, examining mechanisms of anxiety transmission between parents and children in two anxiety provoking tasks: working unsolvable anagrams and the preparation of an autobiographical speech for the child to deliver in front of a video camera. Anxious parents were less productively engaged, and were more withdrawn and disengaged in the interactions. Framing their findings in the context of previous literature, the authors hypothesized that anxious parents may be largely disengaged from such tasks, becoming more controlling in response to displays of negative affect on the part of their child.

As seen above, both controlling and affectionless parenting styles have been linked to the development of anxiety. Rapee (1997) attempted to integrate this diverse literature and concluded that both anxiety and depression are consistently related to affectionless control, with control likely being the more important correlate of anxiety. It has been hypothesized that overcontrolling parenting may contribute to negative affectivity in children by instilling a bias toward viewing the world as a uncontrollably negative and dangerous place, and preventing opportunities to learn otherwise (Chorpita \& Barlow, 1998; Rapee, 1997). Although this hypothesis appears to give more weight to the dimension of control, much of the literature continues to support the importance of the affectionless dimension or the combination of affectionlessness and control. In fact, the overcontrol exhibited by anxious parents is often exerted in an affectionless manner. For example, Dumas, LaFreniere, and Serketich (1995) found that anxious parents 
attempted to exert control through means such as coercion and ignoring. However, such parental behavior appeared to interact with child variables, as anxious children also engaged in aversive behaviors, attempting to exert control through coercion and resistance.

Others have attempted to more directly explore the presence of statistical interactions between parent and child variables. For example, Hirshfeld, Biederman, Brody, Faraone, and Rosenbaum (1997a) reported that maternal criticism was positively associated with higher rates of behavioral inhibition in children, independent of the effects of child psychopathology. Further investigation into this association (Hirshfeld et al., 1997b) revealed an important interaction effect as maternal criticism was found to be associated with increased child behavioral inhibition and increased incidence of child disorders only in mothers with anxiety disorders. The authors hypothesized that the interaction between maternal anxiety and behavioral inhibition "may contribute to a strained mother-child relationship, heightened stress for both, and possibly the exacerbation of symptoms for both" (p. 915). Control mothers, on the other hand, appeared not to respond to this difficult temperamental variable with the dissatisfaction and frustration seen in anxious mothers, potentially leading to a different mother-child dynamic and improved outcomes.

In terms of the controlling dimension, Arcus (presented in Kagan, 1994a) found that maternal overprotection of infants predicted their later expression of fear. However, an interaction was present, as this effect was present only for infants classified as high in behavioral inhibition, and not those low on this dimension. Nachmias, Gunnar, Mangelsdorf, Parritz, and Buss (1996) also explored the interaction between parental and 
child variables. They reported that behaviorally inhibited 18-month-old children showed elevated salivary cortisol levels in response to novel stimuli including an adult female clown, a mechanical robot, and a puppet show. However, examination of the interaction between behavioral inhibition and attachment security revealed that increased cortisol levels were only present in those who were behaviorally inhibited and in insecure attachment relationships. Such attachment relationships were associated with intrusive parenting behaviors that appeared to interfere with children's attempts to cope with these situations. In addition to parent and child behavior, it is important to understand the contribution of cognitive biases that are likely also related to the development and maintenance of anxiety within these parent-child interactions.

\section{Cognitive Biases/Information Processing}

As discussed previously, anxiety is associated with a number of cognitive biases, particularly attentional biases toward novelty or perceived threat. Determining whether such attentional biases represent vulnerabilities related toward the development of anxiety requires an examination of related findings in early development. There is evidence that anxious children indeed evidence attentional biases toward threat-related words on a variety of visual attention tasks as seen in adults, although there is controversy over how early such differences emerge and which experimental paradigms are best suited to explore these effects (Vasey \& MacLeod, 2001). For example, Vasey, Daleiden, Williams, and Brown (1995) conducted the first examination of attentional biases toward threat in a sample of clinically anxious children. The children ranged in age from nine to 14 years, and were presented with a visual dot-probe attention task that included both neutral and threatening words. While clinically anxious children exhibited 
an attentional bias toward threatening words, controls did not show the hypothesized bias away from such words. Although such findings cannot establish a causal link, they do suggest the potential impact of attentional biases as important in the development and/or maintenance of anxiety disorders.

Taghavi and colleagues (Taghavi, Neshat-Doost, Moradi, Yule, \& Dalgleish, 1999) also utilized a dot probe task with a sample of generalized anxiety disorder, mixed anxiety-depression, and control participants ranging in age from nine to 18 . The emotionally valenced words in the task were physically threatening, socially threatening, or depression-related in nature. An attentional bias toward threat related words was observed in the generalized anxiety group only. This effect was rather specific, as these individuals did not show a bias toward depression related words. No attentional biases were observed in mixed anxiety-depression or control participants. Dalgleish and colleagues (2003) had similar findings, as clinically anxious children and adolescents evidenced an attentional bias toward threat-related stimuli on a dot probe task. However, highlighting the mixed findings in this line of research, this finding did not hold up as strongly on a Stroop measure of biased attention, and no significant correlation emerged between the observed attentional biases on these two tasks.

Vasey and MacLeod (2001) reviewed the mixed evidence on attentional biases in children and stated that, "[g]iven that theories concerning the role played by attentional bias in the development of anxiety disorders depend so critically on the age at which the association between attentional bias and elevated trait anxiety becomes evident, it would seem to be of particular importance that future research should endeavor to resolve this issue" (p. 270). Wilson and Gottman (1996) suggested that such a relationship may be 
present even in infancy, with attentional control processes being central to an infant's ability to maintain physiological homeostasis. They suggested that highly reactive infants may have unique difficulties in attentional control, leading them to "spend a large proportion of their time in a state of physiological dysregulation and miss many social and cognitive opportunities" (p. 207). Therefore, early differences in attentional processes may be important links in the development of later psychopathology and may have connections with related temperamental dimensions such as behavioral inhibition.

These anxiety-related attentional biases are likely not specifically confined to objectively threatening stimuli, but may be present simply in response to novelty (Gray, 1982). In fact, cognitive biases of anxious adults are found even in response to ambiguous scenarios, with these individuals rating the probability of personal harm in response to such scenarios as higher than the probability of harm to others (Butler \& Matthews, 1983). This is also supported by psychophysiological studies of skin conductance habituation with anxious patients. For example, Lader and Wing (1964) demonstrated that a mixed group of anxious patients showed a slower habituation of psycho-galvanic reflexes to auditory stimuli than a matched control group. Roth et al. (1990) later had similar findings, with panic disorder patients habituating more slowiy to auditory tones than a control group.

Again, such findings are present in childhood, although there are relatively few studies to strongly support this conclusion. In a preliminary investigation of this topic, Chorpita, Albano, and Barlow (1996) found that increased trait anxiety in nine to 13year-old children was associated with increased likelihood of interpreting ambiguous situations in an anxious manner. In follow-up work, Barret, Rapee, Dadds, and Ryan 
(1996) presented children with ambiguous scenarios that could have been interpreted as physically or socially threatening, but that could just as readily have been interpreted as non-threatening. They found that clinically anxious children interpreted these ambiguous scenarios as more threatening than control children did, and that they tended to choose avoidance as a coping mechanism. Bell-Dolan (1995) presented children with videotaped vignettes of peer interactions that showed either hostile, accidental/non-hostile, or ambiguous behaviors being perpetrated. While both anxious and non-anxious children were equally adept in identifying true hostile interactions, anxious children were more likely to perceive hostile intent when it was not present. Others have reported that when presented with homophones that can be interpreted as either neutral or threatening, anxious children are more likely than controls to utilize the threatening meaning (Hadwin, Frost, French, \& Richards, 1997).

\section{Initial Summary and Integration}

There are multiple constitutional and environmental pathways potentially associated with the development of anxiety disorders. The risk toward developing anxiety disorders may be a fairly non-specific vulnerability toward the development of negative affect, and specific manifestations of anxious pathology may be the product of complex biological-environmental interactions (e.g., Eley \& Stevenson; 1999; Kendler et al., 1987; 1992). Therefore, examinations of the "familial transmission of vulnerabilities" are warranted as an important starting point (Dadds \& Roth, 2001). Any contributions that aid in the early detection of such vulnerabilities will aid in improved theoretical understanding and may ultimately contribute to the prevention of maladaptive anxiety before its resulting human and financial costs are incurred. 
In terms of potentially important vulnerabilities, it appears that anxious adults and children are more cognitively vigilant to the environment, especially novel environmental stimuli, which they are more likely to interpret as personally threatening. Such attentional biases are closely related to distinct neural substrates, particularly reflected in increased activation of right hemisphere structures, and accompanied by unique physiological and behavioral responses. Derryberry and Reed's (2002) results suggest that the difficulties anxious individuals experience in disengaging attention from threatening cues may be present in early stages of automatic cognitive processing, with a bias away from threat later in processing, at which point individuals are better able to exercise attentional control. Along similar lines, Lindh et al. (1999) also presented findings that such attentional biases are seen in pre-attentive processing, as a group of panic disorder patients' attentional processing was affected subliminally by panic related words. Waters, Lipp, and Cobham (2000) showed such an effect in a group of clinically anxious children, suggesting that pre-attentive processing may influence observed attentional biases toward threat related stimuli across development.

The current study rests on the hypothesis that such early attentional biases may represent an essential cognitive vulnerability toward the development of anxiety. While any investigation of anxiety is plagued by the inevitable overlap of the constructs of anxiety and depression, with both states being associated with judgmental/interpretive biases, the bulk of evidence indicates that attentional biases toward novelty or threat are unique to anxiety (Mineka, Watson, \& Clark, 1998). Such biases may be important precursors to the development of more sophisticated cognitive schemas seen in anxious adults (e.g., Beck et al., 1975; Hibbert, 1984). Given the necessary role of attentional 
capacities and attentional control to the development and maintenance of such schemas, Vasey and MacLeod's (2001) call to further evaluate the temporal emergence of such attentional biases in development provides a key rationale for the current work. These cognitive biases toward novelty, likely based in early dysfunction of neuroregulatory mechanisms, may interact with parenting behaviors discussed above in leading to patterns of emotion regulation marked by either interest and cautious approach or the more anxiety-related style characterized by fear and inhibition (Calkins, 1994).

Event Related Potentials in the Study of Anxiety

\section{Defining Event Related Potentials}

Given the potential importance of anxiety-related attentional biases emerging in the earliest stages of development, auditory event related potentials (ERPs) provide a promising tool to explore such vulnerabilities. ERPs are a widely studied phenomenon that hold potential for both informing theory and creating applied techniques within the field of psychopathology. An ERP is the portion of the brain's ongoing electroencephalogram (EEG), recorded at the scalp, that is time-locked to the onset of an experimental stimulus (Molfese \& Molfese, 1997). Because scalp-recorded electrical activity is affected by numerous sources, including non-experimentally related background brain activity and artifacts from muscle activity, ERPs from numerous presentations of the same stimuli must be averaged together in order to increase the signal-to-noise ratio (Electrical Geodesics, Inc., 2003). This procedure ultimately yields an average ERP with its distinctive peaks and troughs for each subject across experimental conditions. This pattern of voltages is thought to emerge from the postsynaptic potentials of many simultaneously firing neurons with similar orientations, 
likely mostly arising from parts of the cerebral cortex (Osman, 1998), although they have also been correlated with limbic activity, suggesting that more primitive brain structures may contribute to ERPs recorded at the scalp (Halgren et al., 1980).

Given the large number of neurons that likely contribute to ERPs, as well as the potential deflection of these potentials as they make their way through layers of cerebral cortex and skull to the scalp, researchers are largely limited in their ability to infer the source of such activity. However, coupling ERPs with other innovations such as functional magnetic resonance imaging allows increasing accuracy in making such inferences. What ERPs lack in spatial resolution, they uniquely contribute in their unparalleled temporal resolution, allowing examination of neurogenic activity milliseconds after stimulus presentation. In this regard, the first $500-700 \mathrm{~ms}$ poststimulus presentation alone are characterized by a number of positive and negative components that have been studied extensively in terms of their hypothesized relation to cognition. These components are grossly divided into what are considered to reflect exogenous and endogenous processing. Specifically, the earliest exogenous components are conceptualized as reflecting more basic, obligatory neural activity, arising in response to the perception of physical properties of a stimulus, while later endogenous components are hypothesized to arise from higher level information processing that may be evoked by processes other than the stimulus itself (Picton et al., 2000). In either regard, ERPs "can reliably indicate the presence and timing of specific cognitive processes" including attentional selection, target detection, and even surprise when an expected stimulus is deviant or absent (Osman, 1998, p. 906). Making this method even more attractive for the present investigation is the fact that no overt behavioral response is required on the part 
of the participant.

Specified ERP components are generally examined in terms of amplitude, latency, and scalp distribution. One of the earliest distinctive features of the ERP is a negative peak occurring within the first $150 \mathrm{~ms}$ post-stimulus onset (N1). Näätänen and Picton (1987) characterize N1 as a multifaceted component, and discriminate between "true" N1 components and other related components (e.g., MMN discussed below) that occur in this time window (p. 387). "True" N1 components, hypothesized to arise from several neural sources including the auditory, association, motor, and premotor cortices are considered to be influenced primarily by physical stimulus properties, as well as the subject's general arousal state. It is believed that these $\mathrm{N} 1$ components are indeed closely linked to attention, perhaps representing the action of an attention triggering mechanism or a mechanism involved in the establishment of a sensory trace against which later stimuli are compared. Näätänen (1990) suggests that N1 may represent neural processes that allow stimuli, whether initially attended or not, to "reach the level of conscious perception" (p. 229). Given the association of N1 generators and attentional processes, therefore, attentional biases may be reflected in enhanced $\mathrm{N} 1$ amplitudes. For example, as reviewed in more detail below, Weinstein (1995) framed N1 differences affected by anxiety as reflective of differences in "preattentive selective attention to threat" (p. 855).

Mismatch Negativity (MMN) is also an early negative component, generally occurring in the time window from 100-200 ms post stimulus onset. The MMN component is elicited in the face of stimulus change when, for example, an infrequently occurring auditory stimulus is presented within the context of a frequently occurring auditory stimulus ("oddball paradigm"). MMN is not dependent on conscious attention 
to the frequently occurring stimulus, and is believed to arise from neural detection of a stimulus that does not match the attentional sensory trace left by the frequent stimulus (Näätänen, 1990). As mentioned above, this initial stimulus trace is likely closely linked to the activity of $\mathrm{N} 1$ generators. The neural sources of the MMN detection system are believed to lie in the supratemporal auditory cortices, with some frontal cortex involvement as well (Näätänen \& Alho, 1995). Given MMN's connection to automatic attention and auditory sensory memory, as well as to detection of novelty in the face of standard stimuli, it is not surprising that it has been of much interest in examinations of anxiety.

It is purported that both MMN and N1 are related to systems for uncontrollable automatic attentional switches to environmental stimulation, representing "powerful environmental control over the focus of attention. They frequently make the organism attend to the present environmental situation by interrupting, though usually only for a very brief while, an attentional state directed at, for example, task performance" (Näätänen, 1990, p.230). As seen in this quote, N1 and MMN generators can be conceptually linked to activity of the behavioral inhibition system. Therefore, it is plausible that such a mechanism would be hypersensitive in the case of anxiety, and that increased activity in these systems might represent a vulnerability toward anxious responding.

Following earlier exogenous components such as N1 and MMN is the emergence of what are considered more endogenous ERP components. N2 is considered among the earliest of these components, and is implicated in consciously controlled target detection, rather than being controlled by only physical stimulus parameters (Cammann, 1990). 
While N2 has not been widely studied in the anxiety literature, a closely following positive wave (P3) has been the subject of great interest. Although P3 is implicated in such cognitive tasks as target detection, stimulus evaluation and response to novelty (Pritchard, 1981), it is not regarded as purely reflecting endogenous processing, as it can be elicited in response to novel stimuli whether or not focused attention is employed. However, certain parameters of $\mathrm{P} 3$ are indeed influenced by more consciously controlled processing (Roth, Dorato, \& Kopel, 1984). For example, P3 amplitude is affected by the degree of attention an individual allocates toward a particular task (Hoffman, Houck, MacMillan III, Simons, \& Oatman, 1986). P3's relation to novelty detection and processing is reflected in Donchin and Coles' (1988) conceptualization of this component as a process invoked in the process of context updating whereby an organism must revise its working model of the environment. P3 is not a unitary phenomenon, as it consists of frontal P3a and parietal P3b in its most basic subdivision (Pritchard, 1981). While P3a is elicited in response to rare and novel stimuli, $\mathrm{P} 3 \mathrm{~b}$ can be elicited in response to both rare and task-dependent stimuli (Molnár, 1994). P3 likely has multiple generators, including sources in the hippocampus (Halgren et al., 1980; Okada, Kaufman, \& Williamson, 1983) or the thalamus (Yingling \& Hosobuchi, 1984). More closely implicating P3 in novelty detection associated with fear and anxiety, it has also been purported to be affected by prefrontal and limbic structures (Knight, 1984; Molnár, 1995), as well as the locus ceruleus (Swick, Pineda, \& Foote, 1994).

$\mathrm{N} 4$ is a late peaking negative component that has greater amplitude in response to presentation of sentences with semantically inconsistent endings (Kutas \& Hillyard, 1980). Kutas and Hillyard (1984) later suggested that N4 not only reflects neurologic 
reactions to information being presented out of context, but reflects language processes responsible for semantic priming. Positive components occurring in close proximity to $\mathrm{P} 4$ have been implicated in the detection of more physically related incongruities (Kutas \& Hillyard, 1980). Neither N4 nor P4 processes have received notable research attention in the anxiety literature.

Metzger, Orr, Lasko, and Pitman (1997) stated that "ERP abnormalities index both trait and state-related functional impairments in cognitive processing, rather than disorder-specific psychopathologies" (p. 1007). ERPs provide a window into consequences on cognitive processing rather than localizing cerebral dysfunction (Morault et al., 1998), and are therefore an ideal tool for examining attentional biases and differences in information processing related to anxious vulnerabilities. Further, ERP technology allows the study of potential emotional vulnerabilities in "populations whose developmental level...limit[s] the reliability of direct observations or subjective reports of emotional states" (Cunningham, 1992, p. 176). Therefore, ERPs measurement is particularly useful with infants, as no planned or observable responses are required (Molfese \& Narter, 1997). In fact, in the domain of the developmental neuropsychology of language, Molfese has established the value of ERPs recorded at infancy in predicting latèr developmental outcomes (2000; Molfese \& Molfese, 1997). While no such prospective examinations have taken place in the anxiety ERP literature, there is a rapidly growing body of work examining anxiety-related cognitive dysfunctions indexed by ERPs in both adults and children.

\section{Anxiety and Event Related Potentials in Adults}

Findings in Panic Disorder Populations 
Panic disorder (PD) is among the anxiety disorders most frequently studied with ERP methodologies. Knott, Lapierre, Fraser, and Johnson (1991) compared 12 PD patients and 10 controls on their evoked responses to a series of auditory stimuli of varying intensities. ERPs were recorded from 16 electrode sites referenced to linked earlobes. In this investigation, PD patients exhibited greater N1 amplitude across all intensities. In light of potential contributions of the temporal lobes in the production of $\mathrm{N} 1$, the results were framed as partial support for hypotheses of abnormal temporal lobe functioning in $\mathrm{PD}$, although the authors pointed out that the observed differences may have been due to a more general arousal associated with increased state anxiety in these patients.

Iwanimi, Isono, Okajima, and Kamijima (1997) utilized a two-tone auditory discrimination task to examine cognitive processing in panic disorder. Twelve PD patients and 12 age-matched controls were presented with the oddball task while event related potentials were recorded from midline frontal, central, and parietal electrodes, as well as two lateral central electrodes, all referred to linked earlobes. Differences emerged between the two groups in early information processing, with the PD group showing increased N1 amplitudes for both target and non-target tones, as well as increased N2 amplitudes for the target tones. No differences emerged for P3, however, suggesting that $\mathrm{PD}$ is associated with abnormalities in very early information processing. The authors suggested that the N1 differences are likely accounted for by differences in processing negativity and/or mismatch negativity, both of which are related to early, endogenous processing.

Turan et al. (2002) presented an auditory odd-ball task to adult PD patients, 
generalized anxiety disorder patients, and controls, recording event related potentials only from central and frontal sites. In contrast to the studies discussed so far, PD patients evidenced no amplitude differences from comparison groups. However, they did exhibit greater $\mathrm{P} 3$ latencies in response to the infrequent stimulus compared to both a group of generalized anxiety disorder patients and a non-psychiatric control group. The differences from the Iwanimi et al. (1997) and Knott et al. (1991) studies were considered likely due to differences in methodology, particularly the fact that these previous investigations utilized a much smaller number of subjects. Given support for limbic structures such as the hippocampus as the source of P3 activity (Halgren et al., 1980; Okada, Kaufman, \& Williamson, 1983), Turan and colleagues purported that the observed P3 differences in their study supported hypothesized roles of limbic structures in the etiology of panic disorder. No differences were found between the generalized anxiety disorder and control groups in any portion of the ERP, suggesting that the possible later information processing disturbances observed may be specific to $\mathrm{PD}$.

Levy and colleagues (Levy et al., 1996) used ERPs to evaluate the hypothesized role of brainstem structures in PD. They recorded brainstem auditory evoked potentials of $16 \mathrm{PD}$ patients and 10 controls during presentation of varying intensities of auditory stimulation. While no differences were found in terms of exogenous processing, PD patients did exhibit decreased latency to N3 and a longer interval from N3 to N5. Further, both of these variables were significantly correlated with general anxiety as assessed by the Hamilton Anxiety Scale (Hamilton, 1959). While their findings supported hypothesized roles of brainstem structures in $\mathrm{PD}$, it is important to note that both N3 and N5 latency were also significantly correlated with depression as measured 
by the Asberg-Montgomery Depression Scale (Montgomery \& Asberg, 1979), potentially implicating negative affect rather than anxiety or panic as specific contributors. Clark, McFarlane, Weber, and Battersby (1996) utilized an auditory discrimination task involving frequent and infrequent tones, and found amplitude differences at $\mathrm{P} 3$ between $\mathrm{PD}$ and control groups. Fourteen PD patients and 15 control participants were presented with the task while ERPS were recorded from 3 midline electrodes, averaged to linked earlobes. In response to both frequent and infrequent tones, $P D$ patients exhibited greater amplitude of the $P 3$ component at the frontal and central sites. Although not mentioned directly, the authors' discussion of these findings appeared to add support for Gray's BIS. Specifically, it was suggested that these findings implied difficulty "adapting to novelty" in PD, stemming from dysfunction in the prefrontal-limbic structures and their interconnections (p. 853). In this regard, the findings may be more generally related to anxiety or negative affect rather than being specific to panic.

In a more conceptually sophisticated examination of cognitive processing in $\mathrm{PD}$, Windmann, Sakhavat, and Kutas (2002) presented 17 patients and 17 controls with a recognition memory task involving negatively valenced (although not panic specific) and neutral words while ERPS were recorded from 28 electrodes averaged to mastoids. Their methodology was grounded in established findings of an emotion-induced recognition bias in which emotionally negative words are more likely to be classified as old in such tasks by normal participants. Given conceptual overlap between hypothesized early information processing deficits arising from prefrontal areas in anxiety disorders, and hypotheses that the emotion-induced recognition bias is associated with such early 
information processing arising from similar neural circuits, it was hypothesized that PD patients would show abnormalities in this emotion-induced processing. As predicted, patients did show abnormalities in comparison to controls in relatively early processing (300-500ms) over prefrontal electrode sites. While control patients showed differences in evoked responses to old and new words, depending on the emotional valence of the words, PD patients showed no such differences. In fact, PD patient's responses to both negative and neutral words were similar to the control's responses to neutral words, supporting findings that anxious individuals interpret ambiguous or neutral information as threatening. Patients did evidence an emotionally dependent recognition bias later in processing $(>1000 \mathrm{~ms})$ over frontocentral sites, however, suggesting that they may "compensate for their automatic processing deficits with slow, capacity-limited, and consciously controlled strategies, which are reflected in the very late part of the ERP waveform" (p. 367).

Pauli et al. (1997) also utilized a task that manipulated the emotional valence of words, visually presenting 15 panic disorder patients and 15 controls with words that were either somatic or non-somatic in nature. The stimuli were presented tachistoscopically at each individual's perception threshold, while ERPs were recorded from four left, four right, and three midline electrodes. Given theories postulating cognitive biases toward somatic cues in panic patients, it was hypothesized that differences would emerge between the two groups through both behavioral and electrophysiological measures in response to these word categories. Behaviorally, PD patients were differentiated from controls in their increased correct identification of somatic compared to non-somatic words. In terms of electrophysiological measures, 
while PD patients were found to have increased P3 amplitudes in response to somatic compared to non-somatic words, significant P3 differences did not emerge between the patient and control groups. However, more robust differences did emerge in the later positive component of the waveform, with panic patients showing more positivity in later processing (400-500ms \& $600-800 \mathrm{~ms}$ ) in response to somatic compared to non-somatic words, with the $600-800 \mathrm{~ms}$ difference differentiating patients from controls. Further, the slow wave of panic patients was most positive at central and parietal locations, and was more lateralized to the right hemisphere.

\section{Findings in Obsessive-Compulsive Populations}

Ciesielski, Beech, and Gordon (1981) presented the first study of evoked potentials in an obsessional neurosis population. Eight patients and 8 matched controls were presented with a visual discrimination task while ERPs were recorded from right and left parietal electrodes. The obsessional group exhibited lower amplitude and shorter latency to N220. A follow-up investigation using the same procedures supported these findings, as obsessional neurotics exhibited reduced amplitude and decreased latency to both N220 and P350 in the face of increasing task complexity, while controls tended to show the opposite pattern (Beech, Ciesielski, \& Gordon, 1983). The findings related to shorter latencies were framed as partial support for propositions that obsessional anxiety is related to lower arousal thresholds in the face of minimal stimulation.

Towey and colleagues (Towey et al., 1990) later replicated this finding in a group of 10 DSM-III (American Psychiatric Association, 1980) diagnosed obsessivecompulsive disorder (OCD) patients and 10 controls using an auditory oddball task. The participants were presented with the task while ERPs were recorded from three midline, 
four right, and four left electrodes covering frontal, central, parietal and occipital sites referenced to the nose tip. In support of the aforementioned findings, OCD patients exhibited shorter N200 and P300 latencies compared to controls. However, contrary to previous findings, these patients also exhibited increased N200 amplitude over the left hemisphere. Together, the findings from these investigations support theories of both overarousal and overfocused attention as key contributors in obsessive-compulsive anxiety.

Towey's group (Towey et al., 1994) later reported on 18 OCD patients and 15 controls who were presented with an auditory tonal selective attention task while ERPs were recorded from frontal, central, temporal, parietal, and occipital electrode sites, all referenced to nose tip. Based on their earlier work supporting overfocused attention in OCD, it was hypothesized that both early $(100-300 \mathrm{~ms})$ and late $(300-500 \mathrm{~ms})$ processing negativity would be enhanced in OCD patients as compared to controls. This hypothesis was supported, as patients showed decreased latency to onset, increased negativity, and longer duration in the portion of the waveform associated with processing negativity. This effect was most prominent at frontal and central scalp locations. Further, group differences emerged in P3, with patients showing relatively increased amplitude in response to unattended non-targets and relatively decreased amplitudes in response to attended targets. These findings supported views of $\mathrm{OCD}$ as a disorder characterized by dysfunction in the allocation of attentional resources, but failed to address the degree to which such cognitive dysfunction is specific to OCD or a component common to anxiety disorders in general.

Miyata et al. (1998) addressed this issue by examining ERPs in a Japanese sample 
of 23 OCD patients, 12 social phobia (SP) patients, and 18 healthy controls. Participants were presented with an auditory tonal oddball paradigm while ERPs were recorded from midline, frontal, central, and parietal electrodes referenced to linked earlobes. Compared to both SP patients and controls, OCD patients had shorter N2 and P3 latencies in response to target stimuli, supporting the hypothesis that this condition is associated with cortical overarousal characterized by increased speed of processing. While these latencies differentiated OCD and SP groups, the two groups were similar in terms of increased negativity in the latter part of the N2 component in response to both target and non-target stimuli. It was suggested that while the differences in N2 and P3 latencies may reflect OCD specific processes, the presence of greater N2 negativity "may represent the cognitive dysfunction commonly observed in both anxiety and depressive disorders" (p. 517), a dysfunction associated with consciously controlled detection, rather than a dysfunction in more automatic mismatch negativity responding.

ERP differences have been observed in OCD populations in less cognitively demanding tasks as well. For example, Savage et al. (1994) presented 15 patients and 30 controls with low level visual and auditory stimuli in passive viewing and listening conditions while ERPs were recorded from 20 scalp locations referenced to linked earlobes. While no differences emerged in the visual condition, OCD patients' responses were marked by shorter $\mathrm{N} 100$ and P200 latencies in the auditory condition. Therefore, it appears that cognitive hyperarousal in OCD during less complex information processing may show material specificity toward auditory stimuli.

Morault and colleagues (Morault, Guillem, Bourgeois, \& Paty, 1998) presented evidence that ERPS could be utilized to predict treatment response in OCD patients. 
Twenty-one patients were compared to 21 controls in an auditory oddball task as ERPs were recorded from midline frontal, midline parietal, frontal left, and frontal right electrodes. Those OCD patients who did not respond to pharmacological intervention had waveforms that resembled those of the control group, while responders exhibited reduced N2 and N3 amplitudes and shorter P3 latencies. Although the design was limited in its adoption of a retrospective approach, it supports the hypothesis that outcomes related with anxious processing can be predicted with ERP methodologies.

\section{Findings in Posttraumatic Stress Disorder Populations}

The examination of ERP components in posttraumatic stress disorder (PTSD) populations is relatively new compared to ERP investigations in other anxiety disorders. In one of the earliest investigations within this population, McFarlane, Weber, and Clark (1993) presented 18 PTSD patients and 20 controls with an auditory tone discrimination task. ERPs were recorded from three midline electrodes referenced to linked earlobes. PTSD patients were found to have longer latency to N200 and reduced P300 amplitudes than controls in response to both target and non-target tones. In light of theories on the functions of N200 and P300, it was suggested that PTSD is associated with cognitive deficits in terms of poor stimulus discrimination, a proposition that was supported behaviorally by the PTSD groups' slower reaction time in identifying target stimuli.

Charles et al. (1995) presented findings from a group of 26 individuals who had been victimized in robberies, with no patients suffering physical insult from these experiences. Sixteen of these individuals had developed a symptom profile that met criteria for PTSD. ERPs were recorded from only one central electrode, referenced to linked earlobes, during a standard auditory oddball task. The PTSD patients exhibited 
lower P300 latencies than the control trauma group, with no differences emerging in terms of latency to this peak. Similar to findings in OCD populations, this was interpreted as a possible reflection of poor attentional control. Alternately, it was also proposed that this may be a reflection of PTSD patients attaching less significance to the oddball stimulus in accord with the "psychological numbing" often associated with this disorder (p.73).

Morgan III and Grillon (1999) examined mismatch negativity (MMN) correlates of sexual assault- related PTSD in women. Thirteen women with PTSD and 16 controls were presented with an auditory tonal oddball task while they read a magazine, with ERPs being recorded from 3 midline and 6 lateral electrodes referenced to linked mastoids. Significant group differences emerged, as the women with PTSD exhibited greater N2 amplitude in response to the oddball stimulus than controls, with this difference being accounted for by increased mismatch negativity in the clinical group. These findings were framed as consistent with the hypothesis that PTSD is characterized by "abnormalities in environment novelty detection" (p. 830), a clinical feature that may be present across the anxiety disorders.

Metzger et al. (1997) presented ERP findings in Vietnam combat veterans with PTSD. Twelve unmedicated patients, 22 medicated patients, and 10 control veterans were presented with a tonal auditory oddball task. These were not pure groups, however, as comorbid disorders in the PTSD group included bipolar disorder, major depression, dysthymia, generalized anxiety disorder, specific phobia, and social phobia. Further, one control veteran met criteria for major depressive disorder, dysthymia, and social phobia. Those with panic disorder were excluded from primary analyses. During the oddball 
task, ERPs were recorded from 3 midline sites referenced to linked earlobes.

Significantly smaller parietal P3s were observed in the unmedicated PTSD group in response to target tones, but the difference was not present when level of depression as assessed by the Beck Depression Inventory (Beck, 1979) was controlled for. Additionally, $\mathrm{P} 3$ amplitude had a significant negative correlation with state anxiety as measured by the State-Trait Anxiety Inventory (STAI; Spielberger et al., 1983). Within the unmedicated PTSD group, further analyses revealed that those with comorbid PD had significantly larger parietal P3 amplitudes than those without PD, although this difference was not observed in the medicated group. The findings of this investigation, although limited by methodological concerns related to group heterogeneity, support the role of $\mathrm{P} 3$ in anxiety disorders, and highlight the importance of considering comorbid depression. Further, they suggest the sensitivity of ERPs to level of anxiety as measured by the STAI, a measure utilized in the current study.

\section{Findings in Studies of Mixed Anxious and Depressed Populations}

ERP differences have also been examined in more heterogeneous groups of both anxious and depressed patients. For example, Daruna and Karrer (1986) examined P3 correlates of response to novelty in an undergraduate population. Those low in trait anxiety exhibited hemispheric asymmetry of the novelty $\mathrm{P} 3$ response, showing less right than left activation. Bruder et al. (2002) explored potential differences between clinically anxious only, clinically depressed only, clinically depressed and anxious, and control groups. Participants were presented with an auditory oddball task while ERPs were recorded from 30 scalp locations. Compared to all other groups, the pure anxiety disorder group exhibited a frontocentrally located increased amplitude early in the P3 
component, possibly indicative of an "increase in orienting or alerting responses to 'oddball' stimuli" (p. 123). Patients with comorbid anxiety and depression had smaller amplitudes in this portion of the waveform compared to controls, but showed increased later P3 amplitudes over parietal sites. These findings highlight the importance of considering the impact of comorbidity between anxiety and depression in ERP tasks.

Building on the literature exploring attentional biases in anxious individuals discussed above, Weinstein (1995) used ERP methodology to examine whether such attentional biases toward threat are actually associated with enhanced processing of such stimuli. She utilized an undergraduate sample of 10 anxious and 10 non-anxious individuals, categorized based on their score on the State-Trait Anxiety Inventory (Spielberger et al., 1983). Participants were visually presented with a semantic matching task that required deciding whether two types of priming sentences (positive or threat) matched a subsequent probe word that was either positive, threatening, or neutral. ERPs were recorded from frontal, central, and parietal midline electrodes referenced to the average of the left and right mastoids. Consistent with the study's hypothesis, anxious participants showed greater $\mathrm{N} 1$ and $\mathrm{P} 4$ amplitudes in response to probes in the threat priming condition compared to non-anxious participants, with the N1 effect emerging across all scalp locations and the $\mathrm{P} 4$ effect emerging primarily at central and parietal sites. Anxiety was also associated with differential processing of emotional incongruity between prime and probe, with anxious individuals showing shorter P4 latency in the face of threat prime/neutral probe and positive prime/threat probe contexts. These results support the proposition that anxiety is associated with both preattentive automatic attentional biases as suggested by $\mathrm{N} 1$, as well as differential cognitive processing of such 
information in later stages such as $\mathrm{P} 4$.

Grillon and Ameli (1994) studied the effects of induced anxious apprehension on ERPs in a presumably non-clinical sample. The 16-person sample was composed of "healthy" undergraduate and staff members from the researchers' university, although no assessment of psychopathology or state/trait emotionality was reported in the study. Participants were presented with four blocks of sounds, with each block including rare target tones, frequent non-target tones, and rare novel and unusual sounds, while ERPs were recorded from three central and 12 lateral electrodes, referenced to linked mastoids. The four blocks were based on presence vs. absence of threat of shock and active (button press required in response to target tones) vs. passive listening modes, with each participant hearing the sounds under "active/threat, active/safe, passive/threat, and passive/safe" conditions (p. 208). While standard tones did not elicit observable P3s, P3 amplitude was significantly larger in response to novel sounds than target tones during the passive/threat condition. These results support notions that anxious arousal is associated with changes in cognitive processing to novelty in the environment.

Hansenne and colleagues (2003) examined the relationship between MMN and Cloninger's Harm Avoidance (HA) personality dimension. Similar to Gray's behavioral inhibition system, HA is a dimension characterized by inhibition/avoidance in the face of perceived punishment or nonreward. Fourteen healthy women and 18 healthy men were presented with a tonal oddball task while engaging in the cognitively demanding task of ordering random strings of digits. It was found that $\mathrm{MMN}$ was related to HA, with increased HA correlating with decreased MMN amplitude over frontal, central, and parietal midline electrodes for women. In men, this effect was present only at the frontal 
midline position. These findings support examinations of clinical populations in which early, automatic processing components are related to anxiety disorders. These findings initially appear to run counter to the same group's previous findings (Hansenne, 1999) in which P3 amplitude was positively correlated with HA. To reconcile this disparity, it was suggested that early, automatic processes (represented by MMN) are facilitated by the behavioral inhibition system, while later, more controlled processes (represented by P3) are impaired by this system. Such an explanation seems to fit well with Gray's description of a system that is very efficient at identifying and orienting to novelty, but then later has difficulty determining the presence of threat and appropriately disengaging from such stimuli.

\section{Anxiety and Event Related Potentials in Children and Infants}

Extending the adult work relating P3 to anxiety (e.g., Daruna \& Karrer, 1986), Daruna, Rau, and Strecker (1991) examined the relationship between this ERP component and anxiety in children. Twenty-two children ages three to seven were presented with a tonal vigilance task. Parent report on the Conners' Behavior Rating Scales (Goyette, Conners, \& Ulrich, 1978) was used to categorize children as either lowanxious or medium-anxious. Results revealed a correlation between anxiety and P3, and also supported the presence of related hemispheric asymmetries. While low-anxious children were found to have smaller P3 amplitudes over the right hemisphere compared to the left, medium anxious children had relatively larger P3 amplitudes over the right hemisphere than the left. The authors argued for the specificity of $\mathrm{P} 3$ to anxiety, as post hoc analyses failed to support a relationship between another component of interest (N2) and anxiety. Further, the findings were framed as support for hemispheric differences 
related to negative affectivity, with potential specificity of right temporal regions in the manifestation of anxiety.

There is evidence that infants have similar ERP responses to adults, making it possible to utilize ERP measures in this population as well. For example, McIsaac and Polich (1992) found that infants and adults had a similar central-parietal P3 scalp distribution in response to an auditory stimulus set, although the infants' waveforms had a longer latency and smaller amplitude. Kushnerenko, Čeponienè, Fellman, Huotilainen, and Winkler (2001) also found similarities between infant and adult auditory ERPs, as they had similar changes in response to increasing sound durations during the $\mathrm{N} 2$ time window, although differences again emerged in terms of amplitude. As adults and infants respond similarly, albeit to different degrees to auditory stimuli, it is established that ERPs can be effectively utilized in the study of infant cognition (McIsaac \& Polich, 1992).

Gunnar and Nelson (1994) presented the first examination of ERPs and emotionality in an infant population. In their investigation, 11 and 12-month-old infants were presented with a visual familiar/novel task that included presentation of frequent and infrequent familiar faces, as well as infrequent novel faces, while ERPs were recorded from frontal, central, and parietal leads referenced to linked earlobes. The infrequent familiar faces reliably elicited a late positive slow wave component similar to the adult $\mathrm{P} 3$ across the sample, and this factor was positively related to both maternal report of positive affect on the Infant Behavior Questionnaire (Rothbart, 1981) and greater observed distress during maternal separation. Further, this factor was related to lower salivary cortisol levels during testing. While the relation between this ERP factor 
and both positive and negative emotionality initially seems contradictory, it is argued that the observed behavioral responses represented higher levels of age-appropriate, adaptive responses, which may be related to enhanced cognitive processing, lending these infants to be "better organized to respond adaptively" (p. 90). Interestingly, this argument is consistent with aforementioned conceptualizations of the adaptive nature of anxiety (Barlow, 2002). Perhaps the observed components represent an adaptive neuropsychological phenomenon that is exacerbated to non-adaptive status through a constitutional-environmental interaction. Whatever the case, these data indicated a relationship between emotionality and response to novelty during infancy. As discussed by the authors, it is also of importance to explore this relationship with non-social stimuli, rather than only stimuli of a social nature.

Our own laboratory (Harvison, Woodruff-Borden, \& Molfese, 2004) had similar findings in the only other know study of ERPs and anxiety in an infant population. Given substantial support for the familial transmission of anxiety (Beidel \& Turner, 1997; Turner, 1987) infants were grouped into high-risk $(n=5)$ or low-risk $(n=6)$.based on their mother's Beck Anxiety Inventory (Beck, \& Steer, 1990) score. ERPs were recorded from neonates in response to the sounds "bidu" and "gibu", spoken by a woman, digitized, and presented through a speaker positioned approximately three feet above the child's head at $80 \mathrm{dBSPL}$ (A). One stimulus was initially presented 50 times for familiarization, followed by 50 additional trials of each sound in a randomized fashion, for a total of 150 trials. The familiar and novel stimuli were counterbalanced across participants. ERPs were collected using a 128-electrode Geodesic Sensor Net, impedances were kept at or below $40 \mathrm{kOhms}$, and filters were set to $.1-30 \mathrm{~Hz}$. 
The 128 electrodes were clustered into 12 anatomical regions (frontal, central, anterior temporal, posterior temporal, parietal, and occipital for each hemisphere). Principal components analysis was used for data reduction, yielding a five-factor solution that accounted for $96 \%$ of the variance. Next, individual 2 (child sex) x 2 (anxiety group, based on maternal anxiety level) $\times 2$ (hemisphere) $\times 6$ (electrode cluster) $\times 2$ (familiar/novel sound) repeated measures ANOVAs were conducted for each factor with Greenhouse-Geisser corrections. Although no significant effects emerged based on familiarity vs. novelty, there was a significant electrode $\mathrm{x}$ anxiety-group effect for factor three (time range $=248-548 \mathrm{~ms}$ ). Post-hoc independent samples $t$-tests revealed significant differences for the frontal and anterior temporal sites, respectively, with the high-risk group displaying significantly more positive brainwave activity during this component.

Based on other pilot data in our laboratory, it is likely that the infants did not have enough exposure to the initial sound to encode it as "familiar," accounting for the lack of an anxiety-group $\mathrm{x}$ condition (i.e., familiar/novel) effect. Despite the absence of this interaction, the results did support other findings that anxiety vulnerability may be associated with more positive frontal electroencephalographic activity, and that the examination of such parameters at birth may aid in the detection of anxious vulnerabilities. Unlike other investigations in which brain responses have been compared based on behavioral observation or maternal report of infant behavior, these findings suggested differences, even in the neonatal period, based on maternal anxiety status alone. The current study aimed to further this investigation of anxious vulnerabilities by using an improved methodology to operationalize the familiar/novel construct, and by 
taking an improved statistical approach in using both regression and ANOVA.

\section{The Current Study}

The current study aimed to further the limited literature on ERP correlates of anxious vulnerabilities in infancy. Drawing on the literature reviewed above, this investigation aimed to examine aspects of neonate neural processing (occurring within $700 \mathrm{~ms}$ of the presentation of a novel stimulus) that were related to the neonate's risk for anxiety (operationalized by maternal level of self-reported anxiety). Work on prenatal perception of speech sounds provides an important basis for understanding the approach used to operationalize novelty in the current study. This work suggests that infants are familiar with and prefer their mother's voice due to prenatal exposure to her voice. Fetuses certainly perceive and discriminate sounds within the range of human speech, including maternal speech (Lecanuet, Granier-Deferre, Jacquet, \& DeCasper, 1999; Lecanuet \& Schaal, 1996). Further, newborns orient to the sound of their mother's voice within the first two weeks of life (Hammond, 1970). Evidence suggests that newborns not only discriminate their mother's voice from that of strangers (Hepper, Scott, \& Shahidullah, 1993), but that they actually prefer her voice to another female's voice (DeCasper \& Fifer, 1980).

Further work by DeCasper's group indicates that such preferences are indeed due to familiarity with the mother's voice developed from intrauterine exposure. For example, in one investigation (DeCasper \& Spence, 1986) mothers read stories aloud twice daily during the last six months of pregnancy. Postnatal testing using an operantchoice task revealed that infants preferred hearing the story that their mother had read daily. Similar results emerged in a later investigation (DeCasper, Lecanuet, Busnel, 
Granier-Deferre, \& Maugeais, 1994) in which infants showed heart rate decreases in response to rhymes that had been recited by their mothers during pregnancy, but no such decreases in response to rhymes they had not heard before. Although these effects also held up when another woman read the same rhymes, they suggest that infant speech preferences are indeed influenced by prenatal exposure to the mother's voice. Therefore, presentation of maternal and stranger voices speaking meaningless consonant-vowelconsonant-vowel sounds provides a useful operationalization for understanding cognitive responses to familiarity vs. novelty in the current study.

The current methodology is among the first known of its type in terms of the examination of electrophysiological markers for anxiety vulnerability in infants. While there is a burgeoning adult literature investigating ERP correlates of anxiety, the child and infant literatures are unfortunately sparse. The current study is in line with recent calls for the study of anxious vulnerabilities (Dadds \& Roth, 2001). It has been suggested that psychophysiological methods are of crucial importance in extending the findings of basic science to applications in psychopathology (Lang et al., 1998). The current study aimed to address this issue by applying findings from basic cognitive neuroscience to inform understanding of factors that predispose individuals toward one of the most costly and debilitating of all forms of psychopathology.

\section{METHODS}

\section{Considerations for Sample Selection}

A power analysis was conducted using G-Power (Faul \& Erdfelder, 1992) in order to determine an appropriate sample size. For the planned regressions, it was determined that 31 mother-child dyads were necessary to detect a relatively large effect 
with a power of $.80\left(f^{2}=.35 ; p<.05\right)$ with 2 independent variables present (child gender and maternal anxiety), while 68 dyads would be necessary to detect a medium effect with the same parameters $\left(\mathrm{f}^{2}=.15 ; \mathrm{p}<.05\right)$. Participants were recruited in the Norton Women's Pavilion of Norton Hospital in Louisville, Kentucky. Norton hospital, located in downtown Louisville's medical center, is a facility that admitted over 17,000 patients in 2003.

The United States Bureau of the Census 2002 estimates characterized Jefferson County's population as approximately $77.3 \%$ White, $19.5 \%$ African American, $2.1 \%$ Hispanic origin, $1.7 \%$ Asian or Pacific Islander, and .2\% American Indian (the estimate exceeds $100 \%$ because Hispanic origin is not considered a race category, allowing individuals from other categories to be considered of Hispanic origin). Given Norton's patient population, the current sample consisted of largely White and African American participants, with African Americans accounting for a much higher percentage than that reported in census estimates. In terms of parents in the sample, fathers were not represented. Detailed descriptives on participants are presented in the results section below.

\section{Materials}

\section{Maternal Self-Report}

Mothers were asked to complete the following self-report measures:

1. The Beck Depression Inventory, $2^{\text {nd }}$ Edition (BDI-II; Beck, Steer, \& Brown, 1996). The BDI-II is a widely used self-report measure of depression that takes approximately five minutes to complete. It consists of 21 groups of statements that assess severity of depressive symptoms over the preceding week. 
Psychometrics reported in the BDI-II manual indicate high internal consistency in both outpatient and undergraduate samples, as well as high test-retest reliability in the outpatient sample. Later work supports the instruments high internal consistency and validity in a number of populations, including undergraduates (Dozois, Dobson, \& Ahnberg, 1998; Osman et al., 1998; Steer \& Clark, 1997; Storch, Roberti, \& Roth, 2004) and primary care patients (Arnau, Meagher, Norris, \& Bramson, 2001).

2. The Beck Anxiety Inventory (BAI; Beck \& Steer, 1990). The BAI is a widely used self-report measure of anxiety severity that takes approximately five minutes to complete. This measure consists of 21 symptoms that are rated on a $0-3$ point scale, indicating whether they have been "not present" to "severe" over the past week. Initial psychometrics on this instrument indicated that it had high internal consistency and test-retest reliability, and that it differentiated anxious from depressed diagnostic groups (Beck et al., 1991). The BAI has demonstrates high internal consistency and differentiates anxiety from depression in non-clinical samples (Creamer, Foran, \& Bell, 1995). Data reported in the manual indicate that this instrument has significant correlations with both subscales of the State-Trait Anxiety Inventory (STAI; Spielberger et al., 1983), another anxiety measure utilized in the present study. Highlighting the inevitable overlap of anxiety and depression, the BAI also shows a significant positive correlation with the BDI, although the relationship is less than that reported between the STAI and the BDI (Beck et al., 1988). Overall, the BAI is a widely utilized and psychometrically sound instrument for assessing anxiety severity; however, its shortcoming for the 
current study is its focus on anxiety during the previous week only.

3. The State Trait Anxiety Inventory - Form Y (STAI; Spielberger et al., 1983). The STAI is another commonly used self-report measure of anxiety, and takes approximately five minutes to complete. It consists of 40 items assessing participants' levels of both state and trait anxiety. The author reports high internal consistency for both the trait and state subscales. He also reports that while the state form shows low test-retest reliability, as expected based on theoretical conceptualizations of the transient nature of state anxiety, the trait form shows high test-retest reliability. Further, extensive data is presented to support the instrument's validity, including findings that it reliably differentiates anxious psychiatric patients from controls and emotionally disturbed medical patients from medical patients without emotional problems. As mentioned above, this instrument is significantly positively correlated with both the BAI (Beck \& Steer, 1990) and BDI (Tanaka-Matsumi \& Kameoka, 1986). Although it has less precision in differentiating anxiety from depression than the BAI, its primary value for the current study lies in its ability to differentiate the constructs of state and trait anxiety.

4. Demographic Questionnaire. Participants were also asked to complete a brief demographic questionnaire that requested information on age, race, educational attainment, occupational status, and yearly income for both mother and father.

\section{Maternal Voice Samples}

Mothers' voices were recorded bedside, the evening before testing, on an Apple G-2 laptop computer, with a Telex M-560 external microphone. Sound Edit 16 Version 2 
software was utilized for recording and editing the sound samples. The experimenter modeled pitch, tone, meter, and loudness for enunciation of the stimulus words, "bidu" and "gibu," by presenting the sound file used in our pilot investigation. The participant was then asked to speak each sound into the microphone repeatedly until a sample of adequate volume, with a sharp onset and offset was obtained. The sound was then edited to a length of $595 \mathrm{~ms}$ (consistent with the stimulus from pilot testing), and converted to .wav format for presentation during neonate testing.

\section{Electroencephalography}

Electrical Geodesics' EGI System 200 (Electrical Geodesics, Inc., 2001) was utilized in the collection of EEG data. This system consists of three primary components: a Geodesic Sensor Net, a set of amplifiers (Net Amps), and a data acquisition computer. The Geodesic Sensor Net consists of 129 silver/silver chloride plated carbon pellet electrodes, each surrounded by a sponge and set inside a plastic pedestal. The sponge protrudes from the pedestal and rests against the participant's scalp. The net structure of this high-array electrode system allows ease of application, and evenly distributes the many leads across the surface of the scalp. Before application, nets are soaked in an electrolyte solution consisting of warm distilled water (1L), powdered potassium chloride $(8.5 \mathrm{~g})$ and Johnson's Baby Shampoo $(.5 \mathrm{cc})$. The potassium chloride serves to increase the electrical conductivity, while shampoo dissipates oils on the scalp that may have interfered with this conductivity. The electrodes in the Geodesic Sensor Net detect the very small voltage changes (on the order of microvolts; Hugdahl, 1995) that occur at the scalp. The voltages are conducted through the sponge embedded silver/silver chloride pellet and an insulated lead wire to a gold plated pin that connects to Net Amps. The 
measured voltage changes at each electrode lead are not absolute, but are measured as the difference in voltage between that lead and a reference. In this case, an electrode located over the scalp's central vertex $(\mathrm{Cz})$, serves as a reference against which electrical activity is recorded at the remaining 128 electrode sites. Net Amps continuously monitors these voltages, and amplifies them approximately 1000 times so that they can be manipulated by the system for the remaining steps.

The measured electrical activity is also influenced by extracranial electrical noise that is present in the room. In an attempt to isolate electrical frequencies of interest, therefore, Net Amps carries out analog signal filtering. In the present study, these filters were set to pass only frequencies between 0.1 and $30 \mathrm{~Hz}$. After amplification and filtering, the voltages for each electrode were sampled 250 times per second, digitized by a 16-bit analog-to-digital converter, and sent to the data acquisition computer via a USB cable. The data acquisition computer hosts Net Station software (Electrical Geodesics, Inc., 2003) that displays and stores the final EEG signal of interest. The data acquisition computer is connected via a serial cable to the experimental control computer that hosts E-Prime software (Schneider, Eschman, \& Zuccolotto, 2002). E-Prime was used to present the auditory stimuli. Through its communication with E-Prime, Net Station marks the onset of each stimulus within the EEG data in order to allow isolation of ERP components of interest during data analysis.

\section{Procedures}

\section{Recruitment and Data Collection}

Dyads were recruited in the Norton Women's Pavilion on the evening before testing. The experimenter collected names and room numbers for mothers of healthy 
newborns from Norton nurses. He then went to each of these rooms and briefly introduced himself and the study. If potential participants were interested following this initial introduction, more detailed information on the study rationale and procedures was provided, and the experimenter fielded questions from the participant. Written informed consent was then obtained in line with an approved Human Studies Committee protocol (456.00). Next, voice samples were recorded and saved for later use in stimulus presentation. Finally, the mother was provided with the self-report measures, which she was asked to complete by the following morning.

Before leaving the hospital for the evening, the experimenter prepared the voice samples for inclusion in the stimulus presentation package as discussed above. The experimenter and a research assistant then returned to the hospital at 7:00 AM the following morning to begin testing. All equipment was transported to a quiet room in the nursery. The equipment was prepared for stimulus presentation, with sound levels of the auditory stimuli being set to $80 \mathrm{~dB}$ SPL (A). The experimenter then checked with the nurses to ensure the neonate's availability, and when all preparations were complete, transported the infant into the testing room in a hospital basinet. The experimenters next measured the infant's head to determine the proper position for $\mathrm{Cz}$, soaked the electrode net, and subsequently applied it to the neonate's head. Data collection began when the infant was in a quiet, awake state and scalp-electrode impedances fell at or below $40 \mathrm{k} \Omega$.

Stimuli were presented from an external computer speaker positioned approximately 1 meter above the midline of the infant's head. If the neonate became physically active, data collection was temporarily suspended until he or she returned to baseline. If the infant was judged to become unduly distressed or could not be soothed, 
data collection was terminated. Stimulus presentation consisted of 120 trials, 30 trials of the neonate's mother saying "bidu," 30 trials of a stranger saying "bidu," 30 trials of the mother saying "gibu," and 30 trials of the stranger saying "gibu." The stimuli were presented in a randomized order with a random inter-stimulus interval ranging from 1500-2300 ms. The stranger for each neonate was the previous mother in the sample. Nets were cleaned and sterilized following each use.

\section{ERP Derivation}

In order to isolate data in the time range of interest, each infant's electrophysiological data was segmented into $800 \mathrm{~ms}$ segments consisting of a $100 \mathrm{~ms}$ pre-stimulus baseline and $700 \mathrm{~ms}$ of data post-stimulus. The voltages recorded during these segments were then re-referenced to the average of all electrodes, rather than the vertex electrode which is used as a reference during recording. Net Station's Artifact Detection procedure was then used to identify all segments that contained more than 10 bad channels (e.g. faulty electrode or interrupted transmission) or yielded voltage changes consistent with eye-blink or muscle movement. Such segments were excluded from further analyses, while data for bad electrode channels in acceptable segments was interpolated using data from surrounding channels. Next, each infant's data was averaged within 12 electrode clusters (right and left: anterior, central, parietal, occipital, anterior temporal, posterior temporal) and 4 experimental conditions (mother "bidu," mother "gibu," stranger "bidu," stranger "gibu") in an effort to remove waveform variability not related to the auditory stimuli of interest. In order to further remove non event-related activity, data were baseline corrected by subtracting the average of all 
samples in the $100 \mathrm{~ms}$ pre-stimulus period from each sample in the $700 \mathrm{~ms}$ post-stimulus segment, yielding a zero-voltage baseline interval and the emergence of the ERP.

To summarize, the time window of interest ranged from stimulus onset to $700 \mathrm{~ms}$, with voltage samples recorded every $4 \mathrm{~ms}$. These averaged voltages were present for 30 subjects across four conditions and 12 electrode clusters. This yielded a $176 \times 1440$ matrix (time x participant/cluster/condition) of electrode voltages. In order to isolate areas of maximum variability within this large data set, Principal Components Analysis with Varimax Rotation was performed as described below.

Planned Analyses

\section{Data Reduction}

Principal components analysis (PCA) was planned as a means of data reduction in order to identify areas of maximum variability in the ERPs across subjects. This widely used procedure is blind to experimental conditions, and reduces the large amount of data described above into a few components that account for the variance in the most parsimonious manner (Coles, Gratton, Kramer, \& Miller, 1986; Molfese \& Molfese, 1997). As reviewed in detail by Coles and colleagues (1986), PCA yields components that are assumed to influence the areas of maximum covariability among data points in the complete data matrix. After components are extracted, varimax rotation allows simplification "of the pattern of loadings so as to localize each component to a portion of the voltage x time function" (Coles et al., 1986, p. 201). The components are orthogonal, thereby minimizing overlapping time points. Within PCA components, each time point is assigned a weighting coefficient representative of the contribution of the component to the variance at that time point. For the present study, the final number of components 
retained was selected based on the Cattell Scree Test (Cattell, 1966). Resulting factor scores for each averaged ERP within each component were subsequently used as dependent variables.

\section{Multivariate Analyses}

A series of regressions was conducted in order to explore the study's primary relationship of interest; specifically, it was hypothesized that neonate anxiety risk (maternal anxiety level) would predict neonate evoked brain response to novelty (stranger's voice). Although previous literature has not been fully consistent in regards to spatial localization of such processing, the bulk of evidence suggested that right frontal or right central electrode clusters would most likely to be involved in the hypothesized

effect. In terms of temporal parameters, the literature has again not been fully consistent, implicating both exogenous and endogenous components of the wave as potentially related to such processes. Therefore, regressions were conducted for each of the four factors detailed above in order to explore potential relationships of interest throughout the first $700 \mathrm{~ms}$ of the ERP. For each factor, regressions were conducted in which infant gender was entered into the equation first, followed by BAI, STAI-state or STAI-trait scores in the prediction of factor scores for response to stranger "bidu" and "gibu" over right frontal and right central electrode clusters. These regressions were also conducted with BDI total score entered as a predictor instead of BAI or STAI scores in order to examine the specificity of the findings to anxiety.

It was also of interest to examine the data in a manner consistent with our pilot data in which anxiety-risk was treated as a categorical variable based on maternal BAI 
score. Neonates were divided into low-risk and high-risk groups based on their mother's BAI total score with 15 (highest level of "mild" anxiety) serving as the dividing score. This yielded 18 low-risk and 12 high-risk neonates. The high-risk group had a mean score of 26.42 , which was significantly higher than the mean score of 8.28 observed in the low-risk group $(t(1,28)=-5.874, p<.001)$. Next, a series of 2 (child sex) $x 2$ (anxiety group) $\times 2$ (hemisphere) $\times 6$ (electrode cluster) $\times 2$ (familiar/novel sound) repeated measures ANOVAs were conducted for each factor with Greenhouse-Geisser corrections. Consistent with the above hypotheses, it was anticipated that group amplitude differences would emerge involving right hemisphere electrode clusters.

\section{RESULTS}

\section{Descriptive Statistics}

A total of 63 mothers consented to participation in the study. Thirteen motherneonate dyads were excluded from the planned analyses because the mother reported smoking cigarettes during pregnancy. An additional 11 were excluded because the neonate was restless or distressed during data collection, resulting in termination of the testing session or rejection of the data due to excessive artifacts. Finally, another 9 dyads were excluded because of miscellaneous circumstances including neonate unavailability due to phototherapy or circumcision, a mother's decision not to continue participation, and an examiner being ill on the day of a scheduled testing session. The final retained sample of 30 mother-neonate dyads is described in detail below.

\section{Maternal Descriptives}

The sample was composed of 21 African American and 9 Caucasian mothers. The greater representation of African American mothers is consistent with the demographic 
composition of the Norton Women's Pavilion patient population, and was therefore expected. On average, mothers in the present sample were 25 years old $(M=25.23, S D=$ 6.07 , Range $=18$ years to 40 years), and had delivered 3 previous children. While 2 participants failed to report on marital status, most mothers were single $(n=18)$, with 8 being married and 2 being separated. While 3 mothers did not complete high school, 8 reported completing a high school education or obtaining a general equivalency diploma (GED), 9 had some college, 6 held an associates degree, and 4 had completed undergraduate or graduate degrees. Family income for the sample ranged from less than $\$ 5,000$ to greater than $\$ 45,000$ (see Table 1). 
Table 1

A. Frequency Statistics for Maternal Variables

Variable . $n$

Ethnicity

African American

21

Caucasian

9

Marital Status*

Single

18

Married

Separated

2

Education

Did not complete high school or GED

Completed high school or GED

8

Associates degree

Some college

9

College graduate

Graduate/professional degree

3

1

Family income

$\begin{array}{ll}\leq 5,000 & 4 \\ 5,000-10,000 & 5 \\ 10,000-15,000 & 0 \\ 15,000-20.000 & 2 \\ 20,000-25,000 & 2 \\ 25,000-30,000 & 2 \\ 30,000-35,000 & 0 \\ 35,000-40,000 & 0 \\ 40,000-45,000 & 7 \\ >45,000 & \end{array}$

* 2 participants did not report on this variable

B. Descriptive Statistics for Maternal Variables

\begin{tabular}{lllll}
\hline Variable & $M$ & $S D$ & Minimum & Maximum \\
\hline Maternal Age & 25.23 & 6.07 & 18.00 & 40.00 \\
Gravidity & 2.87 & 1.78 & 1.00 & 8.00 \\
& & & & \\
\hline
\end{tabular}


Self-report measures indicated that the study sample consisted of individuals with a range of anxiety, from minimal to severe (Table 2). Beck Anxiety Inventory (BAI) total scores ranged from 2 to 49 , with a mean of $15.53(S D=12.16)$. This indicates that, on average, mothers reported experiencing mild levels of anxiety, a finding that is expected given their circumstances and the BAI's bias toward more physiological aspects of anxiety. State anxiety scores as measured by the State Trait Anxiety Inventory (STAIstate) ranged from 20-64, with a mean of $34.30(S D=10.51)$. Trait anxiety scores as measured by the STAI-trait also showed an acceptable range from 24 to 68 , with an average of $38.13(S D=11.40)$. Average scores and standard deviations for both the state and trait forms of the STAI were consistent with those reported in the instrument's manual (Spielberger et al., 1983). Beck Depression Inventory-II (BDI-II) scores ranged from $0-36$, with an average of $12.27(S D=10.06)$, indicating that, on average, mothers in this sample fell within normal limits in terms of self-reported depressive symptoms.

Table 2

Descriptive Statistics for Maternal Self-Report Measures

\begin{tabular}{llllc}
\hline Measure & Minimum & Maximum & $M$ & $S D$ \\
\hline Beck Anxiety Inventory & 2.00 & 49.00 & 15.53 & 12.16 \\
$\begin{array}{l}\text { State-Trait Anxiety Inventory } \\
\text { (State Form) }\end{array}$ & 20.00 & 64.00 & 34.30 & 10.51 \\
$\begin{array}{l}\text { State-Trait Anxiety Inventory } \\
\text { (Trait Form) }\end{array}$ & 24.00 & 68.00 & 38.13 & 11.40 \\
Beck Depression Inventory & 0 & 36.00 & 12.27 & 10.06 \\
\hline
\end{tabular}




\section{Neonate Descriptives}

Frequency and descriptive statistics for neonate and birth-related variables are

presented in Table 3. There were 16 female and 14 male newborns. Eleven were

delivered by cesarean section, while 19 were delivered vaginally. Average gestational age was 39 weeks $(S D=.94$, Range $=37-41$ weeks $)$ with five minute Apgar scores falling at 9 on average $(\mathrm{SD}=.18$, Rang $\mathrm{e}=9-10)$. Average birth weight was 3445 grams $(\mathrm{SD}=$ 416.28, Range $=2370-4170$ grams). Overall, these summary statistics indicate a healthy neonate population.

Table 3

\section{A. Frequency Statistics for Neonate and Birth-Related Variables}

Variable

$n$

Type of delivery

C-section

Vaginal

Infant sex

Female

16

Male

B. Descriptive Statistics for Neonate and Birth-Related Variables

\begin{tabular}{lllll}
\hline Variable & $M$ & $S D$ & Minimum & Maximum \\
\hline Gestational age & 39.27 & .94 & 37.00 & 41.00 \\
One-minute Apgar & 8.43 & .77 & 6.00 & 9.00 \\
Five-minute Apgar & 9.03 & .18 & 9.00 & 10.00 \\
Birth weight & 3445.00 & 416.28 & 2370.00 & 4170.00 \\
& & & & \\
\hline
\end{tabular}




\section{Correlations}

A series of correlations was conducted to explore the relationships between BAI, STAI-state, and STAI-trait total scores and the above descriptive statistics. This yielded only one significant correlation between an anxiety measure and a descriptive variable. Specifically, BAI total score was significantly correlated with marital status $(r=-.39, p$ $=.035)$. Post-hoc exploration of this variable revealed that single mothers reported the most elevated anxiety on the BAI $(M=19.94, n=18)$, followed by married $(M=9.38, n$ $=8)$ and separated $(M=4.00, n=2)$ mothers. Given the discrepancy in the number of participants in each of these cells, however, the stability of this correlation is uncertain.

\section{Principal Components Analysis}

Four factors were retained from the Principal Components Analysis which cumulatively accounted for $93.62 \%$ of the variance (Table 4). Each factor was classified based on the time range corresponding to the greatest variability within the factor (the time range in which factor scores met or exceeded .40). Factor 1 ranged from $344 \mathrm{~ms}-700$ ms with maximal variability at $624 \mathrm{~ms}$. Factor 2 ranged from $192 \mathrm{~ms}-536 \mathrm{~ms}$ with maximum variability at $328 \mathrm{~ms}$. Factor 3 ranged from $72 \mathrm{~ms}-280 \mathrm{~ms}$, with maximum variability at $168 \mathrm{~ms}$, and factor 4 ranged from stimulus onset to $152 \mathrm{~ms}$, with maximum variability at $32 \mathrm{~ms}$. Resulting factor scores for each subject within electrode clusters and conditions were used as dependent variables in the analyses discussed below. 
Table 4

Factors Retained from PCA

\begin{tabular}{llll}
\hline Factor & Time $(\mathrm{ms})$ & \% of Variance & Cumulative \% of Variance \\
\hline 1 & $344-700+$ & 35.12 & 35.12 \\
2 & $192-536$ & 27.45 & 62.57 \\
3 & $72-280$ & 15.89 & 78.46 \\
4 & $0-152$ & 15.16 & 93.62 \\
\hline
\end{tabular}

\section{Regressions}

Results of regression analyses are presented for each of the four factors in succession. No significant effects emerged for right frontal or central electrode sites for factor 1 . In examination of factor 2 (range $=192 \mathrm{~ms}-536 \mathrm{~ms}$ ), no significant effects were observed for right frontal electrode sites; however, maternal STAI-trait anxiety was significant in predicting right central brain response to the stranger speaking "gibu" $(F(2,27)=6.259, p=.006)$. As an individual predictor, STAI-trait anxiety accounted for $18.3 \%$ of the variance in right central response to "gibu" $(p=.012)$. The average responses of neonates of high and low-anxious mothers are presented in Figure 1A to illustrate this effect. As seen in the figure, the neonate of a high trait-anxiety mother (STAI-trait $=63$ ) exhibits more positivity during this portion of the brainwave in response to the stranger's voice than a neonate of a low trait-anxiety mother (STAI-trait $=30$ ). This finding is also illustrated in Figure 1B with chromatic topographical maps in which increasing intensities of red represent greater activation. In these maps, the top of the figure represents the front of the face. Consistent with the above finding, STAI-state anxiety was also a significant predictor of right central response to stranger "gibu" $(F(2$, 
$27)=4.614, p=.019$ ) for factor 2 , accounting for $12.1 \%$ of the variance. When utilizing BAI total score as a predictor, the overall equation was significant $(F(2,27)=3.403, p=$ .048); however, BAI did not remain a significant individual predictor following infant gender $(p=.142)$. These findings are summarized in Table 5 . 
Figure 1

A. Average Right Central Brain Responses to Stranger "Gibu" in Low-Risk and HighRisk Neonates for Factor 2

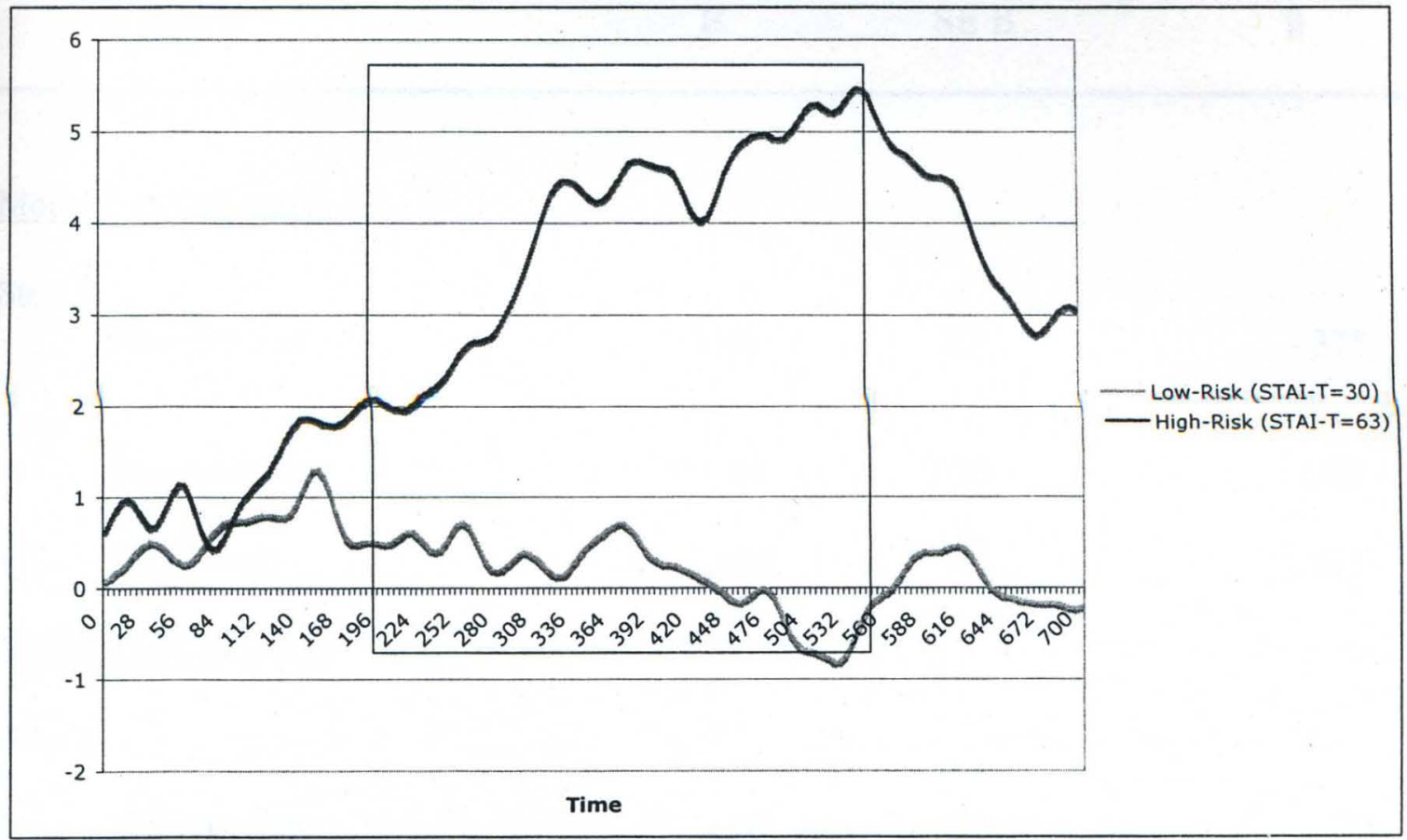

B. Topographical Representation of Brain Responses to Stranger "Gibu" in a) Low-Risk and b) High-Risk Neonates at $328 \mathrm{~ms}$

a.

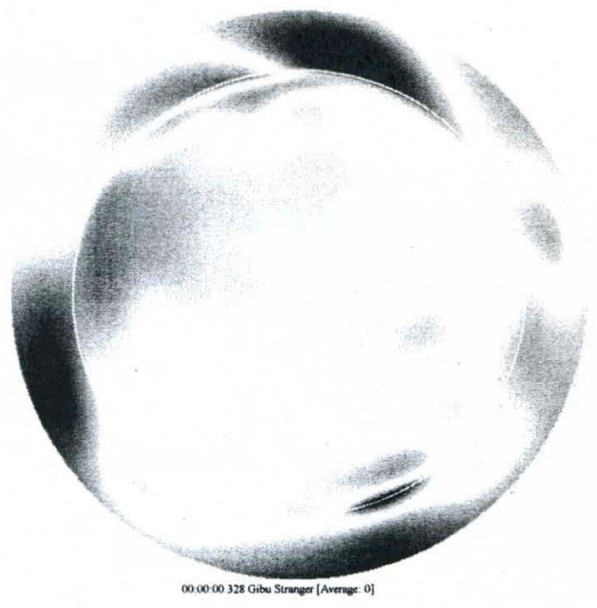

b.

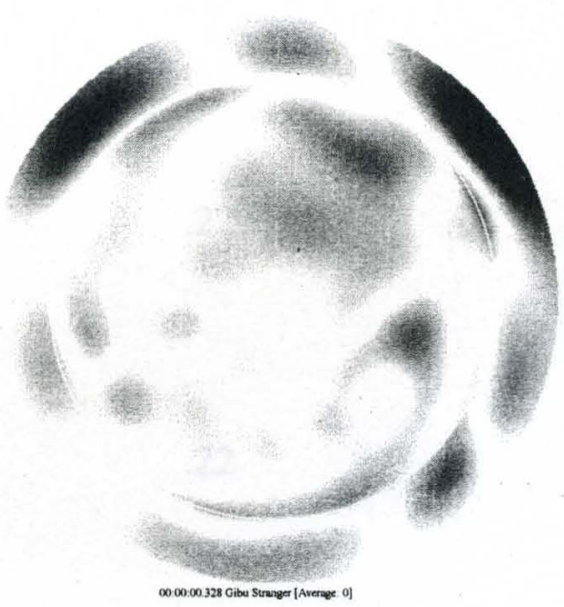


Table 5

Summary of Hierarchical Regression Analyses for Variables Predicting Neonate Right

Central Brain Response to the Stranger Speaking "Gibu” for Factor $2(N=30)$

Variable

B

SE B

$\beta$

Model 1 (STAI-trait)

Step 1

Neonate Sex

$-.46$

.22

$-.37^{*}$

Step 2

Neonate Sex

$-.41$

.20

$-.32$

STAI-trait

.02

.01

$.43^{*}$

Model 2 (STAI-state)

Step 1

Neonate Sex

$-.46$

.22

$-.37^{*}$

Step 2

Neonate Sex

$-.53$

.21

$-.42 *$

STAI-state

.02

.01

$.35^{*}$

Model 3 (BAI)

Step 1

Neonate Sex

$-.46$

.22

$-.37 *$

Step 2

Neonate Sex

$-.54$

.22

$-.43^{*}$

BAI

.01

.01

.27

${ }^{*} \mathrm{p}<.05$ 
No significant effects emerged in examination of factor 3. A regression utilizing component 4 , however, indicated that infant gender and BAI total score were predictive of right central brain response to the stranger speaking "bidu" $(F(2,27)=4.227, p=.025)$ during this early portion of the brainwave (range $=0-152 \mathrm{~ms}$ ). As an individual predictor, BAI accounted for $24 \%$ of the variance in the brain response $(p=.007)$. As seen in Figure 2, a low-risk neonate $(\mathrm{BAI}=3)$ shows greater initial negativity than a high-risk neonate $(\mathrm{BAI}=33)$ over this brain region. When STAI-state anxiety was utilized, the overall regression only approached significance $(F(2,27)=3.029, p=.065)$, although STAI-state anxiety was a significant individual predictor, accounting for $18.3 \%$ of the variance in the brain response $(p=.021)$. STAI-trait anxiety was not predictive of this response. These findings are summarized in Table 6. Each of the above series of regressions was also replicated utilizing BDI as a predictor, and BDI total score did not significantly predict response to novelty over right frontal or central electrode sites for any of the components. 
Figure 2

A. Average Right Central Brain Responses to Stranger "Bidu" in Low-Risk and HighRisk Neonates for Factor 4

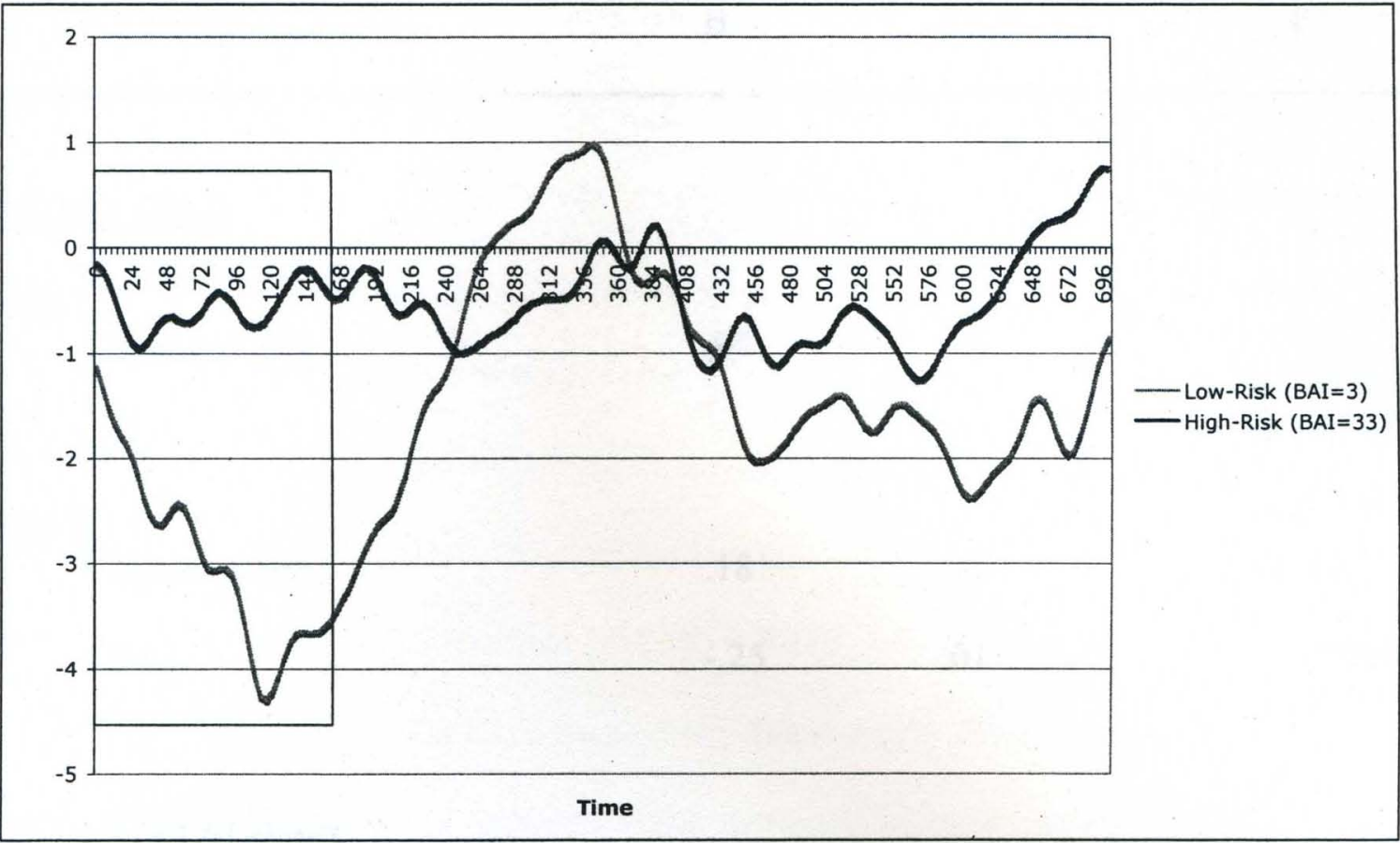

B. Topographical Representation of Brain Responses to Stranger "Bidu" in a) Low-Risk and b) High-Risk Neonates at $75 \mathrm{~ms}$

a.

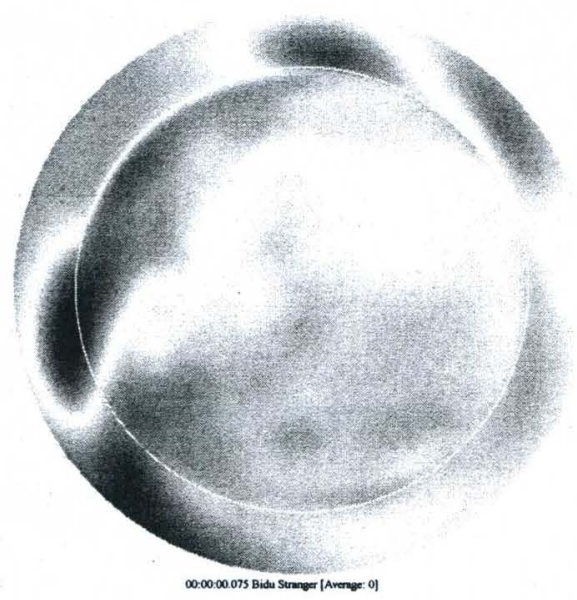

b.

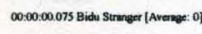


Table 6

Summary of Hierarchical Regression Analysis for Variables Predicting Neonate Right

Central Brain Response to the Stranger Speaking "Bidu" for Factor $4(N=30)$

Variable

$\mathrm{B}$

SE B

$\beta$

Model 1 (BAI)

Step 1

Neonate Sex

.04

.23

.03

Step 2

Neonate Sex

.18

.21

.15

BAI

$-.25$

.01

$-.50^{* *}$

Model 2 (STAI-state)

Step 1

Neonate Sex

.04

.23

Step 2

Neonate Sex

.11

.21

STAI-state

.01

$-.43 *$

Model 3 (STAI-trait)

Step 1

Neonate Sex

.04

.23

Step 2

Neonate Sex

.00

.22

.00

STAI-trait

$-.02$

.01

$-.31$

${ }^{*} \mathrm{p}<.05,{ }^{* *} \mathrm{p}<.01$ 


\section{Analysis of Variance}

Repeated Measures Analysis of Variance was conducted on all factors, with anxiety grouping as a between subjects factor. No significant group or novelty effects emerged for factor 1 . Analysis of factor 2 yielded a significant hemisphere $\mathrm{x}$ anxiety status effect $(F(1,28)=4.796, p=.037)$, with an observed power of .56 . Post Hoc $\mathrm{t}$-tests indicated that the high-risk group displayed greater right hemisphere activity overall $(t(1,28)=-2.092, p=.046)$, while the low-risk group displayed greater left hemisphere activity overall $(t(1,28)=2.236, p=.034)$ during this time range (Figure 3 ). No significant group effects were observed for factor 3. Factor 4 yielded a significant hemisphere $\mathrm{x}$ speaker $\mathrm{x}$ group effect $(F(1,28)=4.182, p=.005)$, with an observed power of .51. Post-hoc ANOVA failed to support any hemispheric differences in terms of processing in response to the strangers voice, however, high-risk infants displayed more positive processing in response to their mother's voice over the left hemisphere $(F(1,28)$ $=5.931, p=.021$ ). 
Figure 3

A. Differences in Average ERPs between Low-Risk and High-Risk Neonates across a) Right and b) Left Hemispheres

a.

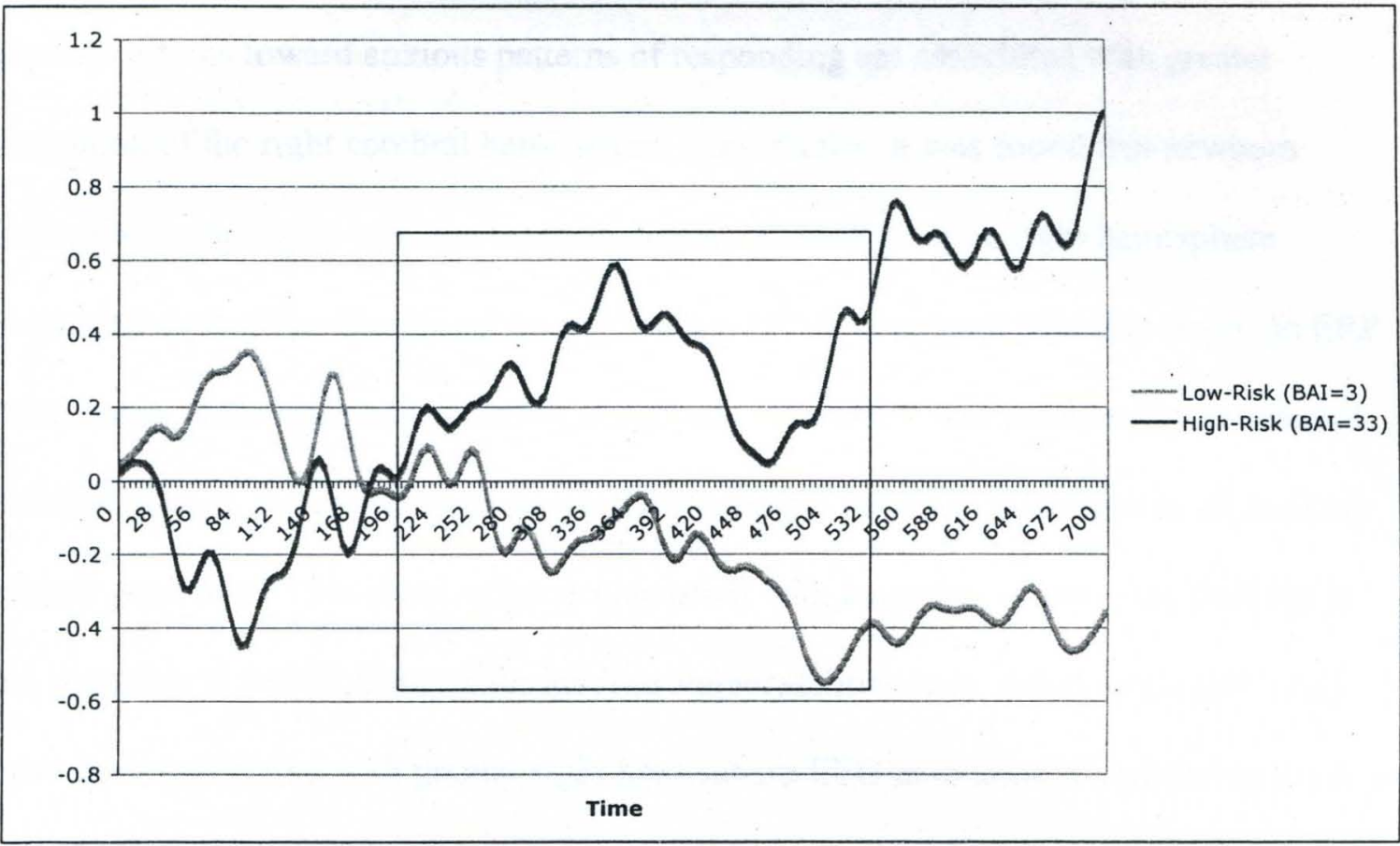

b.

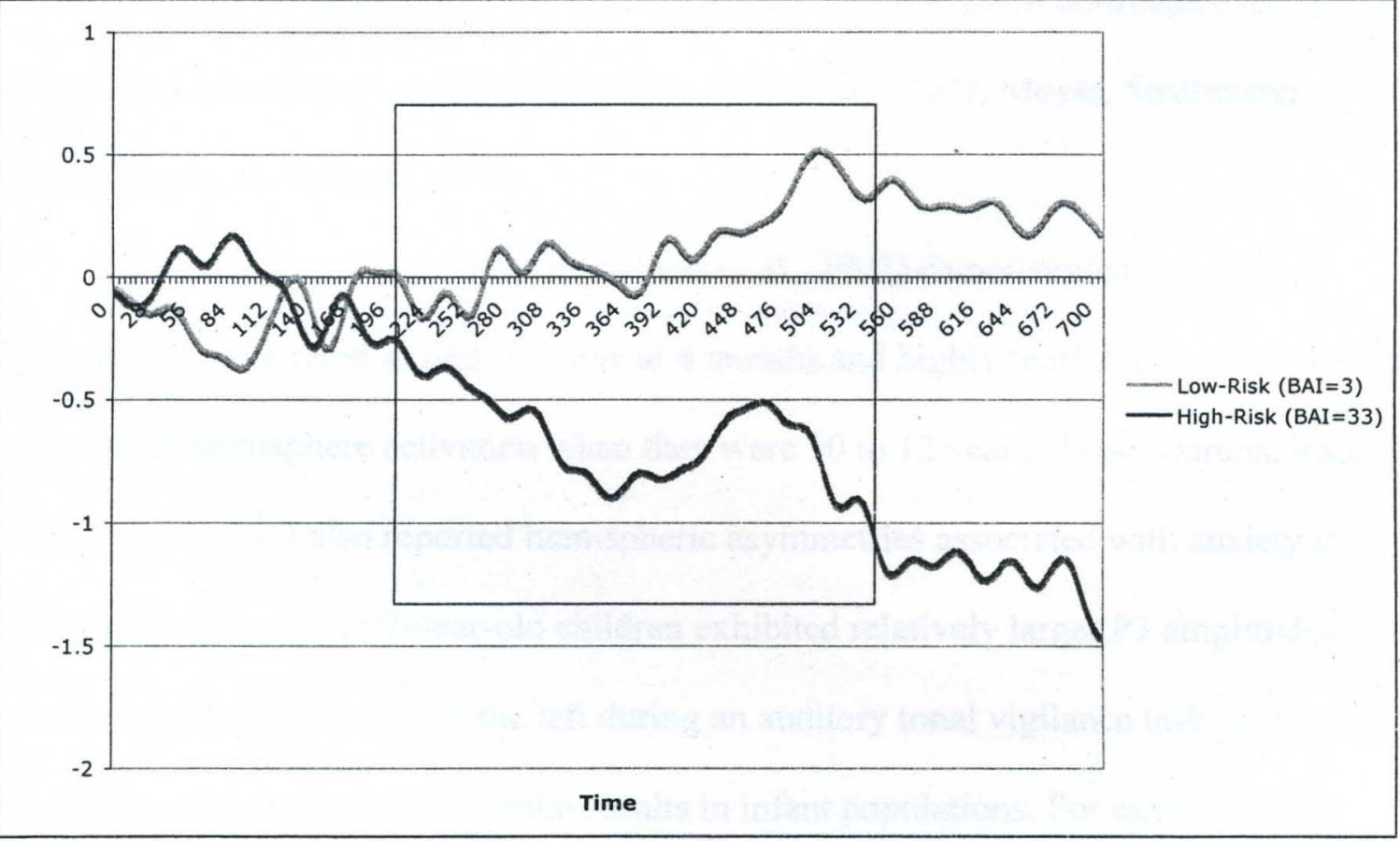




\section{DISCUSSION}

\section{Lateralization of Anxious Vulnerabilities}

The current findings add support to a growing body of evidence that predispositions toward anxious patterns of responding are associated with greater activation of the right cerebral hemisphere. Specifically, it was found that newborn infants of more highly anxious mothers displayed more positive right hemisphere responses during the time frame encompassing $192-536$ ms post stimulus-onset, an ERP component with maximal variability at $328 \mathrm{~ms}$. This effect was not specific to novel or familiar stimuli, but rather characterized the neonates' average responses to all auditory stimuli presented. This observation is consistent with a number of previous findings in the literature in which markers for anxious vulnerabilities (e.g., behavioral inhibition) have been associated with greater right hemisphere EEG activation. Considering the close association between anxiety and autonomic nervous system functioning, the observed assymetires may be reflective of the right hemisphere's established dominance in sympathetic activation (Lee, Meador, Loring, \& Bradley, 2002; Meyer, Strittmatter, Fischer, Georg, \& Schmitz, 2004).

Research from Kagan's lab (McManis et al., 2002) demonstrated that 70\% of children who were rated as high reactive at 4 months and highly fearful at 2 years showed greater right hemisphere activation when they were 10 to 12 years of age. Daruna, Rau, and Strecker (1991) also reported hemispheric asymmetries associated with anxiety in children, as anxious 3 to 7-year-old children exhibited relatively larger P3 amplitudes over the right hemisphere than the left during an auditory tonal vigilance task. A number of investigations have yielded similar results in infant populations. For example, Field 
and colleagues (2002) demonstrated that neonates who showed greater right than left activation across central and parietal sites exhibited more restless sleep, poorer scores on a neonatal behavioral assessment, and higher cortisol levels. Further, greater right hemisphere activation was also observed in their mothers who endorsed higher prenatal depression, anxiety, anger, and inhibition/avoidance, further supporting the contention that these observed hemispheric asymmetries may indeed be linked to vulnerabilities toward anxiety or negative affect. This finding also highlights similarities with the present sample, as these infants would have been considered high-risk based on maternal self-report alone. Importantly, the current findings suggest that these hemispheric differences that are related to maternal anxiety may be present even in newborn infants.

Right hemisphere asymmetries associated with anxiety in early development have been more widely studied in post-neonate infant populations. For example, Buss and colleagues (Buss et al., 2003) found that greater right frontal EEG was associated with negative affect in 6-month-old infants. This pattern of hemispheric asymmetry predicted greater expression of negative affect during approach by a stranger and higher fear scores based on maternal report, and was positively correlated with baseline and reactive cortisol levels. Davidson and Fox (1989) had similar findings in 10-month-old infants, as those who cried upon maternal separation exhibited greater right frontal activation. These differences were found to remain relatively stable over a 7 month period of monthly follow-ups (Bell \& Fox, 1992). Further supporting the stability of these differences, Fox (1992) reported that 14-month-old infants who cried upon maternal separation showed greater right frontal EEG activation during follow-up testing 2 months after the maternal separation assessment. 
The above findings converge to suggest that specific patterns of right hemisphere activation, detectable early in development, may represent vulnerabilities toward anxious outcomes. This contention is even more convincing as support for right hemisphere lateralization of systems related to anxiety continues to be observed into adulthood (Cummings, 1997; Jones \& Fox, 1992; Mainio et al., 2003; Nitschke et al., 1999; Wiedmann et al., 1999), and in animal models (Kalin, 2003). The current study extends the above findings in two important ways. First, it supports Field et al.'s (2002) work, providing a downward extension of the infant, child, and adult literatures by demonstrating that right hemisphere electrophysiological correlates of anxious responding may be discernable as early as the neonatal period. Secondly, it affirms the importance of using event-related measures, rather than only more gross measurements of EEG activation. In this regard, the present study makes a unique contribution by demonstrating that high-risk neonates exhibit right hemisphere differences in information processing of basic auditory stimuli, suggesting an important direction of investigation to follow in order to more fully understand the nature of their vulnerability. While anxious vulnerabilities may be associated with general differences in brain activation, it is also important to further understand more specific patterns of responding to environmental stimuli that may be linked to specific stages of information processing.

In summary, previous investigations have linked greater right hemisphere brain activation to anxious responding from infancy through adulthood, and it has been suggested that "the right hemisphere appears to be specialized for vigilance to and activation by the negative affective aspects of the environment" (Otto, Yeo, \& Dougher, 1987, p. 1205). The present study is among the first to add support for this finding as 
early in development as the neonatal period, and suggests that such asymmetries may be observed in discrete segments of the electrophysiological response to environmental stimulation. As discussed below, the current study also presents evidence for anxietyrelated correlates of the neonate's brain response to novelty, which is important as anxiety has been associated with hypervigilance to cues of novelty or danger (Gray, $1981 ; 1982)$.

\section{Response to Novelty}

Moving beyond more general differences in right hemisphere responding, the measurement of ERPs allows for examination of specific aspects of processing in response to environmental stimuli conceptually related to anxiety. Specifically, it was possible in the present study to examine responses to novel stimuli and the degree to which maternal anxiety may predict the neonate's processing of such stimuli. Measures of both maternal state and trait (STAI-state and STAI-trait) anxiety were significant predictors of the neonate's response to novelty in the time range that encompassed 192$536 \mathrm{~ms}$ post stimulus-onset, with maximal variability at $328 \mathrm{~ms}$. Further inspection revealed that high-risk neonates exhibited greater positivity during this portion of the ERP. This effect was more pronounced when STAI-trait was used as a predictor, accounting for approximately $18 \%$ of the variance in neonate brain responses. This observation, coupled with the fact that BAI (another state-oriented measure) was not a significant predictor, potentially suggests that the observed effects reflect the transmission of constitutionally based vulnerabilities. Although tentative, these findings are consistent with a large body of adult literature that demonstrates differences in endogenous processing for anxious populations. 
For example, Grillon and Ameli (1994) found that auditory-evoked P300, defined as the most positive peak between 250 and $500 \mathrm{~ms}$ post stimulus-onset, was more pronounced in a control population under threat of shock, while Weinstein (1995) reported greater amplitude of P400 (occurring between 300 and $600 \mathrm{~ms}$ ) for participants with higher STAI scores during a threat priming task. Bruder et al. (2002) found that anxiety disordered patients exhibited a fronto-centrally located increase in P3 amplitude (maximal variability at $315 \mathrm{~ms}$ ) during an auditory oddball task. Similarly, Clark, McFarlane, Weber, and Battersby (1996) found that panic disorder patients exhibited greater P3 amplitudes over frontal and central sites during an auditory discrimination task. Interestingly, findings in posttraumatic stress disorder (PTSD) patients have not been consistent with these results; PTSD has been associated with attenuated P3 amplitude, (Charles et al., 1995; McFarlane et al., 1993; Metzger et al., 1997), suggesting that different processes may be implicated in this disorder. However, as reviewed above, the present study converges with a growing body of literature in which adult anxiety is associated with differences in responding in the P300 time range.

As discussed previously, Daruna and colleagues (1991) had similar findings in a child population, with anxious children exhibiting increased P3 amplitudes over the right hemisphere during an auditory tonal vigilance task. However, in their study, P3 was defined as the average amplitude between 600 and $800 \mathrm{~ms}$ post stimulus-onset. This represents a later portion of the brainwave than that implicated in the current study, as well as in the previous investigations from the adult literature. The authors reportedly chose this later time frame because evidence has demonstrated that children have longer latency to the P3 component (Daruna \& Rau, 1987), a finding that is also present in infant 
populations (Gunnar \& Nelson, 1994; McIsaac \& Polich, 1992). While Gunnar and Nelson (1994) also found differences related to later components of the wave (700$1700 \mathrm{~ms}$ ) associated with infant emotionality, their methodology did not consider earlier waveform components. Considering latency differences between infant, child, and adult brain responses, however, it is possible that findings from the current study in the 192$536 \mathrm{~ms}$ time range are not related to $\mathrm{P} 3$, but perhaps an earlier component of the wave. A competing hypothesis, however, would be that high-risk neonates in the current study demonstrated a decreased latency to $\mathrm{P} 3$, a finding that has consistently emerged in studies of anxious populations (Charles et al., 1995; Miyata et al.,1998; Towey et al., 1990).

A number of hypotheses have been presented in the literature for the significance of the relationship between anxiety and $\mathrm{P} 3$ components of the auditory evoked brain response, related to difficulties in adaptation to novelty or the presence of hypervigilance in attentional mechanisms. These constructs have been associated with a variety of neural circuits including frontal, temporal, and subcortical limbic structures. Despite competing explanations, these theories generally support Gray's BIS hypothesis, and add support for its neurobiological basis. The current study adds supporting evidence from the neonatal period, and further suggests that findings in the child and adult literatures may point to a constitutionally based mechanism that predisposes individuals toward anxious modes of responding. This mechanism, which likely incorporates attentional and novelty detection systems, may be initially adaptive for an individual, subsequently leading to the development of pathological anxiety through a variety of dynamic biologicalenvironmental interactions (Gunnar \& Nelson, 1994). Such findings are supported by examinations of behaviorally inhibited children and overcontrolling parents, with such 
combinations having the most deleterious effects in terms of infant outcome. (Hirshfeld et al., 1997a; 1997b; Kagan, 1994a; Nachimas et al., 1996).

In addition to findings related to endogenous aspects of processing, the current study also demonstrated that anxiety-risk, as measured by the BAI, predicted neonatal response to novelty in the earliest component of the brainwave that ranged from stimulus onset to $152 \mathrm{~ms}$, with maximal variability at $32 \mathrm{~ms}$. Further inspection indicated that high-risk neonates demonstrated a less pronounced negativity during this early portion of the response to the novel voice. This finding is not consistent with the adult literature, as such studies have generally pointed toward increased early ERP negativities in anxious populations. Knott et al. (1991), for example, demonstrated that adult PD patients exhibited greater early ERP amplitudes, occurring between 70 and $220 \mathrm{~ms}$ post stimulusonset, in response to auditory stimuli of varying intensities. Similarly, Iwanimi and colleagues (1997) also demonstrated an enhanced early negative component (peaking between 75 and $150 \mathrm{~ms}$ post stimulus-onset) for PD patients during a two-tone auditory discrimination task. Such findings have also emerged in non-clinically anxious populations, as Weinstein (1995) demonstrated that high-anxious adults, as measured by the STAI, exhibited enhanced N1 (range 90-120 ms) amplitude during a threat priming task. Hansenne and colleagues (2003), however, demonstrated that harm avoidance was associated with attenuated negativity during an early component of processing that fell between 150 and 260 ms post stimulus-onset. Unfortunately, such early components of the brainwave have not been well studied in examinations of infant emotionality, and the current results call for further consideration of these early components in future investigations. 
Future Directions

The current study did not correlate ERP variables of interest with objective measures of infant behavior. A number of other studies have utilized such methodologies, demonstrating that electrophysiological differences are related to observable markers of behavioral inhibition (Bell \& Fox, 1992; Buss et al., 2003; Davidson \& Fox, 1989; Field et al., 2002; Gunnar \& Nelson, 1994). Incorporating this approach with the measurement of ERPs would allow for a richer understanding of the behavioral expression of observed differences in brain processing. Establishing such links would be beneficial not only in deepening our theoretical understanding of the development of anxiety, but could also assist in the development of practical assessment and identification procedures that could be applied toward early intervention efforts.

Although the current results correlate with findings observed in groups throughout the life span, in order to fully establish the presence of anxiety-related risk factors, it would be ideal to design and conduct longitudinal investigations. Such investigations would allow for documentation of the progression of these vulnerabilities throughout the lifespan, as well as their interaction with environmental variables. The laboratories of Kagan (McManis et al., 2002) and Fox (Bell \& Fox, 1992; Fox, 1992) have made important contributions in conducting longitudinal investigations within this realm, providing initial support for the stability of correlations between anxious behavior and electrophysiological markers throughout childhood. Such investigations are difficult to bring to fruition, but should continue to be pursued in the future.

In an ideal research scenario, maternal self-report would not be used to operationalize anxiety and depression; it would be methodologically more sophisticated 
to utilize structured diagnostic interviews such as the Anxiety Disorders Interview Schedule, 4th Edition (ADIS-IV; Brown, DiNardo, \& Barlow, 1994) or the Structured Clinical Interview for DSM-IV Axis I Disorders (SCID-I; First, Spitzer, Gibbon, \& Williams, 1997). However, these interviews can require over 2 hours to administer, an unrealistic amount of time to be expected in the current study setting given the mother's energy level, as well as the number of interruptions on the part of visitors and medical staff. The use of self-report did pose an advantage for the current study, however, in that it allowed maternal anxiety to be conceptualized in both continuous and categorical fashions. Future research should continue to consider the appropriateness of continuous vs. categorical classification schemes in operationalizing anxiety-related vulnerabilities.

The current study involved the examination of only auditory ERPs. Given the relationship between the right hemisphere and anxiety, as well as the right hemisphere's dominance in dealing with visuospatial information, additional effects may have been observed if visual stimuli were utilized. A number of researchers have identified anxietyrelated electrophysiological correlates in adults using visual stimuli (Ciesielski et al., 1981; Pauli et al., 1997; Savage et al., 1994; Weinstein, 1995). Gunnar and Nelson's (1994) work supports using such paradigms in infant populations, as they identified visually-evoked P3 differences related to both infant behavior and salivary cortisol levels. Future work may profitably explore both auditory and visual stimulus presentation modalities in neonates and infants, remaining sensitive to the development of these sensory systems when designing such studies.

Failure to consider later portions of the evoked brain response is a shortcoming of the current work, as infants have been hypothesized to show similar components to the 
adult brainwave, only with greater latency to onset. While the current study represents a shortcoming in this regard, other infant work has generally fallen short not only by failing to incorporate event-related measures of brain functioning, but also in failing to examine earlier components of the wave when such measures were used. The current study suggests that there may be important components to consider even within the first $100 \mathrm{~ms}$ of the brain response. Further, given evidence discussed above for reduced latencies to peaks of interest in anxious adult populations, it is possible that high-risk neonates do not exhibit the same increased latencies that controls do. Therefore, future work should continue to examine temporal aspects of brain processing, considering both early and late portions of evoked responses.

Consistent with previous work in this area, paternal anxiety status was not considered in determining of the neonate's risk toward anxiety. The contribution of fathers certainly deserves more consideration in understanding constitutionally based vulnerabilities toward anxiety, as well as in understanding the developmental processes implicated in the psychopathology of anxiety. Building upon the current findings therefore, consideration of paternal variables is an important consideration for future investigations that build upon this work. Like longitudinal designs, this poses a difficult methodological obstacle for future researchers to overcome, but is of sufficient importance that it should indeed be pursued.

\section{Summary}

The current study presented evidence that predispositions toward anxious patterns of responding in neonates are associated with greater activation of the right cerebral hemisphere, and that measures of both maternal state and trait anxiety are 
significant predictors of the neonate's brain response to a stranger's voice. These findings build on previous literature supporting the role of the right hemisphere in the experience of anxiety and the role of attentional biases toward novelty that are associated with the development and maintenance of pathological anxiety. The implication that such processes can be observed in a neonatal population is a novel contribution to these literatures. Building upon these findings with improved methodologies, such as the use of longitudinal designs, the consideration of paternal contributions, and the consideration of constitutional-environmental interactions, holds promise in further informing current understandings of the nature of anxiety disorders and strategies for their prevention. 


\section{REFERENCES}

Achenbach, T.M. (1991). Child Behavior Checklist. Burlington, VT: Author.

American Psychiatric Association. (1980). Diagnostic and Statistical Manual of Mental Disorders $\left(3^{\text {rd }}\right.$ ed.). Washington, DC: Author.

American Psychiatric Association. (2000). Diagnostic and Statistical Manual of Mental Disorders ( $4^{\text {th }}$ ed., Text Revision). Washington, DC: Author.

Arnau, R.C., Meagher, M.W., Norris, M.P., \& Bramson, R. (2001). Psychometric evaluation of the Beck Depression Inventory-II with primary care medical patients. Health Psychology, 20 (2), 112-119.

Asmundson, G.J.G., Sandler, L.S., Wilson, K.G., \& Walker, J.R. (1992). Selective attention toward physical threat in patients with panic disorder. Journal of Anxiety Disorders, 6, 295-303.

Barlow, D.H. (2002). Anxiety and its disorders: The nature and treatment of anxiety and panic. $\left(2^{\text {nd }}\right.$ ed.). New York: Guilford.

Barlow, D. H., Brown, T. A., \& Craske, M. G. (1994). Definitions of panic attacks and panic disorder in the DSM-IV: Implications for research. Journal of Abnormal Psychology, 103 (3), 553-564.

Barlow, D.H. (1991). Disorders of emotion. Psychological Inquiry, 2, 58-71.

Barrett, P.M., Dadds, M.R., \& Rapee, R.M. (1996). Family treatment of childhood anxiety: A controlled trial. Journal of Consulting and Clinical Psychology, 64 (2), 333-342.

Barrett, P.M., Rapee, R.M., Dadds, M.M., \& Ryan, S.M. (1996). Family enhancement of cognitive style in anxious and aggressive children. Journal of Abnormal Child Psychology, 24 (2), 187-203.

Baving, L., Laucht, M., \& Schmidt, M.H. (2002). Frontal brain activation in anxious school children. Journal of Child Psychology and Psychiatry, 43 (2), 265-274.

Beck, A.T., Epstein, N., Brown, G. \& Steer, R.A. (1988). An inventory for measuring clinical anxiety: Psychometric properties. Journal of Consulting \& Clinical Psychology, 56 (6), 893-897. 
Beck, A.T., Laude, R., \& Bohnert, M. (1975). Ideational components of anxiety neurosis. Archives of General Psychiatry, 31, 319-325.

Beck, A.T., \& Steer, R.A. (1990). Beck Anxiety Inventory manual. San Antonio, TX: The Psychological Corporation.

Beck, A.T., \& Steer, R.A. (1991). Relationship between the Beck Anxiety Inventory and the Hamilton Anxiety Rating Scale with anxious outpatients. Journal of Anxiety Disorders, 5, 213-223.

Beck, A.T., Steer, R.A., \& Brown, G.K. (1996). Beck Depression Inventory-Second Edition manual. San Antonio, TX, The Psychological Corporation.

Becker, E.S., Rinck, M., Margraf, J., Roth, W.T. (2001). The emotional Stroop effect in anxiety disorders: General emotionality or disorder specificity? Journal of Anxiety Disorders, 15, 147-159.

Beech, H.R., Ciesielski, K.T., \& Gordon, P.K. (1983). Further observations of evoked potentials in obsessional patients. British Journal of Psychiatry, 142, 605-609.

Beidel, D.C., \& Turner, S.M. (1997). At risk for anxiety: I. Psychopathology in the offspring of anxious parents. Journal of the American Academy of Child and Adolescent Psychiatry, 36 (7), 918-924.

Bell, M.A., \& Fox, N.A. (1992). The relations between frontal brain electrical activity and cognitive development during infancy. Child Development, 63, 1142-1163.

Bell-Dolan, D.J. (1995). Social cue interpretation of anxious children. Journal of Clinical Child Psychology, 24 (1), 1-10.

Biederman, J., Rosenbaum, J.F., Bolduc-Murphy, E.A., Faraone, S.V., Chaloff, J., Hirshfeld, D.R. et al. (1993). A 3-year follow-up of children with and without behavioral inhibition. Journal of American Academy of Child and Adolescent Psychiatry, 32 (4), 814-821.

Biederman, J., Rosenbaum, J.F., Hirshfeld, D.R., Faraone, S.V., Bolduc, E.A., Gersten, M., Meminger, S.R., Kagan, J, et al. (1990). Psychiatric correlates of behavioral inhibition in young children of parents with and without psychiatric disorders. Archives of General Psychiatry, 47 (1), 21-26.

Borden, J.W., Peterson, D.R., \& Jackson, E.A. (1991). The Beck Anxiety Inventory in nonclinical samples: Initial psychometric properties. Journal of Psychopathology and Behavioral Assessment, 13, 345-356.

Brown, T.A., Chorpita, B.F., \& Barlow, D.H. (1998). Structural relationships among 
dimensions of the DSM-IV anxiety and mood disorders and dimensions of negative affect, positive affect, and autonomic arousal. Journal of Abnormal Psychology, 107 (2), 179-192.

Brown, T.A., DiNardo, P.A., \& Barlow, D.H. (1994). Anxiety Disorders Interview Schedule-4 $4^{\text {th }}$ Edition (ADIS-IV). San Antonio, TX: Psychological Corporation.

Bruder, G.E., Kayser, J., Tenke, C.E., Leite, P., Schneier, F.R., Stewart, J.W., \& Quitkin, F.M. (2002). Cognitive ERPs in depressive and anxiety disorders during tonal and phonetic oddball tasks. Clinical Electroencephalography, 33 (3), 119-124.

Buss, K.A., Schumacher, J.R., Dolski, I., Kalin, N.H., Goldsmith, H.H., \& Davidson, R.J. (2003). Right frontal brain activity, cortisol, and withdrawal behavior in 6-monthold infants. Behavioral Neuroscience, 117, 11-20.

Butler, G., \& Mathews, A. (1983). Cognitive processes in anxiety. Advances in Behaviour Research \& Therapy, 5, 51-62.

Calkins, S.D. (1994). Origins and outcomes of individual differences in emotion regulation. Monographs of the Society for Research in Child Development, 59 (23), 53-72.

Cammann, R. (1990). Cammann's reply to Näätänen's article in Open Peer Commentary: Is there mismatch negativity (MMN) in the visual modality? Behavioral and Brain Sciences, 13, 201-288.

Ciesielski, K.T., Beech, H.R., \& Gordon, P.K. (1981). Some electrophysiological observations in obsessional states. British Journal of Psychiatry, 138, 479-484.

Charles, G., Hansenne, M., Ansseau, M., Pitchot, W., Machowski, R., et al. (1995). P300 in posttraumatic stress disorder. Biological Psychiatry, 32, 72-74.

Chorpita, B.F., Albano, A.M., \& Barlow, D.H. (1996). Cognitive processing in children: Relation to anxiety and family influences. Journal of Clinical Child Psychology, 25 (2), 170-176.

Chorpita, B.F., \& Barlow, D.H. (1998). The development of anxiety: The role of control in the early environment. Psychological Bulletin, 124 (1), 3-21.

Clark, C.R., McFarlane, A.C., Weber, D.L., \& Battersby, M. (1996). Enlarged frontal P300 to stimulus change in panic disorder. Biological Psychiatry, 39, 845-856.

Clark, D.A., Steer, R.A., \& Beck, A.T. (1994). Common and specific dimensions of selfreported anxiety and depression: Implications for the cognitive and tripartite models. Journal of Abnormal Psychology, 103 (4), 645-654. 
Clark, L.A., \& Watson, D. (1991). Tripartite model of anxiety and depression: Psychometric evidence and taxonomic implications. Journal of Abnormal Psychology, 100 (3), 316-336.

Cobham, V.E., Dadds, M.R., \& Spence, S.H. (1999). Anxious parents and their children: What do they expect? Journal of Clinical Child Psychology, 28 (2), 220-231.

Cohen, B.H. (2001). Explaining Psychological Statistics ( $2^{\text {nd }}$ Edition). New York: Wiley and Sons.

Coles, M.G.H., Gratton, G., Kramer, A., \& Miller, G.A. (1986). Principles of Signal Acquisition and Analysis. In M.G.H. Coles, E. Donchin, \& S.W. Porges (Eds.), Psychophysiology: Systems, processes, and applications (pp. 183-221). New York: Guilford Press.

Cook, E.W., Melamed, B.G., Cuthbert, B.N., McNeil, D.W., \& Lang, P.J. (1988). Emotional imagery and the differential diagnosis of anxiety. Journal of Consulting and Clinical Psychology, 56 (5), 734-740.

Costello, E.J. (1989). Child psychiatric disorders and their correlates: A primary care pediatric sample. Journal of the American Academy of Child and Adolescent Psychiatry, 28 (6), 851-855.

Creamer, M., Foran, J., \& Bell, R. (1995). The Beck Anxiety Inventory in a non-clinical sample. Behaviour Research and Therapy, 33 (4), 477-485.

Cummings, J.L. (1997). Neuropsychiatric manifestations of right hemisphere lesions. Brain and Language, 57, 22-37.

Cunningham, C.E. (1992). Electrophysiological studies of emotional processes: A developmental-clinical perspective. Brain and Cognition, 20, 176-184.

Dadds, M.R., Barrett, P.M., Rapee, R.M., \& Ryan, S. (1996). Family process and child anxiety and aggression: An observational analysis. Journal of Abnormal Child Psychology, 24 (6), 715-734.

Dadds, M.R., \& Roth, J. H. (2001). Family processes in the development of anxiety problems. In M.W. Vasey \& M.R. Dadds (Eds.), The developmental psychopathology of anxiety (pp. 278-303). New York: Oxford.

Dadds, M.R., Holland, D.E., Laurens, K.R., Mullins, M., Barrett, P.M., \& Spence, S.H. (1999). Early intervention and prevention of anxiety disorders in children: Results at 2-year follow-up. Journal of Consulting and Clinical Psychology, 67 (1), 145150 .

Dalgleish, T., Taghavi, R., Neshat-Doost, H., Moradi, A., Canterbury, R., \& Yule, W. 
(2003). Patterns of processing bias for emotional information across clinical disorders: A comparison of attention, memory, and prospective cognition in children and adolescents with depression, generalized anxiety, and posttraumatic stress disorder. Journal of Clinical Child and Adolescent Psychology, 32 (1), 1021.

Daruna, J.H., \& Karrer, R. (1986). Anxiety level predicts ERP amplitude asymmetries. Cerebral Psychophysiology: Studies in event-related Potentials, suppl. 38, 307309.

Daruna, J.H., \& Rau, A.E. (1987). Development of the late components of auditory brain potentials from early childhood to adulthood. In R. Johnson Jr., J.W. Rohrbaugh, \& R. Parasuraman (Eds.), Current Trends in Event-Related Potential Research. Amsterdam: Elsevier.

Daruna, J.H., Rau, A.E., \& Strecker, C.D. (1991). P3 amplitude in young children: Relation to anxiety. Biological Psychiatry, 29, 837-840.

Davidson, R.J., \& Fox, N.A. (1989). Frontal brain asymmetry predicts infants' response to maternal separation. Journal of Abnormal Psychology, 98 (2), 127-131.

Dawson, G. (1994). Frontal electroencephalographic correlates of individual differences in emotion expression in infants: A brain systems perspective on emotion. Monographs of the Society for Research in Child Development, 59 (2-3), 135-151.

Dawson, G., Frey, K., Self, J., Pangiotides, H., Hessl, D., Yamada, et al. (1999). Frontal brain electrical activity in infants of depressed and nondepressed mothers: Relation to variations in infant behavior. Development and Psychopathology, 11, 589-605.

Dawson, G., Grofer Klinger, L., Panagiotides, H., Hill, D., \& Spieker, S. (1992). Frontal lobe activity and affective behavior of infants of mothers with depressive symptoms. Child Development, 63, 725-737.

Dawson, G., Panagiotides, H., Grofer Klinger, L.G., \& Hill, D. (1992). The role of frontal lobe functioning in the development of infant self-regulatory behavior. Brain and Cognition, 20, 152-175.

DeCasper, A.J., \& Fifer, W.P. (1980). Of human bonding: Newborns prefer their mothers' voices. Science, 208 (4448), 1174-1176.

DeCasper, A.J., Lecanuet, J., Busnel, M., Granier-Deferre, C., \& Maugeais, R. (1994). Fetal reactions to recurrent maternal speech. Infant Behavior and Development, $17,159-164$.

DeCasper, A.J., \& Spence, M.J. (1986). Prenatal maternal speech influences newborns' 
perception of speech sounds. Infant Behavior and Development, 9, 133-150.

Derryberry, D., \& Reed, M.A. (2002). Anxiety-related attentional biases and their regulation by attentional control. Journal of Abnormal Psychology, 111 (2), 225236.

Divon, M.Y., Haglund, B., Nisell, H., Otterblad, P.O., \& Westgren, M. (1998). Fetal and neonatal mortality in the postterm pregnancy: The impact of gestational age and fetal growth restriction. American Journal of Obstetrics and Gynecology, 178 (4), 726-731.

Donchin, E., \& Coles, M.G.H. (1988). Is the P300 component a manifestation of context updating. Behavioral and Brain Sciences, 11, 357-374.

Dozois, D.J.A., Dobson, K.S., \& Ahnberg, J.L. (1998). A psychometric evaluation of the Beck Depression Inventory-II. Psychological Assessment, 10 (2), 83-89.

Dumas, J.E., LaFreniere, P.J., \& Serketich, W.J. (1995). "Balance of Power": A transactional analysis of control in mother-child dyads involving socially competent, aggressive, and anxious children. Journal of Abnormal Psychology, $104(1), 104-113$.

Edelbrock, C., Rende, R., Plomin, R., \& Thompson, L.A. (1995). A twin study of competence and problem behavior in childhood and early adolescence. Journal of Child Psychology and Psychiatry, 36 (5), 775-785.

Electrical Geodesics, Inc. (2001). EGI System 200 technical manual. Eugene, OR: Author.

Electrical Geodesics, Inc. (2003). Net Station Viewer and Waveform Tools. Eugene, OR: Author.

Eley, T.C., \& Stevenson, J. (1999). Exploring the covariation between anxiety and depression symptoms: A genetic analysis of the effects of sex and age. Journal of Child Psychology and Psychiatry, 40 (8), 1273-1282.

Faul, F., \& Erdfelder, E. (1992). G Power (Version 2.0) [Computer software]. Bonn, Federal Republic of Germany: Bonn University Department of Psychology.

Field, T., Diego, M., Hernandez-Reif, M., Schanberg, S., \& Kuhn, C. (2002). Relative right versus left frontal EEG in neonates. Developmental Psychobiology, 41, 147155 .

Field, T., Sandberg, D., Quetel, T.A., Garcia, R., \& Rosario, M. (1985). Effects of ultrasound feedback on pregnancy anxiety, fetal activity, and neonatal outcome. Obstetrics and Gynecology, 66, 525-528. 
First, M.B., Spitzer, R.L., Gibbon, M., \& Williams, J.B.W. (1997). Structured Clinical Interview for DSM-IV Axis-I Disorders (SCID-I): Clinician Version. Washington, DC: American Psychiatric Press.

Fox, E. (1993). Attentional bias in anxiety: Selective or not? Behaviour Research and Therapy, 31 (5), 487-493.

Fox, N.A. (1994). Dynamic cerebral processes underlying emotion regulation. Monographs of the Society for Research in Child Development, 59 (2-3), 153-166.

Fox, N.A. (1992). Frontal brain asymmetry and vulnerability to stress: Individual differences in infant temperament. In T.M. Field, P.M. McCabe, \& N. Schneiderman (Eds.), Stress and coping in infancy and childhood (pp. 83-100). Hillsdale, NJ: Lawrence Erlbaum Associates.

Garcia-Coll, C., Kagan, J., \& Reznick, J.S. (1984). Behavioral inhibition in young children. Child Development, 55, 1005-1019.

Goldsmith, H.H., \& Lemery, K.S. (2000). Linking temperamental fearfulness and anxiety symptoms: A behavior-genetic perspective. Biological Psychiatry, 48, 1199-1209.

Goyette, C.H., Conners, C.K., \& Ulrich, R.F. (1978). Normative data on revised Conners Parent and Teacher Rating Scales. Journal of Abnormal Child Psychology, 6 (2), 221-236.

Gray, J.A. (1981). Anxiety as a paradigm case of emotion. British Medical Bulletin, 37 (2), 193-197.

Gray, J.A. (1982). Précis of the neuropsychology of anxiety: An enquiry into the functions of the septo-hippocampal system. The Behavioral and Brain Sciences, $5,469-534$.

Greenberg, P.E., Sisitsky, T., Kessler, R.C., Finkelstein, S.N., Berndt, E.R., Davidson, J.R.T., et al. (1999). The economic burden of anxiety disorders in the 1990s. Journal of Clinical Psychiatry, 60(7), 427-435.

Grillon, C., \& Ameli, R. (1994). P300 assessment of anxiety effects on processing novel stimuli. International Journal of Psychophysiology, 17, 205-217.

Gunnar, M.R., \& Nelson, C.A. (1994). Event-related potentials in year-old infants: Relations with emotionality and cortisol. Child Development, 65, 80-94.

Hadwin, J., Frost, S., French, C.C., \& Richards, A. (1997). Cognitive processing and trait anxiety in typically developing children: Evidence for an interpretation bias. Journal of Abnormal Psychology, 106 (3), 486-490. 
Halgren, E., Squires, N.K., Wilson, C.L., Rohrbaugh, J.W., Babb, T.L., \& Crandall, P.H. (1980). Endogenous potentials generated in the human hippocampal formation and amygdala by infrequent events. Science, 210, 803-805.

Hamilton, M. (1959). The assessment of anxiety states by rating. British Journal of Medical Psychology, 32, 50-55.

Hammond, J. (1970). Hearing and response in the newborn. Developmental Medicine and Child Neurology, 12 (1), 3-5.

Hansenne, M. (1999). P300 and personality: an investigation with the Cloninger's model. Biological Psychology, 50, 143-155.

Hansenne, M., Pinto, E., Scantamburlo, G., Renard, B., Reggers, J., Fuchs, S., Pitchot, W., \& Ansseau, M. (2003). Harm avoidance is related to mismatch negativity (MMN) amplitude in healthy subjects. Personality and Individual Differences, 34, 1039-1048.

Harvison, K.W., Woodruff-Borden, J., \& Molfese, D.L. (2004, November). Event Related Potentials in the Prediction of Anxious Vulnerabilities. Poster session to be presented at the meeting of the Association for the Advancement of Behavior Therapy, New Orleans, LA.

Hebb, D.O. (1955). Drives and the C.N.S. (conceptual nervous system). Psychological Review, 62, 243-254.

Heim, C., \& Nemeroff, C.B. (1999). The impact of early adverse experiences on brain systems involved in the pathophysiology of anxiety and affective disorders. Biological Psychiatry, 46, 1509-1522.

Heller, W., Nitschke, J.B., Etienne, M.A., \& Miller, G.A. (1997). Patterns of regional brain activity differentiate types of anxiety. Journal of Abnormal Psychology, 106 (3), 376-385.

Hepper, P.G., Scott, D., \& Shahidullah, S. (1993). Newborn and fetal response to maternal voice. Journal of Reproductive and Infant Psychology, 11 (3), 147-153.

Hibbert, G.A. (1984). Ideational components of anxiety: Their origin and content. British Journal of Psychiatry, 144, 618-624.

Himmelhoch, J., Levine, J., \& Gershon, S. (2001). Historical overview of the relationship between anxiety disorders and affective disorders. Depression and Anxiety, 14, 53-66.

Hirshfeld, D.R., Biederman, J., Brody, L., Faraone, S.V., \& Rosenbaum, J.F. (1997a). 
Associations between expressed emotion and child behavioral inhibition and psychopathology: A pilot study. Journal of the American Academy of Child and Adolescent Psychiatry, 36 (2), 205-213.

Hirshfeld, D.R., Biederman, J., Brody, L., Faraone, S.V., \& Rosenbaum, J.F. (1997b). Expressed emotion toward children with behavioral inhibition: Associations with maternal anxiety disorder. Journal of the American Academy of Child and Adolescent Psychiatry, 36 (7), 910-917.

Hoffman, J.E., Houck, M.R., MacMillan, F.W., III,'Simons, R.F., \& Oatman, L.C. (1986). The role of attention in automatic detection: A dual-task, P300 analysis. Cerebral Psychophysiology: Studies in event-related Potentials, suppl. 38, 121123.

Horenstein, M., \& Segui, J. (1997). Chronometrics of attentional processes in anxiety disorders. Psychopathology, 30, 25-35.

Hudziak, J.J., Rudiger, L.P., Neale, M.C., Heath, A.C., \& Todd, R.D. (2000). A twin study of inattentive, aggressive and anxious/depressed behaviors. Journal of the American Academy of Child and Adolescent Psychiatry, 39 (4), 469-476.

Hugdahl, K. (1995). Psychophysiology: The mind-body perspective. Cambridge, MA: Harvard University Press.

Huizink, A.C., Robles de Medina, P.G., Mulder, E.J.H., Visser, G.H.A., \& Buitelaar, J.K. (2002). Psychological measures of prenatal stress as predictors of infant temperament. Journal of the American Academy of Child and Adolescent Psychiatry, 41 (9), 1078-1085.

Iwanimi, A., Isono, H., Okajima, Y., \& Kamijima, K. (1997). Auditory event-related potentials in panic disorder. European Archives of Psychiatry and Clinical Neuroscience, 247, 107-111.

Joiner, T.E., Jr., Catanzaro, S.J., \& Laurent, J. (1996). Tripartite structure of positive and negative affect, depression, and anxiety in child and adolescent psychiatric inpatients. Journal of Abnormal Psychology, 105 (3), 401-409.

Joiner, T.E., Jr., Steer, R.A., Beck, A.T., Schmidt, N.B., Rudd, M.D., \& Catanzaro, S.J. (1999). Physiological hyperarousal: Construct validity of a central aspect of the tripartite model of depression and anxiety. Journal of Abnormal Psychology, 108 (2), 290-298.

Jones, N.A., \& Fox, N.A. (1992). Electroencephalogram asymmetry during emotionally evocative films and its relation to positive and negative affectivity. Brain and Cognition, 20, 280-299. 
Kagan, J. (1994a). Galen's prophecy: Temperament in human nature. New York: Basic Books.

Kagan, J. (1994b). On the nature of emotion. Monographs of the Society for Research in Child Development, $59(2-3), 7-24$.

Kagan, J., Reznick, J.S., Clarke, C., Snidman, N., \& Garcia-Coll, C. (1984). Behavioral inhibition to the unfamiliar. Child Development, 55, 2212-2225.

Kagan, J., \& Snidman, N. (1999). Early childhood predictors of adult anxiety disorders. Biological Psychiatry, 46, 1536-1541.

Kagan, J., Snidman, N., Zentner, M., \& Peterson, E. (1999). Infant temperament and Anxious symptoms in school age children. Development and Psychopathology, 11, 209-224.

Kalin, N.H. (2003). Nonhuman primate studies of fear, anxiety, and temperament and the role of benzodiazepine receptors and GABA systems. Journal of Clinical Psychiatry, 64 (suppl. 3), 41-44.

Kalin, N.H., Larson, C., Shelton, S.E., \& Davidson, R.J. (1998). Asymmetric frontal brain activity, cortisol, and behavior associated with fearful temperament in rhesus monkeys. Behavioral Neuroscience, 112, 286-292.

Kalin, N.H., Shelton, S.E., \& Davidson, R.J. (2000). Cerebrospinal fluid corticotropinreleasing hormone levels are elevated in monkeys with patterns of brain activity associated with fearful temperament. Biological Psychiatry, 47, 579-585.

Kalin, N.H., Shelton, S.E., Davidson, R.J., \& Kelley, A.E. (2001). The primate amygdala mediates acute fear but not the behavioral and physiological components of anxious temperament. Journal of Neuroscience, 21, 2067-2074.

Kashani, J.H., \& Orvaschel, H. (1988). Anxiety disorders in mid-adolescence: A community sample. American Journal of Psychiatry, 145, 960-964.

Kashani, J.H., \& Orvaschel, H. (1990). A community study of anxiety in children and adolescents. American Journal of Psychiatry, 147, 313-318.

Kendler, K.S., Heath, A.C., Martin, N.G., \& Eaves, L.J. (1987). Symptoms of anxiety and depression: Same genes, different environments? Archives of General Psychiatry, 44, 451-457.

Kendler, K.S., Neale, M.C., Kessler, R.C., Heath, A.C., \& Eaves, A.J. (1992). Major depression and generalized anxiety disorder. Same genes, (partly) different environments? Archives of General Psychiatry, 49, 716-722. 
Keogh, E., Dillon, C., Georgiou, G., \& Hunt, C. (2001). Selective attentional biases for physical threat in physical anxiety sensitivity. Journal of Anxiety Disorders, 15, 299-315.

Knight, R.T. (1984). Decreased response to novel stimuli after prefrontal lesions in man. Electroencephalography and clinical Neurophysiology, 59, 9-20.

Kutas, M., \& Hillyard, S.A. (1984). Brain potentials during reading reflect word expectancy and semantic association. Nature, 307, 161-163.

Kutas, M., \& Hillyard, S.A. (1980). Reading senseless sentences: Brain potentials reflect semantic incongruity. Science, 207, 203-205.

Knight, R.T. (1984). Decreased response to novel stimuli after prefrontal lesions in man. Electroencephalography and Clinical Neurophysiology, 59 (1), 9-20.

Knott, V., Lapierre, Y.D., Fraser, G., \& Johnson, N. (1991). Auditory evoked potentials in panic disorder. Journal of Psychiatry and Neuroscience, 16 (4), 215-220.

Kramer, M.S., Demissie, K., Yang, H., Platt, R.W., Sauve, R., Liston, R., et al. (2000). The contribution of mild and moderate preterm birth to infant mortality. Journal of the American Medical Association, 284 (7), 843-849.

Kumar, G., Steer, R.A., \& Beck, A.T. (1994). Factor structure of the Beck Anxiety Inventory with adolescent psychiatry inpatients. Anxiety, Stress \& Coping: An International Journal, 6 (2), 125-131.

Kushnerenko, E., Ceponienè, R., Fellman, V., Huoutilainen, M., \& Winkler, I. (2001). Event- related potential correlates of sound duration: similar pattern from birth to adulthood. NeuroReport, 12 (17), 3777-3781.

Lader, M. H., \& Wing, L. (1964). Habituation of the psycho-galvanic reflex in patients with anxiety states and in normal subjects. Journal of Neurology, Neurosurgery \& Psychiatry, 27, 210-218.

Lang, P.J., Bradley, M.M., \& Cuthbert, B.N. (1998). Emotion, motivation, and anxiety: Brain mechanisms and psychophysiology. Biological Psychiatry, 44, 1248-1263.

Last, C.G., Perrin, S., Hersen, M., \& Kazdin, A.E. (1992). DSM-III-R anxiety disorders in children: Sociodemographic and clinical characteristics. Journal of the American Academy of Child and Adolescent Psychiatry, 31 (6), 1070-1076.

Last, C.G., Perrin, S., Hersen, M., \& Kazdin, A.E. (1996). A prospective study of childhood anxiety disorders. Journal of the American Academy of Child and Adolescent Psychiatry, 35 (11), 1502-1510. 
Lavy, E., van Oppen, P., \& van den Hout, M. (1994). Selective processing of emotional information in obsessive compulsive disorder. Behaviour Research and Therapy, 32 (2), 243-246.

Lecanuet, J.P., Graniere-Deferre, C., Jacquet, A.Y., \& DeCasper, A.J. (2000). Fetal discrimination of low-pitched musical notes. Developmental Psychobiology, 36, 29-39.

Lecanuet, J.P., \& Schaal, B. (1996). Fetal sensory competencies. European Journal of Obstetrics and Gynecology and Reproductive Biology, 68, 1-23.

LeDoux, J.E. (2000). Emotion circuits in the brain. Annual Review of Neuroscience, 23, $155-184$

Lee, G.P., Meador, K.J., Loring, D.M.,\& Bradley, K.P. (2002). Lateralized changes in autonomic arousal during emotional processing in patients with unilateral temporal lobe seizure onset. International Journal of Neuroscience, 112, 743-757.

Lepine, J. (2002). The epidemiology of anxiety disorders: Prevalence and societal costs. Journal of Clinical Psychiatry, 63 (Suppl.14), 4-8.

Levy, E., Kimhi, R., Barak, Y., Demmer, M., Harel, M., \& Elizur, A. (1996). Brainstem auditory evoked potentials of panic disorder patients. Neuropsychobiology, 33, 164-167.

Lonigan, C.J., \& Phillips, B.M. (2001). Temperamental influences on the development of the anxiety disorders. In M.W. Vasey \& M.R. Dadds (Eds.), The Developmental Psychopathology of anxiety (pp. 60-91). New York: Oxford.

Lundh, L., Wikström, J., Westerlund, J., \& Öst, L. (1999). Preattentive bias for emotional information in panic disorder with agoraphobia. Journal of Abnormal Psychology, $108(2), 222-232$.

MacLeod, C., Mathews, A., \& Tata, P. (1986). Attentional bias in emotional disorders. Journal of Abnormal Psychology, 95 (1), 15-20.

Mainio, A., Hakko, H., Niemelä, A., Tuurinkoski, T., Koivukangas, J., \& Räsänen, P. (2003). The effect of brain tumor laterality on anxiety levels among neurosurgical patients. Journal of Neurology, Neurosurgery, \& Psychiatry, 74 (9), 1278-1282.

Mathews, A., \& Mackintosh, B. (1998). A cognitive model of selective processing in anxiety. Cognitive Therapy and Research, 22 (6), 539-560.

Mathews, A., \& Shaw, P. (1977). Cognitions related to anxiety: a pilot study of treatment. Behaviour Research and Therapy, 15, 503-505. 
McIsaac, H., \& Polich, J. (1992). Comparison of infant and adult P300 from auditory stimuli. Journal of Experimental Child Psychology, 53, 115-128.

McManis, M.H., Kagan, J., Snidman, N.C., \& Woodward, S.A. (2002). EEG asymmetry, power, and temperament in children. Developmental Psychobiology, 41, 169-177.

McNally, R.J., Riemann, B.C., \& Kim, E. (1990). Selective processing of threat cues in panic disorder. Behaviour Research and Therapy, 28 (5), 407-412.

Messer, S., \& Beidel, D.C. (1994). Psychosocial correlates of childhood anxiety disorders. Journal of the American Academy of Child and Adolescent Psychiatry, 33 (7), 975-983.

Metzger, L.J., Orr, S.P., Lasko, N.B., \& Pitman, R.K. (1997). Auditory event-related potentials to tone stimuli in combat-related posttraumatic stress disorder. Biological Psychiatry, 42, 1006-1015.

Meyer, S., Strittmatter, M., Fischer, C., Georg, T., \& Schmitz, B. (2004). Lateralization in autonomic dysfunction in ischemic stroke involving the insular cortex. Neuroreport, 15 (2), 357-361.

Mineka, S., Watson, D., \& Clark, L.A. (1998). Comorbidity of anxiety and unipolar mood disorders. Annual Review of Psychology, 49, 377-412.

Miyata, A., Matsunaga, H., Kiriike, N., Iwasaki, Y., Takei, Y., \& Yamagami, S. Eventrelated potentials in patients with obsessive-compulsive disorder. Psychiatry and Clinical Neurosciences, 52 (5), 513-518.

Mogg, K., \& Bradley, B.P. (1998). A cognitive-motivational analysis of anxiety. Behaviour Research and Therapy, 36, 809-848.

Mogg, K., Philippot, P., \& Bradley, B.P. (2004). Selective attention to angry faces in clinical social phobia. Journal of Abnormal Psychology, 113(1), 160-165.

Molfese, D.L. (2000). Predicting dyslexia at 8 years of age using neonatal brain responses. Brain and Language, 72, 238-245.

Molfese, D.L., \& Molfese, V. (1997). Discrimination of language skills at 5 years of age using Event-related potentials recorded at birth. Developmental Neuropsychology, $13(2), 135-156$.

Molfese, D.L., \& Narter, D.B. (1997). Perceptual and cognitive development: Electrophysiological correlates. In S. Christman (Ed.), Cerebral Asymmetries in sensory and perceptual processing (pp. 325-381). NY: Elsevier.

Molnár, M. (1994). On the origin of the P3 event-related potential component. 
Montgomery, S.A., \& Asberg, M. (1979). A new depression scale designed to be sensitive to change. British Journal of Psychiatry, 134, 382-389.

Morault, P., Guillem, F., Bourgeois, M., \& Paty, J. (1998). Improvement predictors in obsessive-compulsive disorder. An event-related potential study. Psychiatry Research, 81, 87-96.

Morgan, C.A., III \& Grillon, C. (1999). Abnormal mismatch negativity in women with sexual assault-related posttraumatic stress disorder. Biological Psychiatry, 45, 827-832.

Morris, T.L. (2001). Social phobia In M.W. Vasey \& M.R. Dadds (Eds.), The Developmental Psychopathology of Anxiety (pp. 435-458). New York: Oxford.

Näätänen, R. (1990). The role of attention in auditory information processing as revealed by event-related potentials and other brain measures of cognitive function. Behavioral and Brain Sciences, 13, 201-288.

Näätänen, R., \& Alho, K. (1995). Mismatch negativity-A unique measure of sensory processing in audition. International Journal of Neuroscience, 80, 317-337.

Näätänen, R., \& Picton, T. (1987). The N1 wave of the human electric and magnetic response to sound: A review and an analysis of the component structure. Psychophysiology, 24 (4), 375-425.

Nachimas, M., Gunnar, M., Mangelsdorf, S., Parritz, R.H., \& Buss, K. (1996). Behavioral inhibition and stress reactivity: The moderating role of attachment security. Child Development, 67, 508-522.

Nitschke, J.B., Heller, W., Palmieri, P.A., \& Miller, G.A. (1999). Contrasting patterns of brain activity in anxious apprehension and anxious arousal. Psychophysiology, 36, 628-637.

Okada, Y.C., Kaufman, L., \& Williamson, S.J. (1983). The hippocampal formation as a source of the slow endogenous potentials. Electroencephalography and Clinical Neurophysiology, 55, 417-426.

Osman, A. (1998). Brainwaves and mental processes: Electrical evidence of attention, perception, and intention. In D. Scarborough \& S. Sternberg (Eds.), Methods, models, and conceptual issues: An invitation to cognitive science, Vol. 4 (pp. 865915). Cambridge, MA: MIT Press.

Osman, A., Barrios, F.X., Aukes, D., Osman, J.R., \& Markway, K. (1993). The Beck Anxiety Inventory: Psychometric properties in a community population. Journal 
of Psychopathology and Behavioral Assessment, 15 (4), 287-297.

Osman, A., Downs, W.R., Barrios, F.X., Kopper, B.A., Gutierrez, P.M., \& Chiros, C.A. (1997). Factor structure and psychometric characteristics of the Beck Depression Inventory-II. Journal of Psychopathology and Behavioral Assessment, 19 (4), 359-376.

Osman, A., Kopper, B.A., Barrios, F.X., Osman, J.R., \& Wade, T. (1997). The Beck Anxiety Inventory: Reexamination of factor structure and psychometric properties. Journal of Clinical Psychology, 53 (1), 7-14.

Otto, M.W., Yeo, R.A., \& Dougher, M.J. (1987). Right hemisphere involvement in depression: Toward a neuropsychological theory of negative affective experiences. Biological Psychiatry, 22, 1201-1215.

Owens, K.M.B., Asmundson, G.J.G., Hadjistavropoulos, T., \& Owens, T.J. (2004). Attentional bias toward illness threat in individuals with elevated health anxiety. Cognitive Therapy \& Research, 28 (1), 57-66.

Pauli, P., Dengler, W., Wiedemann, G., Montoya, P., Flor, H., Birbaumer, N., \& Buchkremer, G. (1997). Behavioral and neurophysiological evidence for altered processing of anxiety-related words in panic disorder. Journal of Abnormal Psychology, 106 (2), 213-220.

Picton, T.W., Bentin, S., Berg, P., Donchin, E., Hillyard, S.A., Johnson, R., et al. (2000). Guidelines for using human event-related potentials to study cognition: Recording standards and publication criteria. Psychophysiology, 37, 127-152.

Pishyar, R., Harris, L.M., \& Menzies, R.G. (2004). Attentional bias for words and faces in social anxiety. Anxiety, Stress, \& Coping, 17 (1), 23-36.

Ponirakis, A., Susman, E.J., \& Stifter, C.A. (1998). Negative emotionality and cortisol during adolescent pregnancy and its effects on infant health and autonomic nervous system reactivity. Developmental Psychobiology, 33, 163-174.

Pritchard, W.S. (1981). Psychophysiology of P300. Psychological Bulletin, 89 (3), 506540 .

Rapee, R.M. (1997). Potential role of childrearing practices in the development of anxiety and depression. Clinical Psychology Review, 17 (1), 47-67.

Reiman, E.M., Fusselman, M.J., Fox, P.T., \& Raichle, M.E. (1989). Neuroanatomical correlates of anticipatory anxiety. Science, 243 (4894), 1071-1074.

Reiman, E.M., Raichle, M.E., Butler, F.K., Herscovitch, P., \& Robins, E. (1984). A focal brain abnormality in panic disorder, a severe form of anxiety. Nature, 310,683- 
685.

Reiman, E.M., Raichle, M.E., Robins, E., Butler, F.K., Herscovitch, P., Fox, P., et al. (1986). The application of positron emission tomography to the study of panic disorder. American Journal of Psychiatry, 143 (4), 469-477.

Rosenbaum, J.F., Biederman, J., Gersten, M., Hirshfeld, D.R., Meminger, S.R., Herman, J.B., et al. (1988). Behavioral inhibition in children of parents with panic disorder and agoraphobia: A controlled study. Archives of General Psychiatry, 45, 463470 .

Rosenbaum, J.F., Biederman, J., Hirshfeld, D.R., Bolduc, E.A., \& Chaloff, J. (1991). Behavioral inhibition in children: A possible precursor to panic disorder or social phobia. Journal of Clinical Psychiatry, 51 (11 suppl), 5-9.

Rosenbaum, J.F., Biederman, J., Hirshfeld-Becker, D.R., Kagan, J., Snidman, N., Friedman, D. (2000). A controlled study of behavioral inhibition in children of parents with panic disorder an depression. American Journal of Psychiatry, 157 (12), 2002-2010.

Roth, W.T., Dorato, K.H., \& Kopell, B.S. (1984). Intensity and task effects on evoked physiological responses to noise bursts. Psychophysiology, 21 (4), 466-481.

Roth, W.T., Ehlers, A., Taylor, C.B., Margraf, J., \& Agras, W.S. (1990). Skin conductance habituation in panic disorder patients. Biological Psychiatry, 27, 1231-1243.

Rothbart, M.K. (1981). Measurement of temperament in infancy. Child Development, 52, 569-578.

Savage, C.R., Weilburg, J.B., Duffy, F.H., Baer, L., Shera, D.M., \& Jenike, M.A. (1994). Low-level sensory processing in obsessive-compulsive disorder: An evoked potential study. Biological Psychiatry, 35, 247-252.

Schneider, W., Eschman, A., \& Zuccolotto, A. (2002). E-Prime-Version 1.0 user's guide. Pittsburgh: Psychology Software Tools, Inc.

Schreter, Z. (1990). Neural networks and the Yerkes-Dodson law. Cognitive Systems, 2 (4), 345-358.

Schwartz, C.E., Snidman, N., \& Kagan, J. (1999). Adolescent social anxiety as an outcome of inhibited temperament in childhood. Journal of the American Academy of Child and Adolescent Psychiatry, 38 (8), 1008-1015.

Sheeber, L.B., \& Johnson, J.H. (1994). Evaluation of a temperament-focused, parenttraining program. Journal of Clinical Child Psychology, 23 (3), 249-259. 
Simeon, J.G., Ferguson, H.B., Knott, V., Roberts, N., Gauthier, B., Dubois, C., et al. (1992). Clinical, cognitive, and neurophysiological effects of alprazolam in children and adolescents with overanxious and avoidant disorders. Journal of the American Academy of Child and Adolescent Psychiatry, 31 (1), 29-33.

Siqueland, L., Kendall, P.C., \& Steinberg, L. (1996). Anxiety in children: Perceived family environments and observed family interaction. Journal of Clinical Child Psychology, 25 (2), 225-237.

Spence, S.H., Rapee, R., McDonald, C., \& Ingram, M. (2001). The structure of anxiety symptoms among preschoolers. Behaviour Research and Therapy, 39, 1293-1316.

Spielberger, C.D., Gorsuch, R.L., Lushene, R., Vagg, P.R., \& Jacobs, G.A. (1983). Manual for the State-Trait Anxiety Inventory. Redwood City, CA: Consulting Psychologists Press.

Steer, R.A., \& Clark, D.A. (1997). Psychometric characteristics of the Beck Depression Inventory-II with college students. Measurement and Evaluation in Counseling and Development, 30 (3), 128-136.

Storch, E.A., Roberti, J.W., \& Roth, D.A. (2004). Factor structure, concurrent validity, and internal consistency of the beck Depression Inventory-Second Edition in a sample of college students. Depression and Anxiety, 19, 187-189.

Swick, D., Pineda, J.A., \& Foote, S.L. (1994). Effects of systemic clonidine on auditory event-related potentials in squirrel monkeys. Brain Research Bulletin, 33 (1), $79-$ 86.

Taghavi, M.R., Neshat-Doost, H.T., Moradi, A.R., Yule, W., \& Dalgleish, T. (1999). Biases in visual attention in children and adolescents with clinical anxiety and mixed anxiety-depression. Journal of abnormal Child Psychology, 27 (3), 215223.

Tanaka-Matsumi, J., \& Kameoka, V.A. (1986). Reliabilities and concurrent validities of popular self-report measures of depression, anxiety, and social desirability. Journal of Consulting and Clinical Psychology, 54, 328-333.

Teigen, K.H. (1994). Yerkes-Dodson: A law for all seasons. Theory and Psychology, 4 (4), 525-547.

Thomas, A., \& Chess, S. (1977). Temperament and Development. NY: Brunner/Mazel.

Thomas, A., Chess, S., \& Birch, H.G. (1968). Temperament and Behavior Disorders in Children. NY: University Press. 
Thrasher, S.M., Dalgleish, T., \& Yule, W. (1994). Information processing in posttraumatic stress disorder. Behaviour Research and Therapy, 32 (2), 247-254.

Torgersen, S. (1983). Genetic factors in anxiety disorders. Archives of General Psychiatry, 40, 1085-1089.

Towey, J.P., Bruder, G., Hollander, E., Friedman, D., Erhan, H., Liebowitz, M., et al. (1990). Endogenous event-related potentials in obsessive-compulsive disorder. Biological Psychiatry, 28, 92-98.

Towey, J.P., Tenke, C.E., Bruder, G.E., Leite, P., Friedman, D., Liebowitz, M., \& Hollander, E. (1994). Brain event-related potential correlates of overfocused attention in obsessive-compulsive disorder. Psychophysiology, 31, 535-543.

Turan, T., Esel, E., Karaaslan, F., Basturk, M., Oguz, A., \& Yabanoglu, I. (2002). Auditory event-related potentials in panic and generalized anxiety disorders. Progress in Neuro-Psychopharmacology \& Biological Psychiatry, 26, 123-126.

Turner, S.M., Beidel, B.C., \& Costello, A. (1987). Psychopathology in the offspring of anxiety disorder patients. Journal of Consulting and Clinical Psychology, 55, 229235.

Vasey, M.W., Daleiden, E.L., Williams, L.L., \& Brown, L.M. (1995). Biased attention in childhood anxiety disorders: A preliminary study. Journal of Abnormal Child Psychology, 23 (2), 267-279.

Warren, S.L., Huston, L., Egeland, B., \& Sroufe, L.A. (1997). Child and adolescent anxiety disorders and early attachment. Journal of the American Academy of Child and Adolescent Psychiatry, 35 (5), 637-644.

Watson, D., Clark, L.A., Weber, K., Assenheimer, J.S., Strauss, M.E., \& McCormick, R.A. (1995). Testing a tripartite model: II. Exploring the symptom structures of anxiety and depression in student, adult, and patient samples. Journal of Abnormal Psychology, 104 (1), 15-25.

Watson, D., Weber, K., Assenheimer, J.S., Clark, L.A., Strauss, M.E., \& McCormick, R.A. (1995). Testing a tripartite model: I. Evaluating the convergent and discriminant validity of anxiety and depression symptom scales. Journal of Abnormal Psychology, 104 (1), 3-

14.

Weinstein, A.M. (1995). Visual ERPs evidence for enhanced processing of threatening information in anxious university students. Biological Psychiatry, 37, 847-858.

Whaley, S.E., Pinto, A., \& Sigman, M. (1999). Characterizing interactions between anxious mothers and their children. Journal of Consulting and Clinical 
Psychology, 67 (6), 826-836.

Woodruff-Borden, J., Morrow, C., Bourland, S., \& Cambron, S. (2002). The behavior of anxious parents: Examining mechanisms of transmission of anxiety from parent to child. Journal of Clinical Child and Adolescent Psychology, 31 (3), 364-374.

Wiedmann, G., Pauli, P., Dengler, W., Lutzenberger, W., Birbaumer, N., \& Buchkremer, G. (1999). Frontal brain asymmetry as a biological substrate of emotions in patients with panic disorders. Archives of General Psychiatry, 56, 78-84.

Wilborg, I.M., \& Dahl, A.A. (1997). The recollection of parental rearing styles in patients with panic disorder. Acta Psychiatrica Scandinavica, 96 (1), 58-63.

Wilson, B.J., \& Gottman, J.M. (1996). Attention-the shuttle between emotion and cognition: Risk, resiliency, and physiological bases. In E.M. Hetherington \& E.A. Blechman (Eds.), Stress, coping, and resiliency in children and families (pp. 189228). Mahwah, NJ: Lawrence Erlbaum.

Wilson, E., \& MacLeod, C. (2003). Contrasting two accounts of anxiety-linked attentional bias: Selective attention to varying levels of stimulus threat intensity. Journal of Abnormal Psychology, 112 (2), 212-218.

Windmann, S., Sakhavat, Z., \& Kutas, M. (2002). Electrophysiological evidence reveals affective evaluation deficits early in stimulus processing in patients with panic disorder. Journal of Abnormal Psychology, 111 (2), 357-369.

Woodward, S.A., McManis, M.H., Kagan, J., Deldin, P., Snidman, N., Lewis, M., \& Kahn, V. (2001). Infant temperament and the brainstem auditory evoked response in later childhood. Developmental Psychology, 37 (4), 533-538.

Yerkes, R.M., \& Dodson, J.D. (1908). The relation of strength of stimulus to rapidity of habit formation. Journal of Comparative Neurology and Psychology, 18, 459-482.

Yiend, J., \& Mathews, A. (2001). Anxiety and attention to threatening pictures. The Quarterly Journal of Experimental Psychology, 54A (3), 665-681.

Yingling, C.D., \& Hosobuchi, Y. (1984). A subcortical correlate of P300 in man. Electroencephalography and clinical neurophysiology, 59, 72-76. 


\title{
CURRICULUM VITAE
}

\author{
Kyle W. Harvison, M.A.
}

Address:
Rush University Medical Center
Department of Behavioral Sciences
1653 West Congress Parkway- 310 Rawson
Chicago, Illinois 60612-3824
(502) 435-3834
harvison@louisville.edu

\section{EDUCATION}

July 2005-Present

August 2000- Present

May 2003

December 1999
Rush University Medical Center

Department of Behavioral Sciences

Clinical Neuropsychology Resident

(APA-Approved Program)

University of Louisville

Department of Psychological and Brain Sciences

Clinical Psychology Doctoral Student

(APA-Approved Program)

Dissertation Title: Using Auditory Evoked Brain

Responses to Detect Anxious Vulnerabilities in

Neonates

University of Louisville

Master of Arts, Psychology

Louisiana State University

Bachelor of Science, Psychology

Cum Laude

\section{PROFESSIONAL AFFILIATIONS}

- Ad Hoc Reviewer for Developmental Neuropsychology, Editor: Dennis L. Molfese, Ph.D.

- American Psychological Association; Graduate Student Member

- Association for Behavioral and Cognitive Therapies; Student Member

- Psi Chi, Louisiana State University Chapter 


\section{SERVICE}

Fall 2002- Clinical Psychology Program Student Representative to the Faculty of the Spring 2004 Department of Psychological and Brain Sciences (University of Louisville)

Dec. 2001 Presented a stress reduction/relaxation training workshop for the Louisville YMCA (Louisville, KY)

June 2002 Presented a seminar on fear of public speaking to Kindred Health Care employees (Louisville, KY)

February 2003 Presented "Building Your Child's Self Esteem and Coping Skills" to parents at St. Pius Elementary School (Louisville, KY)

April 2003 Presented "Developing Self-Esteem and Emotional Well Being in Your Child" to parents at St. Pius Elementary School (Louisville, KY)

\section{RESEARCH EXPERIENCE}

August 2000 -

Present

August 2000Present
Research Student of Janet Woodruff-Borden, Ph.D. University of Louisville, Anxiety Research and Treatment Center

- Current research projects include an examination of the transmission of anxiety in families and a study of the phenomenology of panic and generalized anxiety in an undergraduate population

Research Student of Dennis L. Molfese, Ph.D.

University of Louisville, Developmental Neuropsychology Laboratory

- Through collaboration with Dr. Woodruff-Borden, currently examining electrophysiological indices of anxious vulnerabilities in infants (funded by a University Intramural Incentive Grant)

August December 1999
Volunteer Research Assistant for Phillip Brantley, Ph.D. Louisiana State University, Psychology Department

- Assisted in health psychology research examining both physician's and patient's perceptions of barriers to treatment adherence in a low-income diabetic population 
June -

July 1999

January-

May 1999
Volunteer Research Assistant at The Center for Anxiety Related Disorders Boston University, Department of Psychology

- Assisted in database management and data collection for research examining the role of parenting style in the development and maintenance of child anxiety

Volunteer Research Assistant for Dorothea Lerman, Ph.D. Louisiana State University, Department of Psychology

- Assisted in data collection for research on behavioral interventions for cognitively impaired individuals who engaged in self-injurious and aggressive behaviors

\section{PSYCHOLOGY AND CLINICAL EXPERIENCE}

July 2005- Present Clinical Neuropsychology Resident

Rush University Medical Center

Neuropsychology Director: Christopher Grote, Ph.D., ABPP

- Inpatient and outpatient neuropsychological consultation for rehabilitation, internal medicine, neurology, psychiatry, and other medical departments; Patient population includes dementias, CVA, epilepsy, multiple sclerosis, Parkinson's disease, toxin exposure; Consultation for neurology includes Wada assessment; Psychoeducational assessment; Outpatient psychotherapy with chronically medically ill patients

August 2003-

May 2005

\section{Clinical Neuropsychology Testing Technician}

Southern Indiana Rehabilitation Hospital

Supervisor: D. Bradley Burton, Ph.D.

- Neuropsychological test administration and scoring for adult and pediatric patients with a wide variety of diagnoses, including traumatic brain injury, stroke, Alzheimer's disease, multiple sclerosis, Parkinson's disease, epilepsy, and toxin exposure; Participated in pre and post-surgical neuropsychological evaluation for patients with intractable epilepsy, including WADA and extraoperative cortical mapping procedures through Dr. Burton's affiliation with the University of Louisville Epilepsy Program; Attended neurosurgery for one of our patients

August 2002-
Clinical Neuropsychology Testing Practicum 
July 2003 \&

August 2004-

April 2005

August 2002-

Present

August 2001-

July 2003

August 2003-

July 2004

August 2002-

July 2003
Pathways Neurorehabilitation Program; Louisville, KY Supervisor: D. Bradley Burton, Ph.D.

- Inpatient neuropsychological assessment, report writing, and treatment planning within a multidisciplinary acute neurorehabilitation unit; Experience with patients across full range of functioning, including locked-in syndrome, coma, minimally conscious, vegetative and fully conscious states

Graduate Teaching Assistant for graduate level clinical interviewing skills and cognitive assessment classes. Supervisors: Joseph F. Aponte, Ph.D., Paul Salmon, Ph.D., \& Bernadette Walter, Ph.D.

- Supervision of $1^{\text {st }}$ and $2^{\text {nd }}$ year graduate students learning a range of skills including clinical interviewing, suicidality/homicidality assessment, and mental status examination; Supervision of these students in training on MMPI-II, WISC-III and WAIS-III

Clinic Assistant

Noble H. Kelley Psychological Services Center, University of Louisville

Supervisor: Bernadette Walter, Ph.D.

- Involved in daily clinic operation, intake evaluation of clients presenting with psychological difficulties, and assisting in assignment of clients to specialty clinic teams; In charge of collection and evaluation of data regarding consumer satisfaction with clinic services

Graduate Student Therapist, Trauma Team, Noble H. Kelley Psychological Services Center, University of Louisville Supervisor: Tamara L. Newton, Ph.D.

- Provision of assessment and empirically supported treatments for clients with a history of traumatic stress, including prolonged childhood physical abuse, rape and combat

Graduate Student Therapist, Intra-Interpersonal Treatment Team Noble H. Kelley Psychological Services Center, University of Louisville

Supervisor: Joseph F. Aponte, Ph.D.

- Provision of psychotherapy utilizing both cognitive-behavioral and intra-interpersonal framework to clients with a range of 
difficulties including anxiety and depressive disorders, substance abuse, and anger management difficulties

March 2000-

July 2002

August 2000-

May 2001
Graduate Student Therapist, Anxiety Research and Treatment Center, Noble H. Kelley Psychological Services Center, University of Louisville

Supervisor: Janet Woodruff-Borden, Ph.D.

- Provision of psychotherapy within a cognitive behavioral framework to individuals with a range of anxiety and related disorders including obsessive compulsive disorder, generalized anxiety disorder, depression, panic disorder, and trichotillomania; Diagnostic interviewing using the Anxiety Disorders Interview Schedule for DSM-IV; Co-leader for a social phobia group and a depression/coping skills group at a local high school

Graduate Teaching Assistant for Psychology 201(Introductory Psychology)

University of Louisville, Department of Psychological and Brain Sciences

- Instructor for laboratory component of introductory psychology class; Assisted in course preparation and lectured on relevant material; Led students in exercises to reinforce material; Administered and graded quizzes

\section{PUBLICATIONS}

Harvison, K.W., Woodruff-Borden, J., \& Jeffery, S.E. (2004). Mismanagement of panic disorder in emergency departments: Contributors, costs, and implications for integrated models of care. Journal of Clinical Psychology in Medical Settings, 11 (3), 217-232.

\section{PRESENTATIONS}

Leyfer, O., Harvison, K.W., \& Woodruff-Borden, J. (2005, November). The relationship between maternal anxiety and child effortful control. Poster Session presented at the meeting of the Association for Behavioral and Cognitive Therapies, Washington, D.C.

Harvison, K.W., Woodruff-Borden, J., \& Molfese, D.L. (2004, November). Event related potentials in the prediction of anxious vulnerabilities. Poster Session presented at the meeting of the Association for the Advancement of Behavior Therapy, New Orleans, LA. 
Chapman, L.K., Harvison, K.W., Brewer, V.L., Pemble, M.K., \& Woodruff-Borden, J. (2004, November). Familial anxiety: An examination of parental affectionless control and child disengagement. Poster Session presented at the meeting of the Association for the Advancement of Behavior Therapy, New Orleans, LA.

Ballash, N.G., Pemble, M.K., Leyfer, O., \& Woodruff-Borden, J. (2004, November). The impact of life stress and perceptions of control on anxiety and depression. Poster Session presented at the meeting of the Association for the Advancement of Behavior Therapy, New Orleans, LA.

Chapman, L.K., Pemble, M.K., Ballash, N.G., Harvison, K.W., \& Woodruff-Borden, J. (2003, November). Predicting parental lack of warmth: The role of child negative statements. Poster session presented at the meeting of the Association for the Advancement of Behavior Therapy, Boston, MA.

Harvison, K.W., Marmorato, J., \& Woodruff-Borden, J. (2003, November). The phenomenology of panic and anxiety: Exploring quantitative vs. qualitative differences. Poster session presented at the meeting of the Association for the Advancement of Behavior Therapy, Boston, MA.

Harvison, K.W., \& Woodruff-Borden, J. (2003, November). Independent and interactional contributions of panic and anxiety in the prediction of depression. Poster session presented at the meeting of the Association for the Advancement of Behavior Therapy, Boston, MA.

Marmorato, J., Jeffery, S., Harvison, K.W., \& Woodruff-Borden, J. (2003, November). Prediction of obsessive compulsive symptom subtypes in clinical anxiety patients. Poster session presented at the meeting of the Association for the Advancement of Behavior Therapy, Boston, MA.

Harvison, K.W., \& Woodruff-Borden, J. (2002, November). Panic, Anxiety and the BAI. What is being measured? Poster session presented at the meeting of the Association for the Advancement of Behavior Therapy, Reno, NV.

Buckley, A., Harvison, K.W., Whittle, M., Koch, M., \& Woodruff-Borden, J. (2002, November). Differences in coping and family environment: The role of social anxiety. A poster presented at the meeting of the Association for the Advancement of Behavior Therapy, Reno, NV.

Koch, M., Jeffery, S., Harvison, K.W., \& Woodruff-Borden, J. (2001, April). Family aggregation of anxiety: Constitutional and psychosocial factors. In J. WoodruffBorden (Chair), The impact of parental anxiety on children. Symposium conducted at the meeting of the Kentucky Psychological Association, Louisville, KY. 
Mills, S, Harvison, K.W., \& Woodruff-Borden, J. (2001, November). Self-focused attention, anxiety, and gender as predictors of coping responses. A poster presented at the meeting of the Association for the Advancement of Behavior Therapy, Philadelphia, PA.

Buckley, A.F., Harvison, K.W., Rutherford, J., \& Woodruff-Borden, J. (2001, November). Differences in expressed emotion and behaviors of parents and their children: Examining the role of anxiety. A poster presented at the meeting of the Association for Advancement of Behavior Therapy, Philadelphia, PA.

Thomas, J.L., McCabe B.A., Harvison, K.W., Grimes, J, Jones, G.N., Johnson, J, \& Brantley, P.J. (2000, April) Barriers to diabetic treatment adherence: Perceptions of primary care providers and low income diabetic patients. A poster presented at the meeting of the Society of Behavioral Medicine, Nashville, TN. 